Women, Families, Chronic Illness and Nursing Interventions:

From Burden to Balance

by

Carole A. Robinson

\begin{abstract}
A DISSERTATION
SUBMITTED TO THE FACULTY OF GRADUATE STUDIES

IN PARTIAL FULFILLMENT OF THE REQUIREMENTS FOR THE DEGREE OF DOCTOR OF PHILOSOPHY
\end{abstract}

FACULTY OF NURSING

CALGARY, ALBERTA

SEPTEMBER, 1994

- Carole A. Robinson 1994 


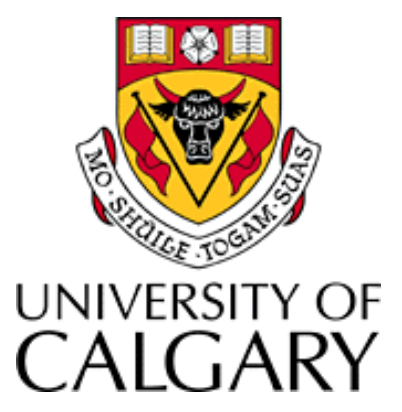

The author of this thesis has granted the University of Calgary a non-exclusive license to reproduce and distribute copies of this thesis to users of the University of Calgary Archives.

Copyright remains with the author.

Theses and dissertations available in the University of Calgary Institutional Repository are solely for the purpose of private study and research. They may not be copied or reproduced, except as permitted by copyright laws, without written authority of the copyright owner. Any commercial use or re-publication is strictly prohibited.

The original Partial Copyright License attesting to these terms and signed by the author of this thesis may be found in the original print version of the thesis, held by the University of Calgary Archives.

Please contact the University of Calgary Archives for further information:

E-mail: uarc@ucalgary.ca

Telephone: (403) 220-7271

Website: http://archives.ucalgary.ca 


\section{ABSTRACT}

This dissertation represents a study that was designed to explore both the process and outcomes of nursing interventions offered within a particular nursing practice to families experiencing difficulties with a chronic illness. The particular practice is family systems nursing offered in the Family Nursing Unit (FNU), Faculty of Nursing, University of Calgary. The study was guided by the grounded theory methodology. As is often the case when doing grounded theory, the research question changed in response to the relevancies that were drawn forth during the research process. Thus, the study became a much broader exploration of what happens to and for women when a chronic illness enters the family.

Fourteen family members from five families who had sought assistance at the FNU in relation to their difficulties with chronic illness participated in the study. The data were comprised of: demographic data in the form of genograms; videotapes of the therapeutic sessions in the FNU; outcome data collected six months after the sessions ended; and transcriptions of indepth, conjoint interviews conducted eight months to two years after the therapeutic work concluded.

Analysis proceeded concurrently with data collection and drew forth a four stage theory of the women's evolving relationships with the family member called chronic illness. The first stage chronicles the evolution of overwhelming illness burden for these women that leads to precarious life balance. The second stage captures a process of falling down and falling apart that occurs after an illness related loss. The third stage deals with the therapeutic change process between nurses and families and the nursing 
interventions that enabled the women to move from burden to balance. The fourth stage addresses the women's evolving relationship with self that was commenced in the therapeutic process and continues as illness is put in its place.

The theory has implications for social policy as well as nursing research and practice. 


\section{PREFACE}

In keeping with the evolving research process as guided by grounded theory methodology and the spirit of qualitative research, the study is presented in a nontraditional manner. It is written in the first person rather than the more objective language of the third person. This is congruent with the integral role I played in coevolving the data with the families and in drawing forth the theory. In addition, the literature was not reviewed prior to beginning the study; instead, this process was deferred until a theory had been drawn forth that was strongly grounded in the data. Delaying the literature review prevented a "wild goose chase" since initially I had no idea about what would be drawn forth as relevant in the families' situations. Further, waiting until the theory was well grounded prevented me from engaging in premature closure, which happens when analysis is constrained by ideas "received" from the literature (Charmaz, 1990; Glaser, 1978). Thus, the literature was theoretically sampled in order to recontextualize the theory that was drawn forth. 


\section{ACKNOWLEDGEMENTS}

The doing of this research has been both an enriching and enjoyable endeavor, thanks in large part to my supervisor, Dr. Lorraine M. Wright. She has been all that I hoped for in a mentor and more. Her immense capacity to open space for my ideas and, at the same time, to contribute to their development through the asking of perturbing questions has been empowering. Most of all, I would like to express my deep appreciation of the many ways she has shown her faith in me.

I would like to thank Dr. Janice Bell for her thoughtful consideration of research process issues. Both she and Dr. Lorraine Radtke have shown enthusiasm for this study that lifted my spirits and motivated me to continue. I appreciate the expertise that Dr. Janice Morse and Dr. Michael Rothery brought to the process.

I owe a great deal to the agencies that funded my doctoral program. I am grateful to: the University of British Columbia for granting me an educational leave and for partially funding my first year of study; the Canadian Nurses' Foundation for awarding me two Hospital for Sick Children Foundation Fellowships; the University of Calgary for awarding me a Silver Anniversary Graduate Fellowship; and, the National Health Research and Development Program for awarding me a Doctoral Fellowship.

Finally, there is my family who did a remarkable job of making space for my research and writing. I am deeply grateful to my husband Dana for his tolerance and willingness to be both mother and father when I was absent in either body or in spirit. I am thankful for the balance that my daughter Amy brought to the endeavor. Her invitations to play were particularly helpful. 


\section{DEDICATION}

To the five women who participated in this study. Through their willingness to tell their stories and to share the everyday heroism of their lives I have been enabled to see old territory with new eyes. Together, we have been able to draw a new map. 


\section{TABLE OF CONTENTS}

APPROVAL PAGE $\ldots \ldots \ldots \ldots \ldots \ldots \ldots$ ii

ABSTRACT $\ldots \ldots \ldots \ldots \ldots \ldots \ldots \ldots \ldots \ldots \ldots \ldots \ldots \ldots \ldots$ iii

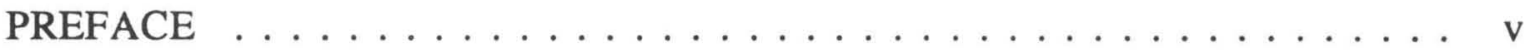

ACKNOWLEDGEMENTS $\ldots \ldots \ldots \ldots \ldots \ldots \ldots \ldots$ vi

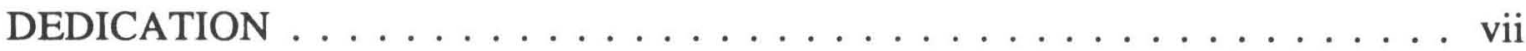

TABLE OF CONTENTS $\ldots \ldots \ldots \ldots \ldots \ldots \ldots$ viii

\section{CHAPTER ONE}

SETTING THE STAGE $\ldots \ldots \ldots \ldots \ldots \ldots \ldots \ldots \ldots$

The Co-Evolution of the Research Question . . . . . . . . . . . . . 2

And the Choice of Method of Inquiry . . . . . . . . . . . . 2

What the Researcher Brought to the Research Process . . . . . . . . . 6

The Theoretical Lens . . . . . . . . . . . . . . . . . 6

Maturana's Theory of the Biology of Knowing ......... 9

Objectivity and (Objectivity) . . . . . . . . . . . 9

Organization and Structure Determined Systems . . . . . . 10

The Contribution of Change Theory . . . . . . . . . . 15

How This Theoretical Lens Influenced the Research Process . . . 17

The Family Nursing Unit: A Significant Contextual Element . . . . . . . . 19

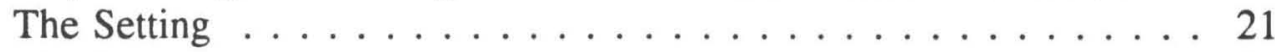

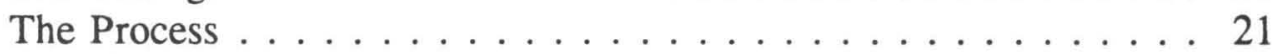

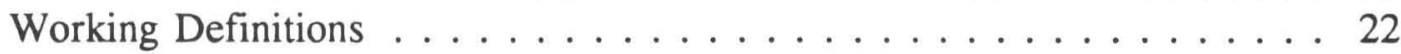

Ethical Considerations . . . . . . . . . . . . . . . . . . . . . . 24

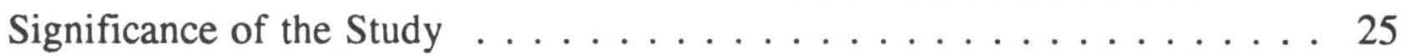

Boundaries of the Theory . . . . . . . . . . . . . . . . 26

The Issue of "Goodness" . . . . . . . . . . . . . . . . . . . . 26

\section{CHAPTER TWO}

THE RESEARCH PROCESS . . . . . . . . . . . . . . . . . . . . . . . 29

A Word About Language . . . . . . . . . . . . . . . . . . . 29

Co-Researchers . . . . . . . . . . . . . . . . . . . . . 30

Criteria for the Invitation to Participate . . . . . . . . . 31

The Evolution of the Research Question in Conjunction With

Theoretical Sampling . . . . . . . . . . . . . . 32

The Families/Family Members Who Joined the Study . . . . . . . 34

The Research Relationship . . . . . . . . . . . . . . . 35

The Data: Windows in Time . . . . . . . . . . . . . . . . . 38 
The Process of Drawing Forth a Theory . . . . . . . . . . . . . . 40

Decision Re: Coding Paradigm . . . . . . . . . . . . . . 43

Writing the Theory . . . . . . . . . . . . . . . . 44

\section{CHAPTER THREE}

DRAWING FORTH A THEORY: WOMEN, FAMILIES,

CHRONIC ILLNESS AND NURSING INTERVENTIONS . . . . 47

Stage One . . . . . . . . . . . . . . . . . . . . . 47

Women, Families and Chronic Illness: Overwhelming Burden . . . . . . 47

Chronic Illness: The Uninvited, Unwelcome Family Member . . 47

In the Name of Protection: Women's Sacrifice . . . . . . . . . 52

The Injunction to Protect . . . . . . . . . . . . 53

The Enactment of Responsibility: Illness Work . . . . . . 57

When Protection Takes Precedence Over Self . . . . . . . . 60

Men and Children: Carrying On With Life As Usual . . . . . . 63

Men and Their Work Outside the Home . . . . . . . . . 63

Sick Children . . . . . . . . . . . . . 70

Well Children . . . . . . . . . . . . . . . 71

The Burden of Health Care Relationships . . . . . . . . . . 72

The Trouble Getting Professional Recognition . . . . . . 72

Diminishing Women's Sense of Self Worth . . . . . . . . 74

The High Price of Protection Over Time . . . . . . . . . . . 77

Unresolved Illness Problems . . . . . . . . . . . . . 77

Stage Two . . . . . . . . . . . . . . . . . . 80

Women Falling Down and Falling Apart . . . . . . . . . . . 80

The Straw That Broke the Woman's Back . . . . . . . . . . . 80

Despair and Isolation: The Absence of Expected Support . 85

Vicious Cycles That Undermine Support . . . . . . . . . . 86

Silence. . . . . . . . . . . . . 86

Anger, tears and withdrawal. . . . . . . 88

Ignoring Obvious Signs of Trouble . . . . . . . . . . . . . 90

Hitting Bottom: Overwhelming Uncertainty and Life's Big

Questions ....................... 92

Desperation: The Trigger to Seek Help . . . . . . . . . . . 95

Stage Three . . . . . . . . . . . . . . . . . . . . . 99

Nursing Interventions: Helping Them That Help Themselves . . . . . . . 99

Enabling Healing: Creating the Circumstances for Change . . . . 99

Bringing the Family Together . . . . . . . . . . . 100

Comfort and Trust: Reciprocal Cornerstones of the

Therapeutic Relationship . . . . . . . . . . . 102

Drawing forth comfort. . . . . . . . . . . . . 103

Drawing forth trust. . . . . . . . . . . 106

Getting Unstuck: Moving Beyond and Overcoming Problems . . 111

Breaking the Silence: "She Got Us Talking" . . . . . . 112 
Nobody Ever Told Me I Was Doing A Good Job . . . . . 116

The Wake-up Call: Women Have Problems That Matter 118

Putting Illness Problems In Their Place . . . . . . . . . 120

Reflections on "What I Learned From Getting Help" . . . 125

Stage Four . . . . . . . . . . . . . . . . . . . . . . . . . . . . . . . . . 127

Taking Charge of Ones' Life . . . . . . . . . . . . . . . . . . . . . . 127

Women's Lives Matter . . . . . . . . . . . . . . . . . . . 127

Nurturing a New Story About a Life That Matters . . . . . 127

Making More Room for Oneself . . . . . . . . . . . . . 129

Looking Out for Oneself . . . . . . . . . . . . . 132

Hanging On To Life Enhancing Balance . . . . . . . . . 135

Supportive Family Relationships . . . . . . . . . . . . . . 137

Conclusion . . . . . . . . . . . . . . . . . . . . 141

CHAPTER FOUR

RECONTEXTUALIZING THE THEORY OF WOMEN, FAMILIES, CHRONIC ILLNESS AND NURSING INTERVENTIONS . . . . . . . . 142

Women, Families, and Chronic Illness: Overwhelming Burden . . . . . . 142

Ordinary Arrangements . . . . . . . . . . . . . . . . . 143

Illness Arrangements . . . . . . . . . . . . . . . . . . . . 147

The Nature of Women's Work: Devalued and Even Invisible . . 149

The Cost of Illness Arrangements . . . . . . . . . . . . . 153

Why Do Women Continue To Care? . . . . . . . . . . . . . 158

Dominant and Dominating Stories . . . . . . . . . 158

Situational Constraints . . . . . . . . . . . . . 160

Personal Choices . . . . . . . . . . . . . . . . 161

Gender Differences in Illness Burden . . . . . . . . . . . . . . 162

Essentialist Explanations . . . . . . . . . . . . . . 163

The Problem of Power . . . . . . . . . . . . . . . . . . 166

Health Care Relationships . . . . . . . . . . . . . . 168

Summary . . . . . . . . . . . . . . . . . 171

Women Falling Down and Falling Apart . . . . . . . . . . . 171

Ambiguous Loss . . . . . . . . . . . . . . . . . . . . . 172

Silencing Inner Conversations . . . . . . . . . . . . . . . 174

Silencing Voice . . . . . . . . . . . . . . . . . . . . . 175

Men's Silence . . . . . . . . . . . . . . . . . . . . 177

The Impact of Men's Silence . . . . . . . . . . . . . . . 179

Crumbling Resources . . . . . . . . . . . . . . . . 181

Transformative Moments . . . . . . . . . . . . . . . 182

Summary . . . . . . . . . . . . . . . . . . . 182

Nursing Interventions: Helping Them That Help Themselves . . . . . . 183

The Power of Language . . . . . . . . . . . . . . . 183

The Power of Stories . . . . . . . . . . . . . . . . . . . 183

Drawing Forth a Healing Context $\ldots \ldots \ldots \ldots \ldots$ 
The Therapeutic Relationship . . . . . . . . . . . . . 185

Re-storying Women's Lives . . . . . . . . . . . . . . . . 187

Drawing Forth Love . . . . . . . . . . . . . . . . 188

Drawing Forth Resources . . . . . . . . . . . . . . . 189

Re-thinking What We Do . . . . . . . . . . . . . . 191

Summary . . . . . . . . . . . . . . . . . . . . 193

Taking Charge of One's Life . . . . . . . . . . . . . . . . . . . . 194

Where Do We Go From Here? . . . . . . . . . . . . . . . . . . . . 195

Social Policy . . . . . . . . . . . . . . . . . . . 195

Nursing Research . . . . . . . . . . . . . . . . . . . . 198

Nursing Practice . . . . . . . . . . . . . . . . . . . 199

Concluding Remarks . . . . . . . . . . . . . . 202

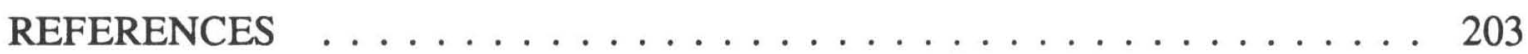

APPENDIX A: Consent for Use of Videotape Recording . . . . . . . . . 234

APPENDIX B: Information/Invitation to Participate . . . . . . . . . 236

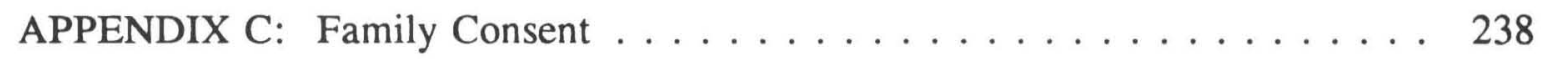

APPENDIX D: Steps of the Analytic Procedure . . . . . . . . . . 240 


\section{CHAPTER ONE}

\section{SETTING THE STAGE}

The future of family nursing research is interventions, interventions, interventions... The most important research that family nurses can do is that which will help patients and their families manage, overcome or live alongside their health problems (Wright \& Bell, 1994).

The essence of family nursing practice is to heal emotional and physical suffering within families (Wright \& Bell, 1994). Nursing's efforts to better understand family responses to suffering due to illness has led to the development of finely honed assessment skills; however, our ability to intervene has lagged behind (Craft \& Willadsen, 1992). Bell (1994) has pointed out that this emphasis on assessment is reflected in both the research and practice literature where description has been the preoccupation. While this has significantly enhanced our sensitivity to families' experiences and responses, it is now time to focus on interventions (Wright \& Bell, 1994). It is time to systematically do something about helping families.

There is a call amongst family nurse clinicians and researchers to identify interventions and to account for their action through outcome studies (Craft \& Willadsen, 1992; Gilliss, 1991; Whall \& Loveland-Cherry, 1994). Nursing has begun to address the challenge of documenting the use and effectiveness of interventions; however, the research to date fails to capture a vital step - the interactional process (Bell, 1994). A "black box" approach to evaluation research has predominated (Swanson \& Chapman, 1994) such that the link between the intervention and the effect or outcomes has been largely ignored. "We need to discover what interventions are the most useful to families who are suffering with illness and how these interventions work" (Wright \& Bell, 1994). 
This contextual milieu provided the impetus for the study.

Further, two personal beliefs have evolved through my immersion in the world of nursing and families that are at the heart of this study. The first belief is that nurses must help the families who come to them. For me, this means that the motivation behind research is ultimately the healing of family and individual suffering. The second is that advancing the nursing of families depends on the development of practice-based theory that systematically accounts for both the process and outcome of our interventions with families.

The Co-Evolution of the Research Question

And the Choice of Method of Inquiry

This study began with a general interest in the process of therapeutic change with families who were experiencing difficulty living with a member's chronic condition. I was concerned about both the process and the outcome of nursing efforts to influence change. Therefore, the question that oriented me as I began the study was: "What do nurses do that assists or hinders families in living with a member's chronic condition and how do the interventions work?" Since "virtually no research had gone beyond the effectiveness question to ask how therapeutic change occurs" (Bell, Wright \& Robinson, 1994, p. 19) this broad question was appropriate to our current state of knowledge development. Unfortunately, little direction can be gained from other disciplines in this area of study. For example, outcome research in family therapy is plagued with ambiguous findings and methodological difficulties (see for example: Asen et al., 1991; Hazelrigg, Cooper, \& Borduin, 1987). 
Grounded theory methodology (Glaser, 1965, 1978; Glaser \& Strauss, 1967, 1970; Strauss, 1987) was chosen to guide the inquiry for several reasons. Most important, there was a clear fit between the methodology and the research question, which oriented the study toward exploring a social process.

Not only was grounded theory a good fit for the question or area of inquiry, it enabled me to address the need for theory development, which is vital to advancing the practice of nursing with families (Gilliss, 1990; Whall \& Fawcett, 1991). As Field and Morse (1985) assert:

Given the state of nursing theory it would be legitimate to argue that generation of theory is more critical than theory testing to the development of nursing knowledge at this time. Grounded theory, as a methodological approach to research, has utility for nurse-researchers who are attempting to identify unknown or unclear phenomena (p. 6; see also Chenitz \& Swanson, 1986).

Swanson and Chapman (1994) are even more explicit in arguing the need for substantive theory in the field of evaluation research.

Grounded theory has been particularly useful to nursing since it so clearly informs nursing practice. It accounts for much of the relevant behavior associated with the phenomenon of concern and thus has great explanatory power. The fit or correspondence of theory to data is assured and the theory works to explain what happened, interpret what is happening and predict (in some measure) what will happen (Glaser, 1978).

Family nursing is a new specialty area in the discipline and as such, theory development is in its infancy. Whall and Fawcett (1991) identify the need for formal, middle-range theory development in order to advance the specialty. In order for theory to be truly relevant to nursing practice with families, I would argue that research efforts 
must address the generation of grounded theory. Given its current lack of exploratory backing, it is apparent that the verificationist approach of theory testing has limited explanatory power in relation to certain family phenomena (for example: Fawcett, 1991; Mercer, Ferketich, DeJoseph, May, \& Sollid, 1991); whereas, grounded theories show significant explanatory power (for example: Norris, 1991; Robinson, 1993; Thorne \& Robinson, 1988a, 1989; Stern, 1986, 1991; Wilson, 1991).

Chenail (1992) makes the case that:

unlike scientists and artists, clinicians are organized by the praxis of their work. They must use methods which produce practical distinctions which can be used in real-time decision making and/or problem solving (p. 1).

He argues that clinical research calls for a method that matches practice. Nursing suffers from a theory-practice gap, which is exacerbated by the separation of researchers and clinicians (Schon, 1983). It is my belief that the generation of grounded theory is one answer to the theory-practice gap because it involves a process that mirrors nursing practice (albeit in a much more formalized manner) (see also Stern, Allen, \& Moxley, 1984 ) and the theoretical product is inherently relevant to practice (for example Morse \& Johnson, 1991). In particular, the grounded theory approach mirrors the process of family systems nursing through the incorporation of hypothesizing, circularity, neutrality and reciprocity. Thus, grounded theory methodology was chosen for its fit with the research question, its ability to contribute to theory development, its explanatory power in the circumstance when little is known and its congruence with family nursing practice.

Morse (1993), a prominent nurse researcher, now states "some qualitative methods are becoming quite standardized - for instance, descriptions of grounded theory 
are now repetitive" (p. 4). The term "grounded theory" is variously used to mean a methodology that guides qualitative research (Glaser, 1978), a set of procedures for analysing data that have some implications for data collection (Strauss, 1987), and a particular kind of theoretical product, that is, a theory that is generated through systematic data analysis rather than theory that is logically deduced (Glaser \& Strauss, 1967). In the context of the current study, I refer to grounded theory as both methodology and research product.

When doing grounded theory, the initial research question simply provides a good place to start and serves to point the researcher in a useful direction (K. Knafl, personal communication, April 27, 1992). Only through the research process does the question become more refined. A broad, general question or area of interest is important at the outset since it opens space for the researcher's sensitivity to what is most relevant to the situation and persons being studied (Glaser, 1978; Glaser \& Strauss, 1967). Whereas, a very specific question or hypothesis imposes the researcher's idea of what is relevant on to the area of study and thus, constrains curiosity.

My interest in what nurses do that helps or hinders a family's ability to manage chronic illness pointed me in a useful direction. Predictably, the research question changed as the research process unfolded and what was most pertinent to the families' situations was drawn forth. Thus, the evolving research question was inextricably linked to the evolving research process. This coevolution resulted in the gradual refinement of the research question, which will be discussed in the following chapter on the research process. 
What the Researcher Brought to the Research Process

The skills and knowledge that I brought to the research process were influenced by: prior experience with the grounded theory approach to qualitative research; extensive research and clinical experience with individuals managing a chronic condition for themselves or a family member; clinical expertise in the area of family systems nursing; and, experience in the area of family therapy. In particular, I have been influenced by White's $(1984,1985,1986,1988 ; \&$ Epston, 1990) narrative approach to family therapy and Systemic Belief Therapy (Robinson, Wright \& Watson, 1994; Watson \& Lee, 1993; Wright \& Nagy, 1993; Wright \& Simpson, 1991; Wright, Watson \& Bell, 1990) as practiced in the FNU.

The Theoretical Lens

Several authors have commented on the absence of conceptual frameworks in reported nursing research about families and have emphasized the importance of their inclusion (Feetham, 1984; Whall \& Fawcett, 1991; Whall \& Loveland-Cherry, 1994). The conceptual framework, or theoretical lens as I have termed it, is intended to make explicit the distinctions the researcher brings to the phenomena that are salient to the research endeavor. As Lincoln and Guba (1985) state, inquiry is value-bound and is influenced by "inquirer values as expressed in the choice of a problem....and in the framing, bounding, and focusing of that problem...." (p. 38). In qualitative research, the researcher enters the field with an open mind, not an empty head (Fetterman, 1991, p. 90). The articulation of a theoretical lens is part of the process of opening the mind as it removes some of the "taken for grantedness" inherent in deeply held views while 
it facilitates the active refutation of those views in the research process. It is the beginning step in accounting for and constraining the influence of my perceptions on the research process.

Another reason for clearly identifying the theoretical perspective I bring to the study lies with the grounded theory methodology itself. Glaser (1978) refers to grounded theory as a "...general methodology for generating theory" (p. 164; see also Field \& Morse, 1985). In other words, grounded theory is a flexible, versatile methodology which must be contextualized within an additional theoretical perspective in order to be fully useful in the research endeavor.

The researcher does not approach reality as a tabula rasa. He must have a perspective that will help him see relevant data and abstract significant categories from his scrutiny of the data (Glaser \& Strauss, 1967, p. 3).

Charmaz (1990) points out that

although Glaser and Strauss are not explicit in The Discovery of Grounded Theory, they do assume that researchers have had solid training in their fields. Also, they assume that such training provides researchers with perspectives from which to observe and on which to build analyses, not merely to apply them. Glaser and Strauss' method fosters both using disciplinary and theoretical perspectives and contributing to their development with new ideas, dense analyses, and theory construction.... [However], ways in which grounded theorists use their prior theoretical perspectives remain somewhat ambiguous (p. 1164).

While nursing has made an explicit methodological connection between grounded theory and symbolic interactionism (Artinian, 1986; Bowers, 1988; Chenitz \& Swanson, 1986; Hutchinson, 1986; Morse, 1992; Morse \& Johnson, 1991; Stern, Allen, \& Moxley, 1984); this is not well supported by the writings of Glaser and Strauss. The early publications of Glaser and Strauss (1967; Glaser, 1978) make no mention of symbolic interactionism except in terms of critical review. In fact, Glaser (1978) makes 
a point of disavowing any connections to a particular theoretical perspective: "[Grounded theory] is not wedded to Sociology or Social Science - let alone to a school or position in Sociology" (p. 164). While Corbin and Strauss (1990a; see also Strauss \& Corbin, 1990) acknowledge the positive influence of Pragmatism and Symbolic Interactionism on the development of grounded theory, they assert that "...one need not subscribe to these philosophical and sociological orientations to use the method..." (p. 5).

I conclude that the methodological connection nurse researchers have made between grounded theory and symbolic interactionism is only one of many possible connections between an informing theoretical perspective and the method. It cannot be assumed that symbolic interactionism is the only perspective from which to develop a grounded theory. Certainly in the area of the nursing of families, Maturana's theory of the biology of knowing, which is a biological explanation of cognition that accounts for humans as essentially social beings, is a compelling alternative (Maturana, 1992; Maturana \& Varela, 1992). As Burman and Margolin (1992) point out, we now need interactional models that encompass biological, psychological and social variables if we are to adequately explain the complexities of health problems (see also Walsh \& Anderson, 1988). Rolland (1993) makes the argument that:

There is a vast literature describing the impact of chronic disorders on individuals and families. However, the impact of individual and family dynamics on disease has historically been defined as psychosomatic processes and almost invariably in pathological terms....An alternative framework would describe psychosomatic in more holistic, interactive, and normative terms. All illnesses can be viewed as having a psychosomatic interplay, where the relative influence of the biological and psychosocial varies over a range of disorders and phases of an illness. From this perspective, a psychosomatic interplay provides an opportunity for psychosocial factors, not just biomedical interventions, to be important influences in the healing process (p. 445). 
It is my perspective that nursing is long overdue in incorporating biology in a theoretical perspective that adequately addresses the reciprocity between persons, families and health/illness. It is time to "reconnect" mind and body.

\section{Maturana's Theory of the Biology of Knowing}

Humberto Maturana is a Chilean biologist whose remarkable work in the area of cognition has had a significant impact on family systems nursing (L. M. Wright, personal communication, September, 1992). His theory of the biology of knowing provides the theoretical underpinnings for the conceptualizations of family, individual/family member and change that inform this study. These conceptualizations will be developed through consideration of Maturana's ideas about objectivity and structure determined systems. Objectivity and (Objectivity)

Maturana (1992; and Varela, 1992) proposes that the basic cognitive operation is the distinction, which is, "any operation we perform that results in the separation of an entity from a background and which simultaneously specifies the entity and the background" (Maturana, 1984a, p. 20). A fundamental distinction he draws is between two views of reality, that is, objectivity-without-parenthesis and objectivity-withparenthesis (Maturana, 1988a, 1988b, 1992; Maturana \& Varela, 1992; Mendez, Coddou, \& Maturana, 1988). Objectivity-without-parenthesis is founded on the belief that there is an objective reality that is independent of the observer. In contrast, objectivity-with-parenthesis is founded on the belief that reality is observer dependent. Thus, existence of objects takes place in the distinctions of the observer (Maturana, 1992). Reality is brought forth through living in coexistence with others - it is "...indeed 
an explanation of the world that we live in with others" (Maturana, 1988a, p. 8). Maturana's (1983) experiments with vision in pigeons, frogs and salamanders has led him to make a compelling argument that "...there is no ultimate reference against which the reality we draw forth can be judged since there is nothing unless we distinguish it - these are all human activities" (Maturana, 1988a, p. 9). Therefore, "...there are as many domains of reality as there are kinds of operations of distinctions" (Mendez et al., 1988, p. 149). Given this, objectivity-without-parenthesis is deemed an inadequate explanation. The distinction between objectivity and (objectivity) is critical to family systems nursing and to the theoretical lens through which I view families and change. This lens is informed by (objectivity).

Organization and Structure Determined Systems

According to Maturana (1978, 1984a, 1984b, 1992; and Varela, 1992), a family like any other system, is characterized by both organization and structure. Organization is defined as "...the relations between components that define and specify a system as a composite unity of a particular class, and determine its properties as such a unity" (1978, p. 32). Thus, "'organization' signifies those relations that must be present in order for something to exist" (Maturana \& Varela, 1992). A family's organization is what permits an observer to draw the distinction of family. "Structure denotes the components and relations that actually constitute a particular unity and make its organization real" (Maturana \& Varela, 1992). The components of a family are its members; while, its relations are the network of conversations that characterize this particular family. The family's organization is a subset of the relations that constitute this particular family and 
pertain to the general distinction of family.

Since family is a composite unity, which is, by definition, realized through its components (Maturana, 1978), I believe that elaboration of structure and organization must begin with the fundamental building blocks of family members as living systems. In order to be distinguished as a living system, a unity must have autopoietic organization (Maturana \& Varela, 1992), that is, it is continually self-producing. All living systems are organized in this manner; while, their structures vary widely. A key characteristic of living systems is autonomy, which means that by being continually self-producing, the unity specifies its own laws or what is proper to it (Maturana \& Varela, 1992, p. 47). This results in what Maturana terms a structure determined system whereby the structure of the unity determines its interaction with the environment (Maturana \& Varela, 1992). The structure of a system is continuously changing in response to perturbations that arise from the environment in which it exists or from its internal dynamics. However, what is essential to grasp is that the structure of the system specifies which perturbations will be accepted and then further specifies how the unity will respond.

The continuous structural change that occurs in a living system is in service of its autopoietic organization, which must remain invariant if the unity is to continue as a member of its class. An analogy that Maturana (1984a) is fond of using is that of a tightrope walker who must be in continual motion in order to conserve balance on the rope. Thus, Maturana's theory encompasses both stability and change. Change is defined as a "difference which occurs across time" (Bateson, 1972, p. 452).

Ontogeny is the history of structural change in a unity without loss of organization in that unity. The ongoing structural change occurs in the 
unity from moment to moment, either as a change triggered by interactions coming from the environment in which it exists or as a result of internal dynamics (Maturana \& Varela, 1992, p. 74).

This means that the system is operationally and informationally closed and that instructive interaction is impossible. That is, the change of state that the system adopts in response to a perturbation can only be specified by its structure and not by the properties of the entity with which it interacts (Maturana, 1978). In nursing terms, an intervention is intended to be a perturbation; however, only the individual can specify any particular intervention as a perturbation.

To this point, I have established family members as living systems, which are autonomous, structure determined entities that, through interaction, specify continual structural change in service of invariant autopoietic organization. The next key aspect of this development is structural coupling. When a living system interacts over time with the environment in which it exists, or another living system, structural coupling occurs. Thus, structural coupling specifies that an encounter has taken place (Maturana, 1988) in which mutual perturbations have resulted in congruent structural changes in both the interacting systems. If structural coupling occurs over time rather than being a brief encounter, the interactions take on a recurrent or more stable nature and a coupled ontogeny results (Maturana \& Varela, 1992, p. 75). This means that a history of congruent structural change is established. It is in this way that family is drawn forth.

The structural coupling of organisms with nervous systems is termed a third order structural coupling (Maturana \& Varela, 1992), which gives rise to social phenomena. Thus, family is a social system in which "the individual ontogenies of all the participating 
[individuals/family members] occur fundamentally as part of the network of coontogenies that they bring about in constituting [this] third order unity" (Maturana \& Varela, 1992, p. 193). Family is drawn forth in the emotional domain of what Maturana (1984b) calls "stickiness" or love (and Varela, 1992), which means that there is mutual opening of space for the existence of the other family member(s) near oneself (Maturana, 1984b, 1992; and Varela, 1992). The organization of a family is the network of conversations and relations that realize a passion for living together (Maturana, 1988a).

Now the fundamental emotion that constitutes the family is the passion for living together. In these circumstances what I think is that as soon as the family is constituted as a group of persons under the passion for living together, there is an organization that is established and that organization is closed in the sense that the family will remain as a family as long as this particular organization has a network of relations and conversations and that the passion for living together is conserved (Maturana, 1988a, p. 7).

Thus, a family can be defined as:

a domain of interaction of mutual support in the passion for living together in physical or emotional proximity generated by two or more people (sometimes including other living beings) either through explicit agreement or because they grow in it in the happening of their living (Mendez et al., 1988, p. 155).

As with all other systems, a family's organization must remain (in principle) invariant or stable in order for it to continue to exist as a family. However, the family's structure, that is, its members and their relations, undergoes continual change triggered by perturbations arising from the environment or from internal dynamics. That is, change occurs in the context of our living.

Mendez and colleagues (1988) draw a distinction between family in general and family of a particular kind, which has implications for our ideas about the invariance of 
organization. Given this distinction, change in families may be of three types: 1. a family may undergo a change of structure such that organization is conserved; 2 . a family may undergo a change of structure such that organization is not conserved; however, a passion for living together remains and a family of a different kind is drawn forth; and, 3. a family may undergo a change of structure such that organization is not conserved and a passion for living together no longer exists so the family, in general, disintegrates (Mendez et al., 1988).

A few thoughts about family as a composite unity are required before moving on to the contribution change theory makes to my conceptualization of change in families. A family, as previously stated, is realized through its members and, as such, can only be known through its members. However, it is important to remember that the members exist in the domain of biology; while, the family exists in the domain of emotion. Therefore, it is critical that one not confuse family for family member and vice versa. Further, when working with family, it is critical to consider both family and family members.

....as an observer makes the distinction of a composite unity, he or she brings forth also the components that constitute it, otherwise the composite unity would not have been distinguished. Similarly, if an observer distinguishes an entity as a component of a composite unity, he or she brings forth also the composite unity that these components integrate, otherwise the components would not have been distinguished (Mendez et al., 1988, p. 163).

It is also important to acknowledge that persons exist in many different domains simultaneously, only one of which is as family member (Mendez et al., 1988, p. 170). Thus, family is different than family member and family member is different than 
person.

Although family is not itself a living system, it is drawn forth through the autopoiesis of its members (Maturana \& Varela, 1992; Mendez et al., 1988), which means that it can be considered a biological phenomenon. Thus, Maturana cautions us not to forget the biological roots of family, that is, family affects the biology of its members and vice versa.

The Contribution of Change Theory

The change theory of Watzlawick, Weakland and Fisch (1974) offers some complementary distinctions on which to elaborate the conceptualization of family change that was developed above. Like Maturana, these authors hold that both persistence (invariance or stability) and change must be considered together. That is, morphostasis and morphogenesis are inextricably linked rather than representing levels of change as Woods and Lewis propose (1992).

Watzlawick and colleagues (1974) arrive at a way of doing this by combining two mathematical theories. These are: 1. the Theory of Groups; and, 2. the Theory of Logical Types (p. 2). Although useful, it is my contention that a theory of change which is founded in mathematics has grave limitations when applied to biological and social systems. Therefore, I choose to use some of the concepts Watzlawick and colleagues (1974) have developed without ascribing to the entirety of their theory. Some of the limitations will be detailed in the discussion that follows.

Watzlawick and colleagues (1974) propose that there are two distinct types of change. First-order change occurs within a given system that itself remains unchanged; 
while, second-order change involves change in the system itself (p. 10). An unstated, underlying assumption of second-order change is that the system changes but does not disintegrate. An obvious limitation of this theory is that it does not account for the third possibility addressed by Mendez and colleagues (1988) that system change results in disintegration. Following from Watzlawick and colleagues (1974) I would call this type of change, third-order change. Despite, this limitation, it can be seen that the conceptualization of types or orders of change is compatible with Maturana's position. I have chosen to use these concepts primarily because they facilitate discussion about change since they are well understood among professionals dealing with change (for example Wright \& Watson, 1988).

First-order change constitutes the continual structural change inherent in the family system. It is what Watzlawick and colleagues (1974) term "commonsense change" because it follows logically from the rules or organization of the system. Both second- and third-order change are always discontinuous or in the nature of a logical jump (p. 12) since a transformation of the system is involved. Several important consequences can be derived from this theoretical perspective (that is, Maturana's theory coupled with concepts from change theory). The first is that, when perturbed, a family system will always respond with first order change. Much of the time this change in structure will be adequate to compensate for the perturbation; however, when it is not, a problem arises. "A problem is something that someone lives as a difficulty, and which he or she defines to him- or herself, or to someone else" (Mendez et al., 1988. p. 144). Thus, a problem is drawn forth in language. 
The second implication is that second- and third-order change are more difficult to achieve than first-order change as they require a change of the rules for change, which are specified by the system's organization. Thus, one of the ways problems arise for families is when first-order change is used in the context of a demand for second-order change (Watzlawick et al., 1974).

Watzlawick and colleagues (1974) propose a third implication with which I am in disagreement. This is that the conditions for second- and third-order change cannot be generated from within the system (Watzlawick et al., 1974, p. 15). In other words, the invariance of the system's organization prevents the generation of a new organization from within the system. While this may be true of mathematical systems, it does not account for the plasticity of living systems and their ability to engage in reflection. Maturana (1992) defines reflection as: "an operation where you are willing to release something you hold." In my mind this applies to the rules for change.

\section{How This Theoretical Lens Influenced the Research Process}

This theoretical lens influenced the research process in a multitude of ways: my conceptualization of the area of concern; my relationships with my co-researchers; my approach to the research conversations; and, the ideas that have been drawn forth in analysis. Here I wish only to comment on the influence of the theoretical lens on circumscribing the area of concern that oriented the study. I will detail the influence on research relationships and conversations in chapter two.

As previously noted, nursing research has focused solely on the effectiveness question in relation to nursing interventions, that is, does a particular nursing intervention 
bring about a predictable, desired outcome. The belief that underpins this aforementioned research is a belief in instructive interaction. This implies that a person can receive instruction from a nurse which specifies a certain change (Aboitiz, 1985).

However, Maturana and Varela (1992; see also, Wright \& Levac, 1992) make the compelling argument that instructive interaction is a biological impossibility since living systems are structurally determined and organizationally closed. A person selects those perturbations that fit its structure and then responds to the selected perturbation in a unique manner determined, again, by its structure. One can never know in advance which perturbation, or intervention, will fit for a particular person or family and one cannot predict the response. Further, Maturana and Varela (1992) draw attention to the context in which a nursing intervention is offered, that is, structural coupling in which there is an interactional pattern of mutual and reciprocal action and response between both the nurse and the individual or family.

It can be seen that this perspective provided a strong foundation for my concern with both interactional process and outcome in terms of accounting for the influence of nursing interventions on families' ability to live well with chronic illness. Further, this perspective draws forth a marked difference between my study and that of Swanson and Chapman (1994). Unlike Swanson and Chapman (1994) I do not believe in the possibility of instructive interaction and therefore, do not believe that outcomes can be predicted in advance. While these authors have tackled a significant issue in qualitative research, that of process in evaluation studies, they have attempted to examine the process of instructive interaction. During the course of their work, they raised the 
following question: "...was it foolhardy for us to have predicted outcomes for the quasiexperimental phase of the study when we were, in effect, exploring uncharted territory?" (p. 81). They do not propose an answer. From my perspective, the answer does not hinge on charting the territory but on the premise that every person will select and respond to a perturbation based on their unique structure. Thus, we are back to the question of what interventions work to heal suffering, how they work and in what circumstances. The search is for interactional patterns rather than linear sequences of standardized interventions and predicted outcomes.

Nursing is not unique in its focus on outcomes from the linear theoretical perspective of instructive interaction. Judd (1987) remarks on the repeated failure of researchers in the field of education to attend to process evaluation. As one might expect when outcomes are predicted in advance, "all too often, of course, this failure to examine the process by which a treatment variable of interest produces its effects results from the failure of outcome evaluations to demonstrate those effects in the first place" (Judd, 1987, p. 24). This clearly identifies one of the limits of approaching evaluation from the perspective of instructive interaction using only the quantitative research methods. If the hypothesized effect is not present and significant, there is no effect.

The Family Nursing Unit: A Significant Contextual Element

I was interested in accounting for nursing interventions offered within a particular nursing practice with families, that is, the practice at the Family Nursing Unit (FNU) in the Faculty of Nursing, University of Calgary. The faculty of the FNU include Dr. Lorraine Wright, Director, and Dr. Janice Bell, Research Coordinator. The FNU is a 
unique education and research unit that offers assistance to families who are experiencing difficulties with health problems (Wright, Watson \& Bell, 1990). Here, the family system is the unit of care, which means that there is a simultaneous focus on the individual/family member and the family (Wright \& Leahey, 1990). The clinical approach developed within the unit has been termed Systemic Belief Therapy (Robinson, Wright \& Watson, 1994; Watson \& Lee, 1993; Wright \& Nagy, 1993; Wright \& Simpson, 1991; Wright et al., 1990). This means that systemic thinking informs clinical practice such that attention is consistently and systematically paid to interaction and reciprocity (Watson, 1992; Wright \& Leahey, 1990), particularly between beliefs and problems since "what we believe is the most powerful option of all" (Wright \& Simpson, 1991, p. 167). The most significant assumption guiding Systemic Belief Therapy is that "...the belief about the problem is the problem" (Wright \& Nagy, 1993). Systemic Belief Therapy emphasizes constraining and facilitative beliefs.

The therapeutic approach focuses on challenging families' constraining beliefs and coevolving facilitative beliefs. Through this process, family strengths and resources are drawn forth that invite the discovering and uncovering of solutions to problems. Constraining beliefs perpetuate problems and reciprocally are perpetuated by problems. Constraining beliefs restrict options and solutionseeking ability. Conversely, facilitative beliefs increase options and avenues for change (Watson \& Lee, 1993, p. 38).

Constraining beliefs are challenged through the offering of new connections between beliefs and behaviors. That is, interventions are offered in the medium of language. When the new connection "fits" for the person or family, the constraining belief shifts and change occurs (Wright \& Nagy, 1993). 


\section{The Setting}

Within the FNU, each family benefits from a clinical nursing team approach. The family is interviewed by a nurse who may be a graduate student or a faculty member. The process is observed via one-way mirror by the clinical nursing team comprised of a supervising faculty member and graduate students who participate in the therapeutic process via a telephone intercom with the interviewer (Wright, Watson, \& Bell, 1990). From time to time, the supervisor telephones questions or suggestions to the interviewer. In addition, each therapeutic session is videotaped. Unless something unforeseen arises, the interviewer remains consistent throughout the therapeutic process.

\section{The Process}

The therapeutic process is organized around the five part session (Selvini Palazzoli, Boscolo, Cecchin, Prata, 1978; Tomm, 1984; Wright et al., 1990): 1. Prior to each session, the interviewer and team meet to discuss ideas pertaining to the family's health problem. Current literature is reviewed and hypotheses proposed that might explain what is going on along with assessment questions designed to elicit a better understanding of the family's concerns. Thus, the interviewer is sensitized to potential issues and the therapeutic session is used to maximum advantage; 2. A therapeutic conversation ensues in which constraining and facilitative beliefs are drawn forth through the asking of questions by both the nurse and the family members (Wright, 1989; Wright \& Nagy, 1993) and interventions are offered; 3. Towards the end of the session, the nurse leaves the interview room and meets with the team to discuss ideas regarding the family's concerns; 4. Summary comments, ideas, opinions and/or recommendations 
(interventions) are offered to the family. These remarks always include specific commendations to the family and family members that address the strengths distinguished by the interviewer and the team. The interviewer may do this on behalf of the team or the family may be offered the opportunity to hear the team discuss, which is called the reflecting team (Andersen, 1987, 1991). When this occurs, the family and interviewer exchange places with the team. The family now is in a reflecting position behind the one-way glass. Following the reflecting team, there is again an exchange of places and the family is asked to comment on the comments of the team, e.g. what stood out for them; what fit for them; what was useful or not useful; and, 5. The interviewer and team meet to discuss the session and ideas for follow-up. Sometimes the therapeutic work formally extends between sessions via letters from the team to the family.

In the past, families have been seen for an average of 6 sessions in the FNU (Wright et al., 1990); however, more recently, families have been offered a total of four sessions. The families then choose how they wish to use the four sessions, that is, they choose when and how often they come to the FNU. It is interesting to note that many families find two or three sessions to be helpful and choose to put one or two sessions "in the bank." If all four sessions are used, then the interviewer, team and family evaluate the progress to date and co-determine if further sessions are required.

Six months after the completion of therapeutic work the families are asked to participate in an outcome study where they evaluate the service received in the FNU.

\section{Working Definitions}

I would like to clarify my working definitions of some key concepts. 
Change: a "difference which occurs across time" (Bateson, 1972, p. 452).

Chronic condition: I am grateful for the sensitizing effect of Kleinman's (1988) clear distinction between disease and illness. He defines disease as one interpretation of a health problem that is made from the perspective of the biomedical model. It is "...an alteration in biological structure or functioning" (p. 5). I prefer to use the word "condition" rather than disease since the word is more encompassing and more acceptable to families. For example, many families have difficulty viewing diabetes as a disease but will readily acknowledge it as a condition. Therefore, the definition I favor is:

Any anatomic or physiological impairment that interferes with an individual's ability to function in the environment. Chronic conditions are characterized by relatively stable periods that may be interrupted by acute episodes requiring hospitalization or medical attention. The individual's prognosis varies between a normal life span and unpredictable death. Chronic conditions are rarely cured, but they are managed through individual and family effort and diligence (Thomas, 1984, p. 165).

Chronic Illness:

By invoking the term illness, I mean to conjure up the innately human experience of symptoms and suffering. Illness refers to how the sick person and the members of the family or wider social network perceive, live with, and respond to symptoms and disability (Kleinman, 1988, p. 3).

Chronic illness is drawn forth within the family through the interaction and reciprocity between family members and the chronic condition.

Family: a social system drawn forth in the emotional domain of love. It is a group of persons constituted under the passion for living together who have a network of relations and conversations (Maturana, 1988a, p. 7). Family members are whoever the family says they are.

Illness Burden: the composite of illness responsibility, illness work and illness 
problems.

Illness Problems: the difficulties of living that are drawn forth when one is in relationship with illness.

Illness Work: the multitude of activities, large and small, that are undertaken to protect family and family members from the influence of illness.

Illness Responsibility: the sense of being ultimately accountable for protecting family members from the influence of illness.

Patriarchy: "a...system in which the balance of power and authority between men and women favours men" (Vickers, 1984, p. 37).

Theory: "...explicates a phenomena, specifies concepts which categorize the relevant phenomena, explains relationships between concepts and provides a framework for making predictions" (Charmaz, 1990, p. 1164).

Therapeutic Change: a difference over time that, from the family's perspective, is influenced by nursing interventions offered in the Family Nursing Unit at the University of Calgary.

Woman: the wife/mother in the family.

\section{Ethical Considerations}

The study was reviewed by the Conjoint Areas Ethics Committee of the University of Calgary and the protocol for insuring adherence to ethical standards was deemed acceptable. Specific strategies that were used to insure confidentiality and anonymity will be discussed in relation to the research process. 
Significance of the Study

I have previously emphasized that the development of the specialty of family systems nursing requires research that focuses on interventions and leads to mid-range theory development. I have also argued that research pertaining to interventions has attended to outcomes while process has virtually been ignored.

In terms of the state of the science of family nursing research, several reviews point to the predominant use of individual level data based on the individual as the unit of data collection (Feetham, 1984; Gilliss, 1989; Hayes, 1993). This continues despite clear evidence of the limitations of attempting to explain interaction from the perspective of single family members (for example Anderson \& Elfert, 1989) and a consistent call among family nurse researchers for attention to the family as the unit of analysis (Feetham, 1984, 1990, 1993; Gilliss, 1983, 1991; Gilliss \& Davis, 1992; Uphold \& Strickland, 1989).

Given this contextual background, the current study is both significant to family nursing and unique within family nursing research for several reasons:

1. both process and outcomes in relation to family systems nursing interventions are the focus of attention;

2. the research product is a theory that gives some insights into both individual and family system responses to chronic illness;

3. the mid-range theory gives direction for nursing practice with families experiencing a member's chronic condition;

4. all the data are transactional level (Fisher, Kokes, Ransom, Phillips, \& Rudd, 1985), 
that is, gathered from family members in interaction. This means that the data are of family rather than about family (Fisher et al., 1985); and,

5. since data were collected over approximately a two year period, the study is longitudinal in design rather than cross-sectional which, again, predominates in family research (Gilliss, 1989).

Boundaries of the Theory

The grounded theory that is the product of the current study pertains to middleclass, Caucasian families who were experiencing difficulty living with a member's chronic condition. Specifically, the families who joined the study, were clinical families who sought professional assistance from the Family Nursing Unit in relation to problems managing chronic illness.

The Issue of "Goodness"

Marshall (1990) identifies "persistent goodness questions" as ones that arise over and over again in relation to considerations of qualitative methodology (p. 189). Answers to many of the questions she raises are accounted for in the grounded theory approach. For example: when permitted to stand out, the research question/problem will always be important; theoretical saturation determines when enough sampling has occurred; the study is finished when the categories and their properties as well as hypotheses about the relationships between them are integrated into a theoretical schema around a core variable or process; the process of constant comparison is a built-in check against researcher bias dominating the theoretical formulations; replicability is a nonrelevant criterion for a theoretical product (grounded theory), which is never considered 
to be fact but rather a never-ending process; and, the writing of the grounded theory conveys credibility through an extensive presentation of both the theoretical framework and vivid description of the substantive area in relation to the theoretical framework.

Several aspects of how grounded theory research is carried out enhance the likelihood of credible findings (Lincoln \& Guba, 1985). These include the systematic processes of constant comparison and theoretical sampling as well as the strategy of returning to participants for endorsement of the grounded theory (Lincoln \& Guba, 1985; Stern, 1985). Confirmability (Lincoln \& Guba, 1985), or reliability of the data on which the grounded theory rests, can be achieved by auditing the readily available paper trail consisting of transcriptions, field notes and memos. In fact, Brink (1991) points out that "grounded theorists who use Glaser and Strauss methods follow a...protocol for data collection and analysis that essentially eliminates the problems of reliability" (p. 180).

The determination of transferability (Lincoln \& Guba, 1985) or theoretical generalizability, rests on whether the theory is "applicable to others who experience the same conditions or illnesses" (Morse \& Johnson, 1991, p. 9). Glaser and Strauss (1965, 1967) view this determination as a joint responsibility of the researcher and reader of grounded theory. The researcher must present the context in which data were gathered (sending context) in sufficient detail such that the reader can make his or her own judgements about the similarities and differences between the sending and receiving contexts (context in which the theory may be applied). Further, the research process should also be made explicit. Both facilitate the "discounting process" (Glaser \& Strauss, $1965)$ that is the responsibility of the reader. 
This ongoing discounting process of qualification by the reader allows the researcher to write his [her] theory in general form, because the researcher knows that the reader will make the necessary corrections, adjustments, invalidations, and inapplications when thinking about or using the theory (Glaser \& Strauss, 1965, p. 292).

Glaser and Strauss (1965, 1967; Glaser, 1978, 1992) also address goodness criteria specifically relevant to theories (product) as opposed to qualitative research (process). To be useful, a theory must: fit the data; work in terms of explaining what happened, interpreting what is happening and predicting what is likely to happen; be relevant to the action of the area; and, be presented in such a way that it is readily modifiable (Glaser, 1978). A grounded theory meets these criteria. Further, a grounded theory is both dense and parsimonious as a result of being organized around a core variable or process. Only categories having a direct relationship with the core variable or process are integrated into the theory.

The issue of "goodness" will be taken up again in chapter two. 


\section{CHAPTER TWO}

\section{THE RESEARCH PROCESS}

...there is a kinship between art and science, and qualitative research bridges these realms of meaning (Sandelowski, 1993, p. 3).

By neither denying nor minimizing the kinship between art and science, qualitative researchers have available to them the distinctive opportunity and even the obligation to show the way toward a poetic for inquiry: toward a science that both acknowledges and celebrates its art (Sandelowski, 1994, p. 49).

As Morse (1991) asserts "the most important quality for researchers in qualitative research is their creative ability, the ability to be perceptive and to think abstractly" (p. 20). This chapter addresses more the science of the research process than the art; however, it is my hope that the creativity inherent in the process will shine through the product of the endeavor, that is, the theory (see also May, 1994).

As with any general methodology, grounded theory's actual use in practice has varied with the specifics of the area under study, the purpose and focus of the research, the contingencies faced during the project, and perhaps also the temperament and particular gifts or weaknesses of the researcher (Strauss \& Corbin, 1994, p. 276).

\section{A Word About Language}

Language is extremely powerful, for it is through language that realities are drawn forth (Maturana \& Varela, 1992). My concern about the power of language has led me to abandon some of the terms/phrases that are an accepted part of the language of grounded theory. As Lowenberg (1993) asserts, language in interpretive research methodologies has come to be seen "...as increasingly complex, situated, and problematic" (p. 63). The following, brief explanation will serve to clarify some decisions I have made regarding language that I found to be particularly problematic in 
grounded theory.

I do not believe that ideas, questions or theory "emerge" from the data. Indeed, as May (1994) asserts: "we talk about 'emerging from the data' which is garbage. We DRAG it out of the data!" (p. 10). Like May, I believe that the researcher draws forth ideas, questions and theory from the data through diligent interaction and the process of making distinctions. I agree with both Morse (1994), who believes that the process is characterized by hard work, and May (1994), who believes that the analytic process incorporates an element of magic. The process is NOT magical; however, there are magical moments when insight is achieved seemingly "out of the blue."

Further, I do not believe that a theory is either "found" or "discovered." As Sandelowski (1994) asserts: "The kinship of art and science can be affirmed in their mutual beginnings in the creative act. Indeed what we typically have called discovery is creation" (p. 50). Again, the term that is most consistent with the theoretical perspective I bring to this study is "drawn forth" (Maturana \& Varela, 1992).

Finally, I do not believe that the data speak to me (see also Charmaz, 1983) and so do not ask questions of the data. Instead, I ask questions about the data to stimulate an internal conversation and interaction with the data that advances analysis.

\section{Co-Researchers}

I have also struggled with how to refer to the families who participated in the study. As Mishler (1986) points out, "in the mainstream tradition the intervieweeinterviewer relationship is marked by a striking asymmetry of power" (p. 117; see also Anderson, 1991). However, as elaborated below, I actively sought to reduce this 
asymmetry in my relationships with the families who joined the study. I have chosen the term "co-researcher" to reflect the families' role in defining the research question, coevolving the data and contribution to analysis. However, this term is not entirely representative in that the families' participation in analysis stopped after a relatively broad framework had been developed. The bulk of the work of interpretation is my own.

\section{Criteria for the Invitation to Participate}

Families were invited to participate in the study:

1. who had sought assistance from the FNU for difficulties associated with a member's chronic condition;

2. who had completed therapeutic work at the FNU at least six months prior to the invitation to participate. All of the therapeutic sessions for three of the families were conducted by Dr. Wright; while, a graduate student conducted the therapeutic sessions for two of the families;

3. for whom there was consent to use the videotapes of the therapeutic sessions for research purposes. This is part of a consent that is routinely obtained at the beginning of all therapeutic work with families (Appendix A). Families have the option of consenting to the use of the videotapes for research purposes;

4. for whom there were outcome data. Families are routinely requested to evaluate the service they received in the FNU by participating in an Outcome Study six months following completion of therapeutic work;

5. who had had no therapeutic involvement with me (I did not conduct the therapeutic 
sessions nor was I involved in any way as a member of the clinical team). This enabled me to enter the research relationship as a stranger (Morse, 1994), which is one way of avoiding bias; and,

6. who Drs. Wright and Bell identified as key informants regarding the process of therapeutic change.

Families who met the criteria were invited to join the study via letter (Appendix B), which was followed by a telephone call approximately one week later. If the family expressed interest in joining the study, a meeting was arranged. All of the research conversations but one took place in the family's home at their convenience. One family was seen at the FNU at their request.

The Evolution of the Research Question in Conjunction With Theoretical Sampling

The first three families who agreed to join the study had a child member who experienced the chronic condition. The children's ages varied from preschool, to adolescent, to young adult. As previously stated, the research question that gave me a starting point for the study was: "What do nurses do that assists or hinders families in living with a member's chronic condition and how do the interventions work?" I was sensitive to the context in which these families had sought assistance, that is, difficulty managing a chronic illness. In addition, previous research with families experiencing a chronic illness had taught me the importance of eliciting the story of life over time with illness. Thus, I set the stage for the families by telling them of my interest in the therapeutic process and at the same time I invited them to tell me about their experiences with chronic illness. In particular, I was curious about what led to their difficulties and 
subsequently to seeking assistance at the FNU. As I listened and participated in drawing forth these stories, I was struck by the existence of a pattern that each of the three families shared. That is, in each of the families it was the woman who had experienced marked difficulty with the chronic condition and it was the woman who had sought assistance from the FNU for herself and her family. The question that arose as most relevant to these families was: "What happens to and for a woman when a child experiences a chronic condition?" Thus, the focus of the exploration became much broader and encompassed the original question.

As the research process was guided by this new question and the shared pattern became more clear, I began to wonder if this pattern was unique to families where a child experienced the chronic condition. Were the implications for women of having a chronic illness in the family only significant when a child was sick? The evolving theory led me to actively seek a family where the woman (wife/mother) experienced the chronic condition and one where the man (husband/father) experienced the chronic condition. These last two families showed the same general pattern: the women experienced difficulty related to the chronic illness and sought help from the FNU. Thus, again the focus of the study shifted toward an even broader question. I learned from the inclusion of the last two families that the most relevant question for all five families was: "What happens to and for women when a chronic condition enters the family?" This was the research question that oriented the ongoing research process of theoretical sampling and constant comparative analysis.

I was unable to obtain a family within the FNU where the husband/father 
experienced a chronic condition, who met the criteria for invitation and who were willing to join the study. Through discussion with Drs. Wright and Bell, it was decided that the best solution was to invite a family who had been seen by Dr. Wright in her private practice. The clinical work would be consistent with that done in the FNU but the drawback to this decision was that the therapeutic sessions had not been videotaped and outcome data were not available. The family did agree to join the study and the advantages of having their perspective far outweighed the limitations of absent data.

\section{The Families/Family Members Who Joined the Study}

The invitation to join the study was issued to the family as a whole with the request for participation of as many family members as possible. I did not restrict participation in the study to only family members who had been involved in sessions at the FNU. This decision was based on the belief that all family members would have been affected by the therapeutic process whether or not they had been present at the therapeutic sessions. Consequently, three family members contributed to the study who had not attended sessions at the FNU. I accepted the family's decision about who would participate in the study; while always being clear that I wished to speak to as many members, together, as possible. All family members demonstrated their agreement to join the study by signing a consent to participate (Appendix C). These consents were kept under lock and key in a different location than the data.

It is common practice among nurses who are working with families to present family data in the form of a genogram. However, I was concerned that genograms with pseudonyms would not adequately insure confidentiality and protect the privacy of my 
co-researchers. Therefore, I have decided to present a very general description of the families and hope that their own words (as found in chapter three) will adequately represent them.

Fourteen family members from five Caucasian families joined me as coresearchers in this study. They ranged in age from eight to fifty-seven. All of the families were traditional in structure in that they consisted of two parents who were joined by marriage and several children. All of the husbands/fathers worked outside the home; while, three of the wives/mothers were employed outside the home. Two women worked full time and one woman worked part time.

The focal chronic conditions (that is, the conditions that brought them to the FNU) were: ankylosing spondylitis, chronic fatigue syndrome, depression, diabetes, myocardial infarction, panic attacks and tetralogy of fallot. As in many families, these were not the only chronic conditions that were present. Other conditions included: alcohol problems, hypertension, manic-depression and non-malignant tumor.

The families were seen between two and four times for therapeutic sessions.

\section{The Research Relationship}

In grounded theory, data collection and analysis proceed simultaneously (Glaser \& Strauss, 1967). "Grounded theorists shape their data collection from their analytic interpretations and discoveries, and therefore, sharpen their observations" (Charmaz, 1983). Thus, what data are collected is guided by the evolving theory. However, little direction is given for how data are collected nor for the development of the context for data collection, that is, the relationship between co-researchers. In fact, one of the 
criticisms of the method is that "...'data' are treated in an overly empiricist and unproblematic fashion" (Emerson, 1983, p. 96; see also Lofland \& Lofland cited in Charmaz, 1983). This criticism centers on grounded theorist's lack of attention to the theoretical perspective they bring to the research endeavor and to the relationship between "data" and the persons whom the data are supposed to represent (Emerson, 1983).

Like Charmaz (1983), I believe that this criticism "misinterprets the aims and methods of grounded theory" (p. 109). However, while Charmaz (1983) attributes the misinterpretation solely to a problem of language, I believe it is also a problem of emphasis. Glaser and Strauss (1967) succeeded in presenting a general methodology that is widely applicable to a variety of disciplines and theoretical perspectives. They acknowledged the need for an additional, informing theoretical perspective but did not emphasize that this must be made explicit (Glaser \& Strauss, 1967, p. 3). In my experience, it is this additional theoretical lens or perspective that offers direction for both the how of data collection and the context of data collection.

As already stated, the theoretical lens that informs this study is based on Maturana's theory of the biology of knowing (1992; and Varela, 1992). I view the data as a reality drawn forth in language through the structural coupling of myself and the family members to form a "research system." Structural coupling implies mutuality, that is, interaction and reciprocity where my actions influenced family members and their actions influenced me. Thus, the data were not collected but were co-evolved in conversation. It is interesting to note that Strauss and Corbin (1994) view this 
"reciprocal shaping" as serving theoretical sensitivity.

I was acutely aware of my responsibility in terms of the research relationship and wished to "live" my beliefs in the non-hierarchical, reciprocal nature of structural coupling. This was done through acknowledging the various expertises we brought to the research endeavor. The family members brought their expertise in living with a chronic condition, experiencing difficulty and receiving help. I brought my expertise in systemic thinking, asking useful research questions, and being equally interested in all perspectives. Thus I approached the families with immense respect and curiosity. They responded with openness and were remarkably forthcoming. Together we were able to draw forth the relevancies in the area of concern. This was assisted by inviting the families to ask questions (Wright, 1989). For example, I freely admitted that I often did not know the most important or relevant questions to ask and then invited family members to offer the questions that I could have asked but had not.

Finally, I was both interested and concerned about the impact the research conversations might have on the family and family members. Therefore, at the conclusion of each conversation and at the beginning of subsequent conversations, I routinely asked this question: "What stood out for you from our conversation?" (Wright, personal communication, September, 1992). This enabled me to track perturbations arising from the research conversations. For example, I learned that in one family the research conversation offered the eldest sibling of a sick child her first opportunity to talk about her experience with illness. She said that it helped her to get it out and now she would not be afraid of saying what was important to her. She learned that her story 
would be heard. Her mother learned things about her daughter that she never knew before and was deeply touched. I learned more about the unexpected power of healing in conversation.

\section{The Data: Windows in Time}

The data were comprised of (in chronological order): demographic information in the form of genograms that were constructed during the first therapeutic session; videotapes of the therapeutic sessions (12 in total); outcome studies where the families evaluated the service they had received and commented on its influence over time (4 in total); transcriptions of the research conversations with the families (9 in total); and fieldnotes. Each of the pieces of data offered a unique view of the phenomenon of interest, that is, what happens for women when a chronic condition enters the family. Thus, they opened "windows in time." I was given access to the demographic data, videotapes of therapeutic sessions and outcome studies with the permission of Dr. Lorraine Wright and Dr. Janice Bell.

For me, data co-evolution (and analysis) began with the indepth, and relatively unstructured research conversations I had with the families. These conversations were initiated eight months to two years after the completion of therapeutic work and they were audiotaped. At the outset I introduced the area of interest as being "what nurses do to help or hinder the family's ability to live with a chronic condition." In particular I was interested in their experience with nurses in the FNU. However, past clinical and research experience with persons experiencing a chronic condition and a belief that I needed to understand the context of the decision to seek assistance at the FNU led me 
to begin by asking the families to tell me about their life with the chronic condition. That is, I asked them to talk with me about chronic illness. As already discussed, this invitation was critical to the process of drawing forth what the families experienced as relevant to their circumstances.

The research conversations continued as the family's explanations stimulated my questions and comments, and vice versa. I had no predetermined hypotheses about what would prove relevant in the families' situations; however, my theoretical sensitivity (Glaser, 1978) was enhanced by being steeped in the literature regarding the nursing of families (p. 3) and prior experience with individuals experiencing chronic illness. Thus, the conversations were structured by the families' unfolding stories (May, 1991).

The research conversations became more and more focused over time as concurrent analysis informed my understanding of the relevancies in the situation (see also May, 1991). I worked intensely with the first three families through the process of repeated conversations over time; whereas, I had only one interview with each of the last two families because by that point I knew most of the useful and relevant questions to ask so the exploratory focus was considerably narrowed.

My co-researchers were all busy people in busy families. Therefore, it took considerable commitment and effort for them to participate in the conjoint interviews. Careful preparation for every interview enabled me to maximize my time with each family and also to address the problem of consistency across research conversations (May, 1991). Preparation included reviewing notes and questions arising from previous interviews and the development of a list of questions to be asked. 
The Process of Drawing Forth a Theory

The analytic process began with the first research conversation. (The analytic process is summarized in Appendix D). I transcribed the first three conversations in order to assist my immersion in the data; while the last six were professionally transcribed by a paid, experienced typist. When each of these last six transcriptions was complete, I listened to the audiotape and read the transcription simultaneously so that I could check and correct any errors (see also Mishler, 1986). This proved to be a critical aspect of the process since, even with an extremely conscientious typist, the multiple voices present in the conversations made for a difficult task. Although errors were infrequent, they often changed the conversation in significant ways. For example: "And it just -- I don't know -- something I never thought about" was corrected to read "And it just -- I don't know -- something wonderful happened."

No names were used in the transcriptions. Instead, family members were referred to by a family role, for example: $\mathrm{M}=$ mother, $\mathrm{F}=$ father, $\mathrm{C} 1=$ firstborn child and so on. When the transcriber had difficulty determining a child's position, she referred to the child by the first letter of the first name. The transcripts and audiotapes were identified solely by codes and were kept under lock and key.

Each research conversation was transcribed and analyzed before another conversation took place (Glaser, 1978; Glaser \& Strauss, 1967). I asked three questions about the data: 1. What is going on here? 2. What is influencing what is going on here? and, 3. How does this relate to what I already know? The constant comparative method of analysis was used (Glaser, 1965; Glaser \& Strauss, 1967). Open coding 
where the data are "fractured" into small pieces (Glaser, 1978; Glaser and Strauss, 1967; Strauss, 1987) occurred virtually simultaneously with theoretical coding (Glaser, 1978), which involves drawing forth the theoretical links between the pieces.

As I developed ideas about what was important in relation to living with a chronic condition I was able to check them out in the next research conversation. Very early in the process, a pattern or core process stood out as being the salient element that organized the families' accounts of chronic illness. This core process revolved around the women's relationship with chronic illness. Thus, coding rapidly became more selective (Glaser, 1978; Strauss, 1987). An analytic framework was drawn forth that was comprised of sequential stages, which was supported and elaborated with each research conversation. Analysis proceeded "by hand" with notes made on transcripts and frequent memos. As the analytic loop (that is reading the transcripts - hypothesizing returning to the transcripts or the families for confirmation and elaboration hypothesizing...) was repeated again and again, the codes became more and more theoretically abstract.

Once a core process was developed that was supported by all the research conversations with all the families, computer analysis was begun for the purpose of systematically confirming and elaborating the stages of the process. This was done using Word Perfect and was initially based on the categories, subcategories and properties that had been earlier identified and organized by hand. The computer analysis was basically a sophisticated version of cutting and pasting and was done using the "switch" command, which enabled me to work in two documents simultaneously. 
I worked from a hard copy of the transcript as well as a copy of the transcript in document one. In document two, I moved in and out of analysis files, that is categories and subcategories as appropriate. I continuously read the transcript with the following questions in mind: "What is this about?" and "How does this fit?" Once I had answers, I moved to document two and called up (or created) the appropriate analytic file. I identified the transcript, line numbers, made comments about my thoughts regarding how the data related to the category or subcategory and then copied the data segment to the analytic file. Macros enabled easy access to analytic files and simultaneous saving to hard drive and floppy disk.

Throughout this analytic process, categories, sub-categories and their properties were eliminated, added, renamed and elaborated; however, the core process remained well supported. The relationships among the elements of the process were also developed. I continued to write frequent theoretical and process memos. The theoretical memos kept track of my evolving ideas about the theory being drawn forth; while, the process memos kept track of my concerns and decisions regarding the analytic process as well as moments of insight and what had triggered that insight.

Once the computer analysis of the transcripts was complete, I viewed the videotapes of the therapeutic sessions. The videotapes were theoretically sampled in relation to the evolving theory. In particular, I paid attention to what the family members said at that earlier time about the problem and the therapeutic process. I was curious about how these data fit with what the family members said during our research conversations. I wanted to account for differences or similarities over time rather than 
using one "slice of data" (Glaser \& Strauss, 1967) to verify another. The outcome study data were theoretically sampled and analysed following completion of the process with the videotapes.

Glaser and Strauss (1967) assert that various slices of data "...yield more information on categories than any one mode of knowing" (p. 66) and this was certainly my experience. Given concerns about the limitations of recall and the lengthy time period that had elapsed between the end of therapeutic work and the beginning of the research conversations, I was amazed at the remarkable consistency among the various slices of data. This supported both the integrity of the theory and my belief that theoretical saturation had been achieved.

Once I had finished with the transcriptions, videotapes and outcome data, the categories became my data. I worked intensively with the analytic categories to insure consistency, coherence and fit.

\section{Decision Re: Coding Paradigm}

Despite Strauss and Corbin's (1994) assertion that "...grounded theory researchers are interested in patterns of action and interaction...." (p. 278), the coding paradigm seems only to capture action. That is, it rests on assumptions of linear causality that are not compatible with the theoretical perspective that informs this study. Therefore, I did not use Strauss' (1987) coding paradigm. I have difficulty with the seemingly prescriptive nature of the coding paradigm since it imposes one theoretical view on the data and on the evolving theory that may not, and in this case does not, fit the area of inquiry. However, the intent may not be prescriptive since Strauss (1987) only 
"suggests" its use (p. 27).

After reading the works of Glaser $(1978,1992 ; \&$ Strauss, 1967) and Strauss (1987; \& Corbin, 1990) I have drawn the conclusion that there are two distinctly different views of grounded theory (Robinson, 1993a). Stern (1994) captures the differences succinctly:

In Glaser and Strauss we have two brilliant men who both do important work. But they go about it in different ways. The crux of the dichotomy is, I think, that Strauss, as he examines the data, stops at each word to ask, "What if?" Glaser keeps his attention focused on the data and asks, "What do we have here?" Strauss brings to bear every possible contingency that could relate to the data, whether it appears in the data or not. Glaser focuses his attention on the data to allow the data to tell their own story (p. 220).

As reflected in my decision against using Strauss' (1987) coding paradigm, my work follows the Glaserian school (Stern, 1994) of grounded theory.

\section{Writing the Theory}

The aim of grounded theory is to move beyond the particular in order to identify general patterns and regularities (Emerson, 1983). The researcher attempts "...to arrive at theoretical statements of general scope and applicability, yet at the same time trying to keep these theories close to the distinctive meanings of actual...life" (Emerson, 1983, p. 93). Thus, a grounded theory both transcends the data from which it is drawn forth and, at the same time, remains sensitive to context (Glaser \& Strauss, 1967; Glaser, 1978). Therefore, the theory is presented in a grounded fashion, that is, in concert with illustrative excerpts of research conversations. Grounded theory is interpretive work and, as such, must include the voices of those we study (Strauss \& Corbin, 1994).

The excerpts presented in the following chapter are verbatim transcriptions that 
have been edited only to enhance readability. The names of my co-researchers are pseudonyms; while, I refer to myself by first name. This is consistent with the nonhierarchical nature of the research relationships.

The theory of Women, Families, Chronic Illness and Nursing Interventions: From Burden to Balance is a four stage process that represents women's evolving relationship with chronic illness. Further, each stage in itself represents a process. Thus, the first stage chronicles the evolution of overwhelming illness burden for these women that leads to precarious life balance. The second stage captures a process of falling down and falling apart that occurs after an illness related loss. The third stage deals with the therapeutic change process that is initiated by the women on their own behalf and on behalf of their families. The fourth stage addresses the women's evolving relationship with self that was begun in the therapeutic process and continues as illness is put in its place.

I have attempted to make the research process transparent and to present the findings in such a manner that the reader can make an informed decision regarding the trustworthiness or goodness of both the process and product. The only facet of the process I have not completed is formal member checking regarding the "finished" theory; however, informal member checking occurred throughout the research conversations. I have made a commitment to the families that they will receive an abbreviated version of the theory and I will welcome their comments at that time.

Sandelowski (1993) presents a compelling argument regarding the theoretical and ethical difficulties associated with the technique of member checking and notes that it 
may draw forth more problems than it solves (see also Opie, 1992). Further, she (1993) warns of the liabilities associated with approaching the issue of rigor in qualitative research from a rigidly rule-bound perspective. For her

trustworthiness becomes a matter of persuasion whereby the scientist is viewed as having made those practices visible and, therefore, auditable; it is less a matter of claiming to be right about a phenomenon than of having practiced good science (Sandelowski, 1993, p. 2).

This chapter has made the research process visible in order to facilitate decisions about whether "good science" has been practiced. I hope that the theoretical product presented in the following chapter captures the creative artistry that is also fundamental to the spirit of qualitative research (Sandelowski, 1993). 


\section{CHAPTER THREE}

\section{DRAWING FORTH A THEORY: WOMEN, FAMILIES,} CHRONIC ILLNESS AND NURSING INTERVENTIONS

The real voyage of discovery consists not in seeking new landscapes but in having new eyes (Marcel Proust).

\section{Stage One}

Women, Families and Chronic Illness: Overwhelming Burden

When chronic illness enters a family it often has a demanding and overwhelming presence. Many adjustments are required, particularly of the women who are the wives and mothers in the household. This stage captures the beginning of the stories of five women, their families and their experiences with chronic illness. It tells of the women's evolving, pivotal relationship with chronic illness that involves a remarkable burden.

\section{Chronic Illness: The Uninvited, Unwelcome Family Member}

Chronic illness entered these families as an uninvited, unwelcome stranger. In some families, the illness entered suddenly; while for others it was insidious. The damage illness wrought was quietly hidden in some families and in others it was openly destructive. The hope that illness would leave, as quickly as it came, kept some families from getting acquainted with the new family member. As Samantha said: "All I can think of is in the beginning, we thought it would go away." For the longest time, they did not realize "what it was." The illness might have been faceless and nameless, but a threatening presence nevertheless. "Her chronic fatigue was like a burglar, I guess, to me. Sneaking."

Each of the families talked about trying to make sense of this unwanted stranger 
in their midst. Some illnesses were harder to get a sense of than others because acceptable explanations varied and thus so did each family's understanding of the illness.

Each family member had a relationship with illness. That is, each member experienced and responded to the presence of a chronic condition in the family in their own unique way. Illness was constituted by the attributes of the chronic condition that were drawn forth in family interaction. For example, in one family the well two year old knew illness as something that took her mother's attention and drew forth worry and preoccupation. The two year old responded by clinging to her mother and demanding attention. The well, older siblings saw the powerful influence that the chronic condition had on their younger brother and responded by protecting him. Illness was a threat to the safety of their brother.

In another family the well sibling experienced illness as something frightening and beyond her control. She responded by learning as little as possible about illness so that her mother would not call on her to attend to the illness. It is now, some seventeen years later that she is able to talk about her relationship with illness.

Thus, illness can be seen as an interactional phenomenon. It is drawn forth in the context of the family through interaction between family members and a chronic condition. For these five families, illness marked one family member as particularly vulnerable but spared no one its influence.

For all of the families illness remained a virtual stranger, an enigma over time, because it rested for long periods not showing its face and then reappeared in a different form or suddenly showed itself in a startling new way. 
Peter: It was sort of something unbelievable, you know what I mean? It didn't seem real to me at first either....

Jill: Like everyday you'd go, and well, she doesn't look so bad, you know. However, at some point the true nature of chronic illness was revealed and its long-term residency in these families was recognized and acknowledged. The illness was not going to go away. Thus, over time, illness changed from being a stranger to a family member.

Alison: You could be, you know, 99 and still be dealing with the same thing. However, the hope that the illness would someday leave coexisted with acknowledgement of chronicity.

Peter: I think in the back of your mind you always think, well yeah, maybe there is a cure.

Jill: I guess part of me thinks that eventually there may be a cure....and part of me, I guess thinks that there's not going to be a cure for Maia.... So I guess, I guess I'm torn....

Leanne: See that's what I'm trying to say, is we're always going to be connected.

These families described illness as becoming a dominant, powerful family member who threatened both the sick member and the family. It was a pervasive presence, always underfoot, who bossed other family members around and "runs the show."

Kevin: The illness decides what is going to happen and then the family decides how it will deal with what is being dished out.

Life for some was likened to a "roller coaster" with unexpected twists and turns, and sudden drop offs. Illness had the power to defy predictions, to change course suddenly and without warning, to quietly do damage, to wreak havoc, and for some families, to kill. The uncertainty engendered by chronic illness was one of the toughest things to 
manage. Thus illness had a pervasive influence on these families; while the families experienced little influence on illness.

Illness influenced decision-making and priorities were reconfigured in these families as protection of the sick member became more and more pressing. To accommodate this reshaping of priorities, what is usual practice in many families became a special treat in one of the families.

Samantha: I was thinking as Cody started ECS and parents were talking about walking their little kindergarten children everyday to school. I thought, my older one's didn't get that special treatment. Cody was a baby when she started kindergarten so as long as the weather was nice I would walk her but I didn't as soon as it got cold. She was on her own because I didn't want to take him out. And then when Jeremy started kindergarten...

Haley: I had to walk him.

Samantha: Ya, Haley walked him because...

Jeremy: No, you drove me.

Samantha: A couple of times, but Haley walked you. Because Cody was going in for his corrective surgery and I needed to keep him healthy.... So they didn't get that special treat.

Illness challenged communication and members' ability to support one another.

This was aggravated by differences in the ways that family members chose to deal with difficulty.

Kevin: Parents really have to talk these things out because if they don't talk, then they have no way of voicing what they are going through. They have no way of supporting each other. You can't read each other's minds.

Samantha: We learned that...

Kevin: You've just gotta, you've just got to communicate at times like this whether you like it or not. 
Samantha: We learned that when Cody went for his second shunt surgery, which was minor, but at the same time we knew what was happening so it was a lot more frightening to me. Kevin withdrew and closed himself off. It was almost as if we don't talk about it then I don't have to worry about it and I wanted to talk and talk and talk. He wouldn't talk to me. And so we had, there was a real strain during that time and then after that was over we were able to sit down and say - I could say "You did this and I needed to do this" and he was able to say "Well it bothered me because...." And so we talked it all out and so when it was time for the corrective surgery he knew what I needed and I knew what he needed. So I didn't put on as many demands but at the same time he listened when I needed to talk.

Illness stretched these families' resources of time, energy, faith, communication and support.

In each family, illness influenced its unity or "togetherness." Illness came between all family members, separating them both physically and emotionally, which drew forth wounds that were a long time healing.

Samantha: [Before Cody and I went to the hospital] Jeremy would come in every morning and lay down and cuddle with me before we would get up in the morning. And when I came back from Edmonton, he wouldn't do that anymore. It took him about a year and a half before he would start again. Um, almost as if, he felt like I had left him. And very jealous of Cody. He's always been very jealous of Cody -- and all the attention.

Linda: Like when I first had it and I'd come home, my, um, middle child there, he wouldn't even come near me for quite awhile. And he'd look at me really funny and he didn't want, like to touch me or I don't know what he thought, you know. But he'd write essays in school and that's what he'd always write about. How I got so sick and had a heart attack, you know. So um, it must have bothered him.

Thus it can be seen that illness influenced family decision-making, priorities, communication, support and cohesiveness. Family members' relationships with illness were intimate and consuming. As one father repeatedly stated: "We were almost living like diabetics ourselves." The influence of illness changed family life. 
Illness was so intrusive that for some family members it was experienced as an extreme violation. Numbness followed horrific relationships with illness, which changed family members' views of the world. This prompted a recalibration of the family system, whereby catastrophic illness became the "yardstick" by which everything else was measured.

Haley: My mum and dad used to feel really sympathetic [when I was sick or hurt] and now they aren't. They feel sad but they never show it or - they don't really. Like if I get hurt they say "Oh well."

Samantha: I have to admit, we've become quite callous.... We've seen too many sick and injured children - that's just a bruise, too bad.

Illness was experienced as an intrusive, unpredictable, and dangerous family member who was a constantly threatening presence. Illness demanded attention and the women in the families responded to the call.

In the Name of Protection: Women's Sacrifice

The threat posed by illness called forth protection of the sick person by all family members. Even young siblings gave spontaneous examples of protecting their sick brother from harm.

Haley: What he's done for me is he's made me very protective of my brothers and sister...Two years ago we went camping and this little girl came up and hit Cody and I hit her back 'cause I was really protective of my little brother.

However, it became clear that the women, that is, the wives and mothers in these families, were responsible for day-to-day, twenty-four hour, day in, day out protection. What underlies the women's acceptance of the primary responsibility to protect? Perhaps it is not even an acceptance, which implies choice, for as these women were quick to point out, they felt there was little choice in the matter. 


\section{The Injunction to Protect}

These women's relationships with illness revolved around the injunction to protect. As one woman summarized it: to "try to make things as easy as possible." The injunction to protect was internalized as both a loving commitment and an abiding sense of responsibility toward partners and children. Thus, all of the women's efforts to protect family members and their relationships from illness were influenced by a combined sense of commitment and responsibility.

A clear distinction must be drawn between illness responsibility and illness work. To be responsible for illness means to be accountable for insuring protection from illness; while, the enactment of this obligation to protect is seen as work. That is, all the efforts both large and small that mediate the influence of illness in the family. In these families where the women's partners were committed family members and showed this through their active involvement in illness work, the women still carried both the burden of responsibility and the lionshare of work. This happened "just because, that's the way it is." As Samantha said:

Well...even though Kevin did a lot, I felt like I was still responsible for everything.

It became apparent that a web of beliefs shaped and reinforced the women's experience of primary responsibility for illness.

Samantha: Women tend to be very emotional. We're supposedly stronger emotionally than men are, because we can show our feelings and we're also the caregivers. It just -- it's an instinct and there's, I don't care how many people try to get rid of it, it's there. And so we tend to keep saying yes, yes, yes, I can do that; or I'll do that; or don't worry about it; well, let me handle this, well, and take all of the burdens and all of the cares and everything on ourselves because we don't want to overburden our husbands. We don't want our children 
to have to deal with these.

A key family belief acknowledged by these women was that women are the caregivers, the protectors. The unstated facet of this belief was that it is the responsibility of women, not men, to give the care that protects. For Samantha caregiving was an instinct, whereas for Jill caregiving was part of being mother and health care professional. For Alison it was part of being wife. Both the women and the men in these five families were committed to protect by virtue of being family members; however, it was the women who shouldered the responsibility to protect by virtue of being women. It was the women who could not say no to illness demands.

Each woman showed the tendency to extend protection to all family members except herself in terms of the influence of illness. This is where the women's strength worked against them. Their belief in the cause they championed and their own ability to make a difference that mattered encouraged them to persevere without attending to, and thereby sacrificing their own needs.

Beliefs about men and illness were another strand of the web. The overarching belief stated explicitly by some of the women and implied by others was that men have trouble dealing with illness. They were uncomfortable or lacked knowledge and therefore distanced from involvement. As a forty year old mother of an ill teenager noted: "Illness scares men."

Peter: At first I was -- I was removed from it [illness] more than Jill was.

Jill: But I -- I think that's um, I mean just even from the male patients that I've had and the men that I know, I think that's a very typical response. If you can't - you know, if it doesn't fall into your usual, and it's something that you don't know anything about and you're, you're possibly even afraid of it, you just sort 
of stand back from it.

Thus, developing an intimate, day-to-day working relationship with illness was often not expected of the men in these families or, at very least, the discrepancy between their involvement and the women's involvement was understandable.

Beliefs about children varied. In general, the women believed that children, whether sick or well, were vulnerable and in need of protection from the influence of illness. Children were either too young to understand or it simply was not their job to be involved with illness. Thus children were seen as needing to maintain a life beyond illness.

Linda: Well when you do get that scared you just don't -- you don't care if you live or die or get better. But then on the other hand you gotta keep going 'cause you can't be like that in front of your kids all the time. You know what I mean? You can't, 'cause they don't understand.

In the circumstance of catastrophic illness, one family made the decision that protecting the well siblings was not in their best interest.

Samantha: Well we decided, especially when we went to Edmonton for one thing, we wouldn't leave these two [siblings] at home. Because, I thought how would they feel 20 years from now looking back on the fact, say, if he had died. They got a telephone call, and they weren't there. And they didn't get to say goodbye and they didn't get to be there when these things happened. That was something that we just always felt was important that we do things as a family that everything is family related.

However, these children experienced long-term sequelae of the "stress and pressures" and the woman experienced regret. Thus when there was a decision to override the dominant belief that children should be protected from the influence of illness, the woman experienced lingering consequences - anxiety about whether they had done the right thing. 
Samantha: There's been times that I wished that I hadn't said anything because of all the worry that the children have gone through. I wish I hadn't put them through that.

These beliefs invited the women to not only protect the sick family member but also to protect well family members from the influence of illness. Part of protecting involved the added burden of concealing or simply not revealing their own experience with illness. Others were put before self. This is graphically illustrated in the following excerpt. Linda had to protect herself because it was she who experienced the chronic condition; however, her efforts were configured around concern for the emotional well-being of her husband and children.

Carole: Well you know what I think you're saying, um, which I think is so interesting, is that part of your relationship with illness is not only protecting yourself but protecting your other family members. 'Cause you're - you're trying to protect the children from ...

Linda: Yeah.

Carole: ...from, the impact that illness is having on you. Does that?

Linda: Yeah. Well you don't like them to know. Because it -- it upsets them. It really does.

Carole: Yes.

Linda: You know if you're sick. You don't think it ever would but it does, you know. And so you just don't, I guess, let your feelings come across or show on the outside, you know -- that you don't want your husband worrying night and day sick about you. You know? It -- I don't know. It's really hard.

The responsibility to protect belonged to these women and they persevered valiantly, largely without revealing the work or the cost of the work.

Carole: Well you've had a big illness load, haven't you? I mean not only your relationship with Jared's illness but your relationship with your own illness. 
Margaret: $\mathrm{Mm} \mathrm{hm}$.

Carole: And how that's influenced all your relationships with your family.

Margaret: Holding the family together is tough.

\section{The Enactment of Responsibility: Illness Work}

For these women, illness work was not a choice but an obligation.

Carole: This is what's striking me is that in families where fathers are very much involved in the process, well it seems to me that the women may be carrying a higher burden. Like if you talk about family illness, that the women are carrying more of the illness load. Would that make sense to you?

Kevin: $\mathrm{Mm} \mathrm{hm}$.

Carole: And that in some ways the burden is hidden until the point at which there's a pile-up and an overload and then it starts becoming more evident. Would you say that's true? That because you do it so easily it's not...

Samantha: Because you just do it.

The unrevealed and unrecognized nature of work occurred, not because of the ease with which the women undertook the endeavor, but because of perseverance. The work was done and continued to be done regardless of cost. These women could be counted on to do the job.

Illness work was constituted by all the efforts, large and small, routine and extraordinary that the women undertook to diminish the influence of illness on family members and their relationships. They were the primary caregivers, with assistance from others.

Peter: And I think as far as, like she would always, almost always drive Maia to her doctor's appointments or, you know, arrange this type of -- you know. I mean that was her job....Like ordinarily, fine, I'll drive her to the dentist. You know, I mean fine, that's something that I do. I'll drive them to the dentist or get them to their appointments. 
Illness work grew over time from early recognition that "something is wrong" and included monitoring symptoms, managing symptoms, making decisions that professional medical help was required, seeking professional assistance, and persevering in getting professional recognition of the chronic condition. Once the chronic condition was professionally acknowledged and labelled, the women often spent a great deal of time getting to know both the condition and the illness, educating family members about the condition and its treatment, implementing therapeutic regimens, maintaining a vigilant watch over illness problems which involved monitoring symptoms, anticipating difficulties and attending to the effects of illness and treatment. Illness work also included making decisions about day-to-day management of the condition, planning, organizing and carrying out interaction with health care professionals, monitoring professional health care, worrying, giving up employment outside the home or rearranging employment outside the home to accommodate illness, carrying on without complaint, monitoring the sick member's compliance with medical advice and encouraging the sick member to be responsible for illness. Illness work involved picking up the pieces of family work that had been dropped by the sick person. The women did this work while setting aside their own problems with illness. Clearly, the presence of illness in a family makes more work for women. This was particularly burdensome for the woman whose husband experienced the chronic condition. Alison, who already had two small children she cared for with little assistance, was faced with another dependent member when her husband became sick.

Alison: I don't know how I managed it. I mean, [illness] came in and it became a big force in our life and with the, you know, with the kids so young. And, and 
you're right, I felt alone and...I just remember feeling there was Lucas and Sara and Scott.

Scott: Resentment was a pretty strong emotion.

Alison: You know? Yeah.

Thus illness acted to exaggerate the discrepancy between women's work and men's work in the home.

The more influence illness wielded, the harder the women worked.

Samantha: And looking into my situation. She said the time when we were in the hospital, in a way, even though the illness was controlling me, I was still trying to gain control....I had to be (pauses) -- had to know everything that was going on. Had to make sure everything, you know, try to stay on top of it.

It seems that only when illness work pertained to the woman's own illness did the extent of the work become constrained by time and preempted by other obligations. The woman who experienced a massive heart attack revealed the relatively short time she worked at rest and recuperation before resuming her normal routine of work both inside and outside the home.

Carole: So after, let's see 18 days [in hospital] you went home. And then what? Linda: Well then I slept a lot. For a long time.

Carole: You were able...

Linda: I went back to work about a month after [the heart attack].

For this woman, who made a remarkable medical recovery, the work then centered on containing her experience so she could appear as if she was carrying on as normal.

Carole: ...the other women I've spoken to have said to me that...this notion of having a relationship with an illness, it's a lot of work.

Linda: $\mathrm{Mm} \mathrm{hm}$. 
Carole: And that the work is um -- a lot of it is just hidden. You just do it. And nobody else really knows how much work it is.

Linda: That's right.

Carole: For you as well?

Linda: Yeah. Like people make remarks and I just think to myself, boy if it -the shoe is on another foot for a day 'cause there's so much inside.

In fulfilling the injunction to protect the sick person in particular and all family members in general, these women became servants to the illness at their own expense, an immense sacrifice. Illness responsibility and illness work contributed to overwhelming illness burden.

\section{When Protection Takes Precedence Over Self}

In all five families the women experienced multiple pressures other than those exerted by the focal chronic illness. These included: pregnancy, childbirth, caring for young children, moves, absence of support, job changes, other chronic conditions, caring for ageing parents, employment outside the home, and extended family problems. Thus it must be remembered that illness burden was experienced in the context of multiple other concerns and served to exaggerate existing patterns of attending to others before self.

Peter: And this [referring to discussion about another chronic illness in the family] has absolutely nothing to do with the diabetes (laughs).

Jill: No, but I think Carole needs to know the kind of stresses that, like you're interested in the long term and you're interested in families. Well, and when you have a sick child or something going on, it does affect you.

This burden of multiple, competing demands weighed the women down and commanded their attention in an outward direction. In an attempt to protect family from the incessant 
demands of illness these women continued to give of themselves without experiencing the nurturing that would replenish their resources. They became so other focused that there was little room for self and, as a result, life balance became more and more precarious. Samantha's narrative illuminates the story of "No room for self."

Samantha: I came home from the hospital with my fourth child, got home on Sunday and that morning Cody had had blood in his urine, like quite a bit of blood in his urine. Kevin rushed him into emergency and then came picked me up. Well the next day we were off to a doctor's appointment for Cody. Well, I had to do it. I mean, Kevin had to work so...I had to do it. New baby. Child -- just out of the hospital. Child with this oxygen tank off of it. My neighbor said, "My sister-in-law just had a baby, her husband took 2 weeks off and she's staying in bed." I mean that was unheard of for me.

Kevin: laughs

Samantha: I thought (sighs)

Kevin: Made me feel bad.

Samantha: I said, it was real life, is you go on. And I think that that's what happens, is that the husband goes back to work. The women are the ones that take everyone to the doc --even if it's just a sick husband or themselves that are sick, they're the ones that go to the doctor's appointments. They -- I mean husband comes sometimes for the real biggies but I was the one taking him to all of his blood tests. Was the one that will take him in every time he got a cut. Everytime there was an infection. Everytime there was a concern. Everytime there was an ear infection. Just because that's the way it is. And -- or even in working families, it's usually the mom that takes the time off to take the child to a, you know -- to the doctor's appointments. Occasionally, dad does it, but usually mom's the one who's dealing with everything.

The giving up and sacrificing of self in the name of protection occurred every time the women automatically dismissed their own needs in favor of the illness or another family member. Thus, in the context of juggling multiple compelling demands, the women's own needs were often pushed into the background. This created an unresolved stockpile of illness problems, which, combined with illness responsibility and illness 
work, constituted a growing illness burden. When the pattern of too much attention to illness and too little attention to self was repeated over time, personal resources were eroded. Thus, the women's life balance became more and more compromised as resources were overwhelmed by burden.

What enabled these women to persevere with the burden of chronic illness and all that it entailed? It is critical to consider the relationship between giver and recipients of care. All of these women were mothers who were deeply concerned about the wellbeing of their children. Regardless of whether children were sick or well, the women explained their protective efforts as an integral facet of caring about and for children. They persevered because it was necessary to do so and they were able to do so. Perseverance was encouraged by the heroic efforts of sick family members to stand up to illness.

Jill: She was so determined.

Maia: I was going to have a life (laugh).

Jill: She was so depressed. That's it. I think that was it altogether, that she, no matter how she felt, she was going to go to school. That's all there was to it.

In some instances illness invited the women to develop an especially close relationship with the sick family member, which inadvertently also strengthened the woman's bond to illness and contributed to isolation from other family members.

Carole: So...the first phase is one that seems to be characterized by illness work. All the things you do to try and keep the illness in line, to protect the person who's sick. What do you think?

Jill: Yeah. Very much so. And I think -- I think so much so that you exclude - like you're in so protective a mode that you exclude other -- your other family members. I think, like as a mother.... 
Carole: So the relationship with illness becomes an exclusive one, sort of?

Jill: That's right.

This special connection that some of the women developed with their sick family members provided incentive to persevere but diminished the possibility of sharing the burden.

Carole: You were saying that -- that sometimes you get so protective of the child that the relationship for you is so intimate with Maia and the illness that it sort of pushes other family relationships out a bit.

Jill: I was thinking mostly of her diabetes, but when I think about her chronic fatigue as well....it was the same. Yeah, it was the same.

These women bore too much of the illness burden for their own good. The question then arises, what was happening with the other family members while the women became more and more overextended while continuing to make overwhelming sacrifices?

Men and Children: Carrying On With Life As Usual

What happens in these families to leave women carrying the burden of illness responsibility, work and problems? In relation to the women's pattern of carrying too great a burden for their own health, there were patterns of too little burden taken by other family members.

Men and Their Work Outside the Home

It seems that for these men, that is, the husbands and fathers in the families, illness was intertwined with their work outside the home. When they recounted their relationships with illness the nodal events were often work rather than illness related. The men located illness happenings in the context of work or other personal activities outside the home. 
Peter: I'm trying to think of the whole situation there. I'm trying -- [to wife] was I working on the golf course there? [no answer]. 'Cause I was president of the golf course at that time....Um, but I'm wondering, because I came up and we stayed here for quite awhile and then I went back and then went to Victoria after that....and then worked there for awhile.

Work invited the men out of the home and away from illness responsibility, illness work and illness problems. As Kevin noted with a laugh, it was an escape. Some of the men used work to handle illness related stress, working longer and harder as things got tougher at home. As Jill stated: "He's just not there." Thus, women were often abandoned for work. However, from the men's perspective, work outside the home could also be an obligation, which often did not leave room for choices just as illness work did not leave room for options for the women.

Jill: I think we went through a lot of changes 'cause with you [husband] leaving as soon as we got, I guess Maia got out of the hospital, we went back and Peter had, having been laid off work... he was looking at options. And with no money coming in and stuff like that, you sort of have to look at your future. So when I took Maia home...from the hospital, he went to [the West Coast]....And you were gone for 3 or 4 months?

Peter: I was gone 'til Christmas, just after Christmas.

Jill: Ya, it was a long time. I was really mad at you for that (laughs)....

Peter: Well you were staying with your mum at the time.

Jill: No, we were back home....And you went the day after we got home. I was really upset.

Peter: Ya, well I pretty much had to.

Although upset by the priority given to work, none of the women questioned how this had come to be. Thus, at least in the context of the research conversations, these women accepted the men's explanations. In three of these families, the women also worked 
outside the home for pay. One worked full time and two worked part time; however, in contrast, the women's work was background to their concerns with family and illness. Women's work outside the home accommodated illness and acted as an additional challenge in terms of balancing conflicting demands.

Jill: There were times when she couldn't get out of her bed to get downstairs to eat and being diabetic, she has to eat. Wasn't hungry, you know. Didn't want to -- it hurt to chew or it took a long time to chew. So I started working night shift so I'd be there.

These men did not make space for illness the way the women did. In addition to the influence of work, the men explained their lack of involvement in a number of ways. Kevin was clear about the choice he made to leave the responsibility with Samantha.

Carole: So your response [to the illness] Samantha -- I'm not sure if this also fits for you Kevin is -- is a vigilance and it also sounds like a thinking response. You're always anticipating, wondering...

Samantha: $\mathrm{Mm} \mathrm{hm}$.

Kevin: She does more of that than I do.

Carole: Yeah?

Kevin: Yeah, I don't do that much.

Carole: And how do you get away from it Kevin? How do you explain your difference?

Kevin: I let her take care of it (laughs).... Rather than us both worrying, I just let her do all the worrying.

Samantha: Very obvious.

Carole: And do you think -- I have this other idea that sometimes dads are a bit more immune to it because they can get distance from it by leaving the house for work. 
Kevin: Yeah. I -- I keep my mind pretty occupied with other things. So maybe I don't have the time to dwell on it like she does.

Peter's lack of involvement with illness occurred simply because the situation just "wasn't bothering" him; whereas for Scott, who experienced the chronic condition himself, the relationship with illness was kept distant by the belief that medication was the answer. He took his medication, and, except for work outside the home, became a "couch potato" and waited for things to improve. Rob was the only man who showed high commitment and caring on a day to day basis; however, it was not at the expense of a "normal" life. That is, illness work did not impinge on his life beyond the family.

One of the hazards of keeping illness at a distance was that these men also inadvertently distanced from their wives who needed support in order to persevere with the burden of responsibility, work and problems. This left the women out on a limb.

Samantha: Dads have to watch -- be careful though because sometimes they completely block it out....They'll do -- they'll ignore it. And we went through that.

Kevin: I don't remember that.

Samantha: Of not wanting to talk about it.

Kevin: Oh, okay. Not wanting to talk about it, yeah.

Samantha: The subject would come up and we all would go up and...

Kevin: I'd change the subject.

Samantha: And he'd change the subject. Stop talking. Start watching TV. Just -- I mean, shut me right off.... That was really bad then.

Several women made the point that the problematic interactional patterns drawn forth by illness were not new to their marriages. Instead, they were exaggerations of 
preexisting patterns. For Samantha and Kevin a communication pattern became enlarged;

whereas, for Alison and Scott inequity in their "partnership" was placed in stark relief.

Samantha: I just remember (laughs), we had a really interesting pattern in our marriage (laughs). We go through, we do really good and then it gets to the point that he gets busy and I need somebody to talk to and I talk and he stops listening and then...

Kevin: I listen, I just fall asleep.

Samantha: I blow up. Like it builds up and builds up and then I'll blow and yell and cry for two hours (makes sounds of crying). (Laughs) and then he's really good for awhile. It seems to me that's probably what happened is that it was one of those -- it had built up and I just sat on the bed crying "You won't listen to me."

Alison: I guess to use that term I felt abandoned right after when Sara was born and...I was totally alone here, and with the two kids 17 months apart and then as soon as it started to seem okay...then I felt abandoned again [when Scott got sick] with -- with the help. I mean like, you know -- like I... with the partner I didn't feel like for a long time that I had an equal partner. I felt like I had three people I needed to take care of all the time. And that was, uh, not what I had hoped when I went into ---

Scott: Didn't sign up for that.

Alison: I didn't sign up for that (laughs). No. We were eight years without even having children. So then when we decided to have children, I thought that, you know, I was hoping that we would be [equal partners] -- and it is now. It's much more so now, but I'm just saying that, that we -- as the two of us would have children together. Right?

Carole: $\mathrm{Mm} \mathrm{hm}$.

Alison: And -- and all of a sudden when the children came along and there I was. Um, I felt, by myself...and that's not what I had I thought I had bought into.

Thus, for these families, several interactional beliefs seemed to be influencing their organization around illness. The first was that the men's work outside the home, 
whether for pay or pleasure, took precedence over work inside the home. The second was that illness burden belonged to women; however, illness work could be shared with men provided it did not interfere with their first belief. Jill summed this up nicely.

Jill: ....and [the chronic illness has] been going on for 5 months. There's nothing you can do about it. There is no treatment. And -- and it was extremely frustrating and I think that's partly that, um, that's why Peter couldn't get a handle on it. But I think that also -- I'm the nurse and I -- that's what, I mean, somebody's sick, and I'm the mother, you know. Meaning that's my -- I think you saw it as, well it's kinda her job, you know.

Peter: What -- yeah.....in a sense, I think I did with that.

Jill: And I mean, she's the woman, she's the mother, she's the nurse, she can do this part. You know? 'Cause I [speaking as if husband] can't - I can't do anything about it so I'll just go to work and make sure there is food and, you know, the usual man things, you know. That's just my idea, but -- but that's sort of how I see things, you know.

Peter: Ya.

The third belief was that women should do the illness work without complaint. It was their job and they should just do it. Nowhere was this more clear than in the family where the man experienced the chronic condition.

Alison: I didn't think that he was trying -- he was at all trying to manage it. And -- and he resented the fact that I would think that, that I didn't feel, um (pauses) -- uh, sympathetic enough or --

Scott: Supportive.

Alison: Supportive...enough of him when he was in that...and so that's where the big fight was.... Well (sighs) it's hard for...the unsick person to say, you know, but I'm going to be, you know, brutally honest with you.... I just felt he was giving in to it too much. He was, um, almost to the point of chronically being depressed about it. And I know that that comes a part with, I know that comes along with chronic illness and with pain.... I just was getting frustrated, you know, after, after what I felt like at the beginning giving so much. He was just feeding into it and getting to a point where he just felt sorry for himself 24 hours a day. And I was just getting frustrated with that because, I just thought 
that he had to manage it and not only physically but, you know, and his doctors were saying, you've got to do this and you've got -- you've got to at least walk in order to get to this point....I didn't feel that he was even attempting to try it, right? And I was worried that the depressions and the feeling sorry for himself was just feeding into it....I just think that at some point you've got to stand up and say, okay, well this is what I've got and I've got to....

Scott: Down deep and certainly upon reflection, Alison was right. I mean she was just telling me the same thing that the doctors were telling me and from an analytical point -- from an objective point, I mean it was -- it was right, but it wasn't what I wanted to hear from my wife.

While the men did acknowledge the women's more intense emotional experience with illness there was no acknowledgement of the underlying inequity in responsibility, work and problems that influenced the different emotional experience. Thus the intense emotional experience was stereotypically attributed to the women's emotionality rather than to the incredible illness burden they carried. This left little room for hearing the women's plight.

The men did tend to pick up the pieces of the women's work during times of illness related crisis; however this too had its limits. To do some of what women did day in, day out was a challenge. For example, the following quote pertains to a telephone call Samantha received in hospital in another city, where she had spent three months with a critically ill child while her husband managed at home with two other children.

Kevin: I phoned up Samantha in tears and said, "I can't do this anymore." And so she basically took the ball and phoned some people for me 'cause I didn't want to phone anybody to help out 'cause I'd had enough of that.

Samantha: And the lady came in...

Kevin: The lady came in and took care of all of it for us. So like I say, I would have lost it if I hadn't had the help of others. 
Carole: And what was the hard part for you to phone others? You were saying that you'd had it by then, you couldn't do it anymore.

Kevin: It was just having to phone somebody else to watch the kids and I couldn't just have a normal life. I had all these interruptions that were extra that I had to do.

Samantha: We had, he had three meals a week brought in plus people watching the kids everyday before and after school and it was getting to the point by the end, he was running out of people to ask.

The men clearly had more choices or options in terms of the level of their involvement with illness and when enough was enough, the women picked up the pieces.

\section{$\underline{\text { Sick Children }}$}

For several of these families, the sick member was a child who first experienced the chronic condition at a very young age. Their young age and the seriousness of their conditions limited the ability to assume some of the illness burden. Thus, at various points, these children relied totally on their mothers. However, over time, this changed and there was evidence that some sick members resisted taking on more responsibility and work even when encouraged to do so.

Jared: I think my biggest problem is that I never ever have liked taking blood tests, monitoring my blood. It's just something...I hate doing it. It just drives me -- it only takes two minutes to do but I just hate doing it.

Carole: The pokes?

Jared: The pokes don't bug me. It's just the whole process. Either I didn't want to know that my test was too [high] so I didn't bother taking mine or something like that. Or I figured it was okay, so I didn't figure I needed to take one because I knew it was okay or something like that.

When children did not grow into a responsible relationship with illness, the women could not grow out of theirs. 


\section{Well Children}

Some well children did not want involvement with illness and parents did not "push it." This followed from the belief that illness work was not children's work.

Carole: What about your other children -- did they participate in this?

Margaret: They didn't want any part of it. They're only starting to come around now a bit [seventeen years after diagnosis].

When the children distanced themselves from illness this occurred primarily out of fear, whether it be fear of the power of illness or the implications of taking on some of the burden. Margaret recounted a recent conversation with her grown-up daughter about an earlier time with illness:

She said "My worst fear was if I would ever be caught at home with Jared during a reaction," you know. She didn't want that -- to be caught in the middle of it with him.... She said she just tried to distance herself so she wouldn't learn anything and then I wouldn't be able to ask her.

Other well children ignored illness and carried on "as usual."

Carole: And how about for you Leanne, what was that time like for you?

Leanne: I was going to school.

Carole: For you - you were just doing your own thing?

Leanne: Well I couldn't do anything about it. And I hardly ever saw her. I'd go to school, I'd come home and do my homework and watch TV. And sometimes she'd be downstairs but most of the time she was in her room.

However, like fathers, the well children often took responsibility "in a pinch."

Margaret: And yet they did participate. One time I was downtown and he had a reaction....and they phoned me and said that Jared says "The floor is falling off." And he had been riding his bike too much. They were very protective.

Jared: When I was in trouble they certainly took control -- I remember that....I remember that they looked after me. 
Margaret: As far as us trying to tell them things like with his meal plan, they didn't want to have anything to do with it.

Jared: Just the daily routines.

Margaret: And so we didn't push them.

Rob: We didn't really make it an issue.

Thus, the daily routines were left to the women. Managing illness belonged in the domain of women and was added as another piece of the job description entitled "Wife and Mother."

\section{The Burden of Health Care Relationships}

In addition to the relationships within the family that encouraged these women to carry too much of the illness burden, health care relationships often supported and even contributed to the women's oppression.

The Trouble Getting Professional Recognition

The women told many stories about having to fight for professional acknowledgement of the chronic condition. Since medical care is organized around diagnostic labels rather than the experience of sickness, professional involvement was difficult to achieve without a diagnosis. Often health care professionals distanced themselves from the illness until a crisis had occurred.

Jill: And so we took her into...a doctor, and he was in another town and so we just went for a drive and said could you check her out. And he, I mean we've never had a family history of diabetes and Peter, when he was talking to him, he never had either. Like it did cross my mind but, and so when I was talking to [the doctor]...I said, well, maybe we could just do some blood work and it was 5:30 by that time and the lab was closing and he really felt that it was, maybe fluish or whatever....And so we just went home. The deal was, if she's still bad on Monday, bring her back and of course we'll do all the work, you know. Well, by Sunday I couldn't get her out of bed. And so we rushed her in and her 
blood sugar was 80 or 800 in B.C. figures, or however they work their labs and it would have been the equivalent of 80 here. And he arranged for us to come in to Children's by ambulance and that was the start of it all.

Thus, very early in the illness, some of the women were pushed into sole responsibility for managing the chronic condition.

Another way the health care professionals distanced from supportive involvement was by treating the chronic condition as a static rather than a dynamic entity.

Samantha: He was on the waiting list for 9 months before he had surgery. And we could see him declining but he was listed as moderate, which is what he went on the waiting list as, was moderate.

Thus lack of acknowledgement of the changeable nature of chronic illness hampered the sharing of responsibility and work. Samantha improvised illness management, waited and hoped for professional intervention before it was too late. As the child became more and more ill, the mother's life became more and more focused on illness. By the time her son had surgery, his heart was so weak that he required hospitalization for 3 months and underwent seven operations. When this mother finally collapsed, her physician said "It's about time."

Samantha: She laughed. She said "I've been waiting for you to come." And "I expected this." She couldn't believe that I had held up that long with all...that we went through... she expected me to fall apart sooner.

This alarming, non-interventionist stance was part of a pattern of behaviors that invited the women to carry a burden that was far too heavy for them. What this says is that the women's difficulties were visible and that collapse was predictable for at least some of them yet nothing was done. Thus, in relation to recognition of illness, illness responsibility, illness work and illness problems, health care professionals often let the 
women down.

Diminishing Women's Sense of Self Worth

The second way that health care professionals contributed to the women's experience of oppression by illness was through interactions that diminished their sense of self worth. These women already showed a pattern of setting their own needs aside in favor of illness, which was only reinforced through these negative health care encounters.

Paternalism seems to figure prominently in the women's experiences with health care professionals. One woman told of a physician who dismissed her knowledge and withheld appropriate treatment until a tumor had invaded her child's bone and muscle.

Jill: Well it turned out that she had a tumor on her femur and then it was almost a year of frustration between getting her to specialists. We saw one and he did bone scans and this thing and that thing. And he wasn't sure what he was looking at so he was just going to wait.... Our first visit I was saying, well the only way to determine what it is, is by a biopsy. Like you know where it is and how big it is but you don't know what it is. Right? So the only way to determine that is by a biopsy. Is that right? And he says "That's right and we're not doing one".... But anyway, it was very upsetting for me because, obviously when you're a nurse you know all the things that can be wrong. And the name, they kept talking about was possibly sarcoma and sliding this into the conversation. So I was getting really upset, um, and finally um, he just, I don't know if he finally did the biopsy just because I nagged him to death but he did it (laughs). And like Leanne said, she was in the hospital the next day having surgery.

These encounters made the women feel invalidated and even erased; however, they persevered. An added burden was that sometimes the sick member needed protection from health care professionals. This placed the women in a wrenching dilemma. On the one hand they were dependent upon professional care; while on the other hand, professional care sometimes made things worse by increasing the power of illness by 
invalidating/oppressing the women's knowledge.

Health care professionals also hampered the women's efforts to protect the sick member at the same time they devalued their knowledges and silenced their voices.

Jill: We would make our 3 month appointments and come in and when we got there, there was a doctor, the nurse clinicians - two or three of them - and the dieticians, psychiatrists, the residents and everything else. And we would be in a room and the, and I would be on a chair, they would put Maia in a bed across the room - a small room, crowded room. And we were separated. And she was just bombarded with all these people. And she was --

Maia: Poking and prodding and asking --

Jill: She was, well both of us would get upset, really upset. And I know that's just their practice, that's just the way it was done, but it wasn't explained to her and it was very scary for her. And it was scary for me too. I felt very, I felt threatened because I felt I wasn't able to protect her. And I know most of this was a learning situation for a lot of people that were there but the, she was especially bothered by the psychiatrist or the psych component of it. Because they would be asking her all these questions that she didn't understand where they were coming from and I wasn't allowed to answer any of them, you know. Like they would say "You be quiet we're talking to her...." She didn't understand it and it was really threatening and she got to the point where she wouldn't go.

Here the message was that the woman and her relationships with the sick child and with illness did not count.

Another message that diminished a woman's sense of self was given when she was held solely responsible for managing the illness and at the same time was told that her efforts were inadequate.

Margaret: Well I found it frustrating, you know, because the doctor, the specialist, I felt he was just so strict. He was always on my case....I guess I was the one that ended up going to the doctors and they kind of chewed me out or something. And Dr. X would be really hard on me. He wouldn't see Rob [husband]. Like I got so I didn't want to go in there. He wouldn't see Rob alone unless I came.

Carole: So he didn't let you off the hook did he. 
Margaret: No.

Rob: No, he sure didn't. It wasn't totally fair and, of course, I never picked it up I don't think.

Margaret: No.... One time Jared had a reaction and the doctor just yelled at me. He said..."You're supposed to have some sweet coke around" and I had given him coke. But he didn't even wait to ask me, you know, what I had done about it. He just yelled at me.

Thus some health care professionals attempted to use their position of authority and the women's position of need, to shame the women into quiet obedience. Another approach was to withhold information and to ignore the personhood of the woman.

Linda: You don't know really what's happened to you. The doctors don't tell ya.... You're just left there hour after hour to think, you know....Then the doctor comes by and he's got 15 interns and you want to ask him questions, you know, and he's got no time. And you just wonder, well, you know, what the hell's happening here? And there's so many people at you all the time. You just feel like a piece of meat after awhile.

The lesson that was repeated over and over again for these women was that the chronic condition counted but the women did not.

Linda: But like I said, they got me pretty paranoid about everything.

Carole: Well I think that sometimes it seems that medical people almost want you to behave like there isn't any life outside of the illness.

Linda: That's right. And there is.

Scare tactics were one way of insuring an unwavering focus on illness.

Margaret: They gave us, when we took our instructions, they gave us this whole list of -- of um, problems that diabetics will have. And we thought that he was going to get all of them. At that time, we didn't realize that he may just get one, like we are realizing that now. But at that time we thought well he was going to get all of them and I just thought, the kid's just going to die on us any day.... And the doctor would say that too. "You don't want a kid that's blind." And for many years, you know, and they'd throw these things at you too. 
These women were dependent upon health care relationships that had the power to diminish them as human beings while they simultaneously elevated the status of illness. Clearly, the expectations of some influential health care professionals rested on the belief that illness work is women's work; however, women need professional guidance in order to adequately fulfil their duties.

Thus for these five women, both family relationships and health care relationships supported and even encouraged a concern with illness that took precedence over concern for self.

\section{The High Price of Protection Over Time}

There were two significant consequences of the women's efforts to protect their families from the influence of chronic illness over time. These were being out of touch with self and a pile-up of unresolved illness problems.

\section{Unresolved Illness Problems}

The unfinished business of illness problems made it difficult to persevere, but persevere they did. Little space was given these problems, which became more pressing over time and, as a result, it depleted more and more energy from these remarkable women. The most compelling problems were exhaustion, isolation and lack of respite. As Margaret reflected:

Well, I just -- I don't know, I just never had much escape from it, you know. It's just, having to be there constantly, you know.... It just seemed like it was just overwhelming for me at times.

The women were vulnerable to emotional devastation as their best efforts did not bring about desired results. As Jill discovered, sometimes protection was elusive. 
Jill: And I think that the emotional changes that I'd seen in Maia as well - they were so devastating. I mean you see this happy, active, kid that you know, and all of a sudden she's - I mean, as depressed as she was, she did really well. But you can't read, you can't watch TV - she couldn't even concentrate on a show. She would have to, for her own self she needed to take a bath every day. Well, that process could take all day (laughs). Do you know what I'm saying? Things like that, it was just really hard for her. No friends. Nobody would call except for one....So for her it was very devastating and it was for me watching all this and trying to help and not knowing where to help.

Peter: The trouble is you couldn't do anything.

Jill: I couldn't do anything.

Peter: And so it leaves you helpless. It's just like watching your kid drown and you're tied up.

Each time Margaret "failed" in her efforts to protect and her son experienced an insulin reaction, she was haunted by memories for months. Even her husband did not appreciate the power this illness problem had to affect her life.

Margaret: It would upset me for quite awhile. I wouldn't even sleep in my own bed. I made Jared sleep with Rob for awhile until we felt secure enough to put him in his own bed again.

Carole: So what was worse - this may seem like a really odd question - what was worse about Jared's reactions, was it the effect for Margaret or the effect for Jared?

Rob: Well, maybe you [Margaret] should answer. But the way, what I would say is that...there can be long-term effects, permanent disabilities if the, you know, not controlled....I suppose that is the concern of mine and still is. And I'm sure of Margaret's today too.

Margaret: Ya, but at the time of these reactions I would, it would affect me, like I don't know why. I just had a hard time forgetting about it. It just stayed with me for up to 3 months after.

Alison and Samantha were haunted by troubling emotions such as guilt and resentment.

Scott: I mean, we both resented the illness but for different reasons -- I resented it 'cause it was affecting mys -- meself... 
Alison: Meself.

Scott: Myself and you resented it because it was affecting, um --

Alison: Our whole life.

Samantha: Well I know the hardest part for me -- there was one week in February, there'd been a family at the [place where we were staying] with us the whole time. Their daughter had had [extensive surgery]. And the reason Cody did not come out of intensive care, the reason, and he had failure to thrive, which is why he was there for so long, they found that the tricuspid valve had been ruined. So in February they had to take him back in to replace the tricuspid valve.

Kevin: Basically, the whole time he was there, he had 7 open heart surgeries.

Samantha: Ya, he was opened up 7 times.... and they, so they took him back in. The morning he went in, the little girl...died. Cody was only given a $5 \%$ chance and he pulled through with flying colors -- did great. He was in intensive care the next week and during that week, like on the Tuesday morning, I was awakened by a phone call..."this family wants to talk to you, please come downstairs." Their little boy with the exact same repair, exact same complications, they put him on ECMO, everything --

Kevin: He died within 24 hours.

Samantha: He died during the night. I got to the hospital and spent the morning, went to lunch and came back and I was greeted as I walked through the intensive care doors by a sobbing mom. Her baby had gone into cardiac arrest while I was gone for lunch. That day, same day, a little girl had been brought into intensive care severely physically and sexually abused - two years old. There wasn't an inch that didn't have a bruise on her body. Two days later another child died. It was just, I phoned [the doctor] that week and I said "Get me home"....All the people I got close to, their children all died.

Carole: Do you have a way of making sense of this? When you talk about how many of these children died and that Cody's chances were --

Samantha: Really slim.

Carole: Slim. Do you have a way of making sense of his living, for yourself? 
Samantha: Well I went through, boy, I mean he came home, he was at [another hospital] for a month, he came home end of March, he was on oxygen until August, Kristen was born the end of May. But I felt guilty that he was alive. Kevin thought I was nuts, but I felt guilty because I'd seen all of these children die.

Each woman experienced her own constellation of illness problems which varied from maintaining necessary but difficult health care relationships to being able to let go of responsibility. However the physical and emotional experience of exhaustion was common to them all.

What was the price these women paid to protect as well as to fulfil their other duties as wives and mothers? Samantha summarized it succinctly: "I find I go out to doctors' appointments, grocery stores and meetings." She had no life for herself. Life was organized around family and illness, with less and less space for self. The price these women paid to protect their families from illness was a life dominated by illness and weighed down with problems they had no time or energy to address.

\section{Stage Two}

\section{Women Falling Down and Falling Apart}

The five women entered this stage in an extremely vulnerable position because of their precariously balanced illness burden of responsibility, work and problems. Despite this unbalanced situation and an accompanying sense of being overwhelmed, they persevered. Then something unexpected happened to knock them off their feet.

\section{The Straw That Broke the Woman's Back}

The trigger for each woman's fall was an illness related loss that was often augmented by other stressors. For two of the women, the significant change was an 
improvement in the illness, that is, illness took a vacation. These women lost their relationship with illness and at the same time lost the reason to persevere with the illness burden they had been carrying.

Samantha: Cody was taken off oxygen the middle of August and all of a sudden I didn't have to cope anymore.... and I fell apart, you know. I had something that I had to be strong for, and then I fell apart.

For Samantha, the change was abrupt and the impact unexpected; whereas, for Alison the change was gradual. The following quotation gives some clues as to how far removed Samantha was from her own experiences in relationship with illness. Here she was explaining her fall.

Samantha: It was everything that I had been through in the last year.

Carole: And did that make sense to you?

Samantha: Oh yeah. But initially it was -- but why should that be the problem? I dealt with it.

Carole: Uh huh, I'm through it.

Samantha: I'm through it. It's over. Why should I be depressed now?

The sudden change was loss of a relationship with illness.

Carole: So could it be...could it be that your life was really wrapped up in Cody and then when Cody was better there wasn't a life for you?

Samantha: There wasn't anything left, yeah. Right....The work was gone. There was nothing more to do.

This was compounded by Samantha's niece and parents returning to their homes. There was a loss of support and as Samantha puts it, she no longer had to "put up a front." For Alison, the gradual improvement of her husband's illness did not bring any relief of burden. Thus, the inequity in their marriage became an even more pressing problem. 
Carole: Things were getting better with the disease.

Scott: The illness, but the damage had been done.

Carole: But things weren't getting better for you?

Alison: $\mathrm{Mm} \mathrm{hm}$.

Carole: Well that's interesting. That's been an experience for some of the other families where, you know, there's an expectation almost that once the illness gets better, things are going to improve.

Alison: Yeah

Carole: And they don't, so there's this sense of "Oh dear."

Alison: That's exactly...that's exactly our experience.

Like Alison, Margaret lost her long hoped for release from illness burden. However, unlike Alison, Margaret expected relief would come with the maturity of her son rather than an improvement in the chronic condition. Jared grew up but did not grow into assuming the burden of his chronic condition. Margaret despaired at what she experienced as her son's lack of cooperation and was overcome by depression. Thus, she also faced the loss of her own health.

In another family, the illness seemed to strengthen its grip on the sick person no matter what the woman did. The change here was Jill's experience of being worn down and overcome by illness.

Jill: A lot of it was, I was getting really tired and frustrated, um, with the illness. Frustrated with, with the fact that no matter -- I guess what I was doing, nothing was changing. It was just getting worse, and worse, and worse....The way I see it now it, it's almost like -- this is going to sound a little strong -- but it's almost like the whole family was raped, you know. Um, you just feel -- you feel violated and helpless, and um --

Maia: Scared. 
Jill: Yeah, scared and...it's endless. You just -- it's just like there's no seeing your way to the end of this nightmare, you know.... You just -- you just feel violated. So -- so violated and helpless that there's nothing you can do to change anything.... There is nothing you can do, and yet you're just sort of watching -like you, you've got absolutely no control over it -- over the situation at all. Over anything. And um, there is nothing that you can do to improve the -improve it. You can't protect. You can't protect from further violation or whatever. It's just going to have its way with her, you know.

This loss was one of hope. The "light at the end of the tunnel" was gone. Jill no longer believed that she could bring about change, which was a problem because "she's supposed to know everything." Again, this was unexpected. "Like something that you really didn't expect was going to be....It's just a shock." As the illness got more and more powerful, Jill lost the daughter she knew.

Jill: And I think that the emotional changes that I'd seen in Maia as well -- they were so devastating. I mean you see this happy, active kid that you know, and all of a sudden she's -- I mean, as depressed as she was, she did really well....It was just really hard for her. No friends. Nobody would call except for one.

For Linda, the experience that knocked her over was her mother's sudden loss of health.

Linda: So [my mother] went to [the doctor] and he said, have you ever had a -a stress test or anything like that? You see that's how it all started. I was doing fine. She went for a stress test, couldn't even make it 30 seconds and then they gave her an angiogram and she has one artery left open, a little wee bit. So right away they're going to do a bypass. They -- so that's how all this started....'Cause I was doing fine. Like I was managing well with it and stuff. And then when that happened to her it just, boom.... The only thing that I could think of is I just put [my heart attack] out of my mind kind of. And like I said when mom got sick there, it just hit home....I don't know if I'm dealing with my own mortality or what.

For Linda, the most terrifying loss was the possibility "that I won't see my kids grow up."

The loss that was triggered by a change in each woman's relationship with illness 
was often compounded by a pile-up of work pressures, fatigue and family problems.

Jill: And at that point in time, Maia was still in the throes of the chronic fatigue and very depressed, I was working nights, not sleeping real well, you know. And I think I was just getting worn down. My mum and dad were having a lot of family problems, um, and I was sort of trying to intervene on their behalf for them....

Peter: Everything was piling up.

As Linda commented, "I just felt wore out, you know, all the time."

These women were knocked off their feet, no longer able to manage the burden they had been carrying. Jill spoke eloquently about how she got trapped in the vicious cycle of continuing to "do for" when she was well beyond her limits. She got trapped in a "should," believing that since she had always been able to do it, she should be able to continue. Thus, part of the problem was that these women continued to believe they should be able to carry the load even as they found they could not.

Jill: I think there's, um (sighs), the saying "You never say die." Well, I -- I think a lot of women -- and it's not just in this instance, but I think just generally speaking...like they give and give and give and they're -- I mean maybe not doing physical things, but I think they're just giving a lot of themselves and their emotion and everything else. Well I think burnout happens.... You've given past the point where you should have and could have, you know.... Until you just -there's nothing left.

Carole: What...seemed to happen is you get tipped over.

Jill: Yeah, exactly. Like Humpty falls off the wall.

Thus, these women were knocked off their feet by various illness related losses that encompassed loss of connection with illness, loss of hope that things would change for the better, loss of a "known" loved one, and loss of faith in one's own body. 


\section{Despair and Isolation: The Absence of Expected Support}

Falling down is not the same as falling apart. However, when these women were knocked off their feet, there was no one there to assist them up. They did not have the resources to pick themselves up as they had done in the past and no one was looking out for them. So, they not only fell down but they also fell apart.

Peter: So it started piling up on her and, in a way, I don't think it came as a shock to us, but we were sort of drifting along. All three of us....

Jill: It was piling up ya, but not only that, but we were all getting so far apart from each other. We didn't talk about anything, there was nothing constructive, it was like we all had a little wall around us. Like everybody is trying to cope in their own way with their own things and, and nobody was helping each other anymore.

Family members could not or would not hear concerns.

Linda: So I read books and I -- I did everything. I didn't know what to do and, um -- of course I talked to my mom, you know. And her only reaction was well, are you happily married, you know, instead of getting to the root of the problem, she figures it is my marriage and -- couldn't be anything in my illness is bothering me of course....

Carole: So it's hard to get a sense of anybody understanding where you're at with it.

Linda: Yeah. Even my mother doesn't understand [who also experienced a heart attack], you know....I don't even talk to her about it anymore. But I've said, um, I wonder what's next or when the next one is, you know. And she'll say, "Oh don't talk so stupid"....And for her, she's been through it, she should know.

The lack of expected support from family was devastating.

Margaret: Like when I got depressed this last time, my doctor said that, you know, if my family would like to come in she would explain it to them. And uh, nobody wanted to go in (crying) to understand me. I really felt bad about that....My doctor was really good (voice is sad). She's very compassionate and, um, really... willing to do all she could for me at the time and I couldn't figure out why my family wouldn't try for me too....'Cause I always feel like a family should pull together when someone isn't feeling well. I always pulled for them 
when they weren't well and yet nobody pulled for me.

When expected support was absent, the women began to question whether their families cared about them and came to believe that their concerns were not taken seriously.

Peter: Like even with Maia's diabetes, okay it was something that I could grasp. And sure, you know, like I mean I could take some of the load. With your family I couldn't do anything....

Jill: You couldn't do anything for my family but you could for $m e$.

Peter: Well no, but I mean it wasn't my concern and you would come to me and say, you know, certain things and...I was at a loss....

Jill: And I think I got the impression you were just blowing it off.

Not only was there an absence of support but, in some families, the women were criticized for their efforts.

Peter: It doesn't seem to matter what Jill does, the rest of the family gets on her.

Thus, the women experienced isolation and abandonment at a time of great need.

\section{Vicious Cycles That Undermine Support}

Interactional patterns were at play that served, as Jill put it, to create walls between family members.

\section{Silence.}

Jill: Life for me at that point in time, I think I was burn out in all the areas....

Carole: So the other piece is you go beyond your limits?

Jill: You also at that point in time, I think, have stopped communicating 'cause at that point in time you don't know where your -- I mean you've obviously crossed the line so you don't know where your limits are anymore. And that also goes with -- with just functioning in every area. I don't think you're functioning well in any of them, you know.

Leanne: That and I think the feeling of hopelessness. 
Jill: Hopelessness and lack of support. I think it's just the -- it's all contributory.

Initially the women were silent about their burden because it was part of life. There was nothing to talk about, they just did it. However, after the fall when communication became imperative, the women were silenced by their overwhelming circumstances and a constellation of supporting beliefs. Linda was constrained by the beliefs that "I must manage illness on my own," and "No one can understand this who hasn't been through it."

Linda: But I don't know if it was something that I -- because as understanding as my husband is in that way, we never really talked about it too much, you know....And it's something anyway you gotta kinda cope with on your own.

Carole: That's what you think....that it's for yourself.

Linda: I think so. Because nobody knows -- you have to go through it to, um, you know. And you have to live with it kinda day to day.

Samantha was constrained to silence because she believed that sharing the burden meant sharing the pain.

Samantha: You couldn't talk to your mom. I couldn't go tell my mom and cry on her shoulder because she hurt, because I hurt. It was very hard, and so she couldn't help me.

Jill questioned the legitimacy of her own feelings, indicating a belief in a "right" or "correct" response to illness. As well, the right time to talk eluded her.

Jill: Another big part of it was the things I was feeling wasn't appropriate. Like Peter was busy. He wasn't there when I needed to talk to him and -- at a specific point in time or whatever. And Leanne was at school and I was working nights, and I think a lot of it was I was just getting really tired and frustrated.

The women tended not to involve friends because of the combined beliefs that illness wears people out and illness should be managed better, that is, there should be a 
"better" story to tell.

Samantha: One of the reasons I withdrew is, all my friends had heard the story before and you can only hear it so many times and you think, yeah, yeah, get on with your life. You know, that's how I felt that they were feeling. I don't know if they were....People would come and say, "Well how are things going?" and I'd want to tell them. And they don't really want to know. They don't want to know the whole, indepth -- they want to know about basic, brief.

Silence was transformed into deception when the imperative to protect again took precedence over self. Linda's strong belief that she must protect her family from the influence of illness meant that she hid her experience of sickness.

Carole: If you're worried about how your family will respond to the illness you might hide what's happening.

Linda: Yeah, that's right.

Carole: And so then maybe it's tough to get support.

Linda: Well it is if you don't ever let them know what's bothering you, you know. 'Cause (sighs) you just say lots of times you're okay. Isn't anything bothering you and you just say "No."

This explains the women's silence, which the women did not see as a matter of choice. Initially they were just trying to do their job and later they were too overwhelmed to know where to begin. However, what about their families? It seems that as far as their families were concerned "no news is good news." Silence was met with silence.

Anger, tears and withdrawal.

At some point the women moved beyond silence to explosive anger and tears. As Leanne stated: "Well I noticed that there was a lot more tension in the house. Like fights would break out like nothing you've ever seen."

One woman explained her contribution to the family's lack of understanding of 
the problem with illness this way:

Jill: I think a big part of it is, um, a lot of times I handle stress by just -- I cope. And I don't let everybody in on -- on every little detail. Anger is the same way, like it -- it, um...many things I'll just let go, let go, let go, until all of a sudden I'll explode.... I mean I may be upset. I may not communicate that upset --

Leanne: Until it snowballs.

Jill: Until it snowballs.

Thus anger often did not assist family understanding any more than silence because the heart of the matter was not uncovered.

Maia: I think maybe that she would get frustrated or angry or whatever she was feeling, but it -- she wasn't telling us the underlying thing that she was angry about or frustrated about. She'd -- it'd come out in other little things. So we didn't realize what was really wrong.

Most of the women were not in touch with the "real" problem as they responded

to an onslaught of unearthed emotions.

Samantha: Kevin would come home and I would yell at him because the house hadn't been cleaned all day or supper wasn't ready or -- I don't know how he put up with it....I would yell at him because nothing was done. It was all his fault. It was his fault because he didn't -- because supper wasn't ready, it was his fault. Because the house wasn't clean, it was his fault.

For this family, a vicious cycle of blame and withdrawal ensued.

When the women's silence was replaced by anger, typically there was not enough information in the system for family members to respond supportively. Thus, another vicious cycle of anger meeting anger drew forth more isolation.

Leanne: Like, 'cause she felt she had all this weight on her shoulders and so she'd get mad at me for doing something and I wouldn't understand because I didn't know half the stuff that was going on.... But see, I didn't understand, so I'd get mad at her for getting mad at me 'cause I didn't know what I did wrong and then she'd feel that we weren't relating anymore. 
For other women, silence overflowed into tears.

Carole: And how did your family fit into this? Do you think they knew how serious it was for you?

Linda: No

Carole: How is it that -- that they wouldn't have known?

Linda: Well I guess 'cause I didn't say anything about it at first. And then I got to where I was bawling all the time.

In only one family did the woman's partner sit down with her and request that she speak about what was troubling her.

\section{Ignoring Obvious Signs of Trouble}

All the families admitted to knowing "something was wrong." As Peter said:

"Ya, I think we all recognized that there was something going on." Thus, even if the women were verbally silent, their nonverbal behaviors were not.

Margaret: Well, he drove me to Emergency with my panic attacks a few times and he was getting pretty disgusted. So I don't know. He knew about that. And he knew that I was going through a really terrible time.

While it is clear that vicious cycles of interaction do not invite supportive behaviors, the question remains, why did these families not respond to the obvious, continuing signs of trouble and distress shown by these women? One explanation was that the family was too busy.

Maia: Well everybody was really busy and it's not like we ever really sat down and had some quality time, you know what I mean? Like we never sat down at the dinner table and ate dinner together, we just, nobody had time. Everybody had their own thing going on.

Busyness pulled energy away from attention to family, which was supported by the belief that, even if there was trouble, "we can work things out as always." 
Maia: I didn't really think there was a problem, like I was, I guess I was a little depressed about everything but I didn't think there was, I thought we could work it out like we'd worked everything else out....

Peter: I think, myself, I thought like I would probably let it pass as well. You know what I mean? Like, I thought well okay, it'll eventually go.

However, there was no acknowledgement that to "work things out as always" was dependent on the woman/mother/wife in the family. It was only later in the process that families began to see the woman as pivotal to the management of daily life.

Another common belief was that the problem belonged to the woman. Somehow if it was the woman's problem, it was her responsibility to solve it. In other words, women must look after themselves.

Peter: I think, ya, I think I realized there was a problem but I didn't realize, I don't think until we got there how much it was bothering Jill. You know what I mean? Ya, I understand that there's a problem and so on --

Jill: He thought it was my problem.

Peter: Ya, in a way.

The unstated facet of this belief is that if the problem belongs to the women then it does not belong to others. In other words, "It's not my problem."

Margaret: [Jared] was balking a lot then and I didn't like it, maybe because of me being a bit depressed at that time. I found it really difficult to cope with.

Carole: Balking? About?

Margaret: Everything I would suggest he would just --

Jared: Shrug it off.

This constrained every level of problem management from simply talking about the problem to problem solution. 
Acknowledging the women's plight meant opening space for renegotiating family work. At least one man dismissed his wife's concerns based on the belief that he was already doing his share. "I'm doing my part so what's the problem."

Peter: I mean there's a lot of things that I do, you know, I mean in the house. Like I -- especially at this time we were talking about.... I don't have to go into - but let's say I would pay all the bills....Then I know that when it came to a head with Jill and it started to boil over, basically she was coming at me and saying well, you know, I don't want to organize all this. I don't want to, you know -- why am I always doing all this stuff. And I was out in left field, to be honest with you, at that time. I didn't know what she was talking about. Well, you know -- well, what do you want to do? You go ahead and pay the bills then or you do this and I'll do some of this other stuff....I was thinking, well, you know, I'm doing stuff.... Why should I do everything too.

Thus these women, stretched beyond their limits by an overwhelming illness burden, fell from their position of precarious balance when faced with unexpected loss and continued the downward spiral of falling apart as they experienced the additional loss of expected family support.

\section{Hitting Bottom: Overwhelming Uncertainty and Life's Big Questions}

Until the fall, these women had managed to keep uncertainty at bay. However during the downward spiral they were no longer able to contain their worries. Space was now opened for unremitting uncertainty. This uncertainty drew forth fear that crowded out the spirit of life. As Linda said: "Well when you do get that scared, you just don't - you don't care if you live or die or get better."

Overwhelming uncertainty was fueled by life's big questions such as: When will he die? When will I die? Am I going to be able to get through today? Does my family care about me? Will my marriage survive? Will my family survive? The uncertainty knocked self confidence and raised serious doubts for the women about their ability to 
manage as they had been doing. The downward spiral consisted of increasing uncertainty and diminishing self confidence. In addition, uncertainty drew forth a heightened sense of obligation so the women were caught with a sense of even greater responsibility at a time when their personal resources were at an all time low. Worn down by the unending burden of illness and the uncertainty that things may never change, these women now hit bottom. As Jill reflected: "Illness felt like a blanket that was smothering us all."

The women responded to hitting bottom in various ways. Exhausted, Samantha retreated from responsibility by "locking herself away." No longer able to persevere, she went through the motions of living.

Samantha: I would fix my children their meals, because they had to eat. And then I would lock myself in the bedroom with a book or we have this really nice, ahm, swing outside that -- I would go out and sit on the swing and read and read and read. And then Kevin would come home and of course the house would be a disaster because I hadn't done anything all day and the kids were just kind of being left on their own all day. I was here and then -- I had to deal with something they did but I avoided it.

Jill took a stress leave from work so she could give herself some breathing space to better care for her sick child. However, this drew forth more worries about loss as she faced the possibility that she could not continue to "do it all." Her full time work was not a luxury for the family; instead, it was a necessity in order "to maintain any kind of a life style." Like each of the other women, she was caught in a dilemma of conflicting demands and severely limited resources. Alison also contemplated whether she would be able to continue her part time work. Linda and Margaret experienced immobilizing panic attacks that drew forth fear of dying.

The women were stuck in an intolerable present with little hope or ability to focus 
on the future. This was exemplified by Samantha's big question about her young son: "When will he die?" She thought that death was imminent yet Cody was more healthy medically than he had been in a year, which points to what might appear to be a paradox. Illness problems did not disappear when the chronic condition improved. Instead, as the illness became a less demanding presence, space was opened for long denied illness problems to emerge. Thus, for three of the women, the biggest fear of all, that of continuing decline and death, dominated thought.

Samantha: So every day I was looking at him to see if he was going to die tomorrow. Um, even now, I have people say "Why do you think he's not going to live very long?" "Why do you worry about him dying?" I don't know....I was grieving for him every day.

Jill: It's like endless. You just...like there's no seeing your way to the end of this -- this nightmare, you know....I was spending all my time worrying.

Linda: 'Cause when I first had it [heart attack] -- the very first night I had, I wondered. I thought to myself, "I bet you I'm not going to wake up in the morning. Whereas, now, I don't think that every night when I go to bed, you know? But, I did for quite a long time. I wondered if I'd wake up or -- if I did wake the next day I'd be real thankful that I was awake.

Illness problems became life consuming.

Linda: I got just horrendous anxiety attacks like you couldn't believe. Just out of the blue. And I didn't know what was happening. Well, of course, you kind of feel like you're going to die when you get those.... I couldn't think of anything else anymore.

And thus arose life's big question for self: "Am I going to survive?"

Jill: I was afraid for my own -- I don't know if you'd call it sanity or self or -or whatever, it was at the time. Or maybe that's what you call the fall, you know.... Yeah, I guess that's what I was afraid of. That I would lose myself and 
that, therefore, there would go the family, you know. And who would look after Maia?

For various reasons, all of the women worried that their marriage or their family or both were in jeopardy of falling apart.

Jill: I was just seeing the whole situation deteriorating for everybody here and I thought, well, our survival has always been because we're together you know. And, um, I couldn't stand the thought that this could mean the breakup of our family.

When the woman herself believed that the problem belonged to her, this worry had an even greater impact since she saw her own behavior as influencing a breakup.

Samantha: I thought, I'm going to lose my husband if I don't straighten up.... Obviously there was a problem and I kept...I asked him I don't know how many times how he could live with me.

This was a time of heartache, loneliness, fear and desperation - a time when day-to-day living was a struggle. As Jill stated so succinctly: "I was really desperate at the time....Basket case would describe it." Thus it became imperative for these women to alter their present life situation by seeking a way out - a change.

\section{Desperation: The Trigger to Seek Help}

Even as the women hit bottom and realized that their families were not with them in their struggle, they began the work of change.

Linda: 'Cause you just gotta, I don't know, you gotta come to grips with things sooner or later and (pauses) it just doesn't do any good to let it kinda overcome you, you know. 'Cause it...eats away. You can't function. 'Cause that's all you ever think about.

Each of the women was resourceful in trying to help herself by experimenting with such things as journal writing, seeing physicians, taking medications, talking with friends, praying, listening to tapes, reading, and accessing alternative health care. 
Although many of these attempted solutions were somewhat helpful, the women continued to feel stuck in their difficulties. That is, they were not experiencing success in changing things on their own. Two of the women talked about it this way.

Linda: I guess (pauses) I tried. Believe me, I tried.

Carole: You had all -- a lot of good ideas and I just wondered with all these good ideas, what sort of held you back from going forward with the ideas?

Margaret: They weren't working at the time.

Carole: Oh, you had the ideas and had tried them?

Margaret: Yeah.

These are women who were used to solving problems; however, their circumstances were so overwhelming it was hard to find a start point.

Jill: I didn't even know where to start to cope and, I don't know if you've ever been that stressed or that um, bombarded but it's almost like you can't find a path for your thinking. You can't, there's no starting point for you to start sorting things out logically and get a game plan going. And I was at that point.... Because I've always coped with things eventually, at some point in time. And the way to do it is you go, okay, this is my problem and I have to go from point $\mathrm{A}$ to point $\mathrm{B}$ to point $\mathrm{C}$ and that's how we're going to deal with this.... But there were so many things coming in at me that I didn't know, I couldn't start with any of them. I didn't know how to get a handle on it.

This led them to acknowledge the need for outside help.

Samantha: I knew what I was doing but I was doing it anyway....

Kevin: We knew there was a problem. We just had to find the right way to deal with it.

Samantha: I agree that I was not behaving the way I should, but I -- and I knew that I couldn't stop on my own....I had to have some help.

Despite feeling as if their personal resources had dried up, the women were able to seek 
and find help for themselves and their families. Their courage and perseverance were indeed heroic.

Jill: When you're that scattered you really feel like you have, have no coping mechanisms....I think that sometimes problems are looming over you. They're overwhelming.

Carole: Swallow you up.

Jill: Ya, you can't see your way through them to the solution.

Ironically, it was also the women's job and responsibility to find help. Some of the women obtained family support for the idea that help was needed but no one in the family assisted with the illness work.

Linda: And then I got to where I was bawling all the time and finally Bill sat me down one day and said "You gotta tell me what's wrong." And I told him what's wrong. He said "Well you better get some help then."

Jill: There were a lot of changes going on with me. And I think the time that we decided we would [get help] was because of my instigation. I was the one that thought it would really help us.

Like family members, health care professionals were usually supportive of the idea of seeking help; however, they varied in the appropriateness of their responses to the women's pleas. Sometimes they were helpful and sometimes they were not.

Margaret: It [her own attempts to change things] just wasn't working so I phoned the nurse educator at the [hospital] and I think I cried on her shoulder. She said um, I'm going to get back to you in a little while to make a referral.

Linda: Like I said, I couldn't stand it and besides, I thought I can't stand thinking like this all the time, all the time, all the time.

Carole: Well, you knew what needed to be done.

Linda: Yeah. Like I went to the doctor. He says, "Well we could put you in 
the psychiatric ward in the [hospital]. I'm going, God, couldn't I talk to somebody first.

Not only did the women do the work of finding help, they also did the work of involving family in the process of change.

Peter: We were sort of drifting along and then Jill sort of said, whoa, wait, hold it -- you know, I need some help with this.

At times the idea alone of getting help acted as a temporary bandaid but, eventually, the situation broke down again.

Alison: We'd talk about [getting help] and then it would be okay -- and then things would go okay for another couple of months and then it would just, you know.... Then just finally thought, well I better go - we better go do it.

Something different needed to be done.

Maia: I think we thought maybe if we did something differently than what our pattern was that maybe things would work out a little better. 'Cause I think that we were all in such a set pattern that we were thinking everything is going to go on like it was going on for a long time unless something kind of-

Carole: shook it out, shook it up?

Leanne: Ya.

For some families, the opportunity for help came just "in the nick of time." For one family it was an alternative to separation.

Scott: I guess we kind of said we were fighting so that's why we went but... yeah, it was getting kinda out of control there in terms of the kinds of things you say. Well, where is this heading? And the marriage and -- So that is probably -- we better go get some help or do something more drastic.

Once the women found help, all of their families were willing to participate.

Peter: So when this came up, when Jill suggested this, I think we all said "yes" you know, right away. I mean nobody said, well gee, I don't know if we should do that. 
They were willing to come to help mom.

Peter: I mean, like we said at the start of this, we all -- we all felt that we came because of Mom.

Thus, in the end, the women sought change and brought their families along with them. This brings us to the third stage in the process, "Helping Them That Help Themselves."

\section{Stage Three}

Nursing Interventions: Helping Them That Help Themselves

This stage exemplifies the process of therapeutic change, that is, change that was influenced by professional nursing intervention at the FNU. The women and their families entered this stage committed to the idea of change and often had clear notions of the direction of desired change. This stage, like the others, represents a process within a process: the process of therapeutic change within the larger process of managing life with a chronic illness. The two major components of therapeutic change from the families' perspective are: creating the circumstances for change and moving beyond/overcoming problems.

\section{Enabling Healing: Creating the Circumstances for Change}

When asked what was helpful, the family members talked about two relationship systems: relationships between family members; relationships between family members and the nurse. Initially it was critical that the family members come together in concern around the problem and then it was important to coevolve a helping relationship between themselves and the nurse. These relationships enabled healing. 
Bringing the Family Together

All of the women entered this stage feeling alone and isolated with their concerns. As Samantha said: "I was feeling on my own." However, the clear family focus provided by the Family Nursing Unit provided an unusual opportunity to change the family's organization around the problem. Instead of maintaining the "in house" organization of the woman's isolation and unrelieved illness burden, which might have occurred had the woman been seen alone, the family was invited. The family focus offered these women the opportunity to request family support and, at the same time, offered family members the opportunity to be meaningfully supportive. Two of the men explained their participation in the therapeutic conversations this way:

Kevin: It was more, well she needs help and support and my input to this decision, things might help, 'cause they wanted my input and stuff....They wanted to hear what I had to say rather than just -- just come and be with me kind of thing.

Peter: I think it allowed -- it allowed myself to sit and put some input into it then. You know, I mean there was, it sort of stopped us and said, okay, yeah there is something I can do about this.

Thus, family members' belief that it was the woman's problem and her responsibility to solve on her own was challenged. Each family member had a role to play.

The participation of family in the therapeutic process was immensely significant to these women who had come to wonder if their families cared about them or if their families would survive the trouble they experienced. One of the beliefs that had encouraged the women to persevere over time was that family should come together in times of trouble. Thus, bringing the family together when the women experienced 
trouble was crucial.

Jill: I just felt that the family has always been together and it's because we've always been there for each other that we've gotten through all the things that were going on with us. And I really felt that it was necessary for $m e$ to go for counselling and one of the places to go for counselling was the Family Nursing Unit. And I thought, okay, it's good for me but, if it's good for me it's good for the family too, you know. Like I'd really like it if we'd be in this together.... Our survival has always been because we're together you know.

Some women were so used to carrying the illness burden alone that family members' agreement to participate in therapeutic sessions was totally unexpected.

Margaret: I was surprised to hear him say that he would go with me.

For Margaret, the opportunity to shift family dynamics drew forth an entirely new belief about her husband.

Margaret: I know I have his support now.

By bringing the family together, the belief these women held that their families were in jeopardy of falling apart was challenged. As Jill reflected: "Well I think what it helped us believe was that we weren't really apart."

The Family Nursing Unit provided a context in which family members could commit to coming together, in support, to talk about difficulties. As one man said: "It focused us." This was a difference that made a difference.

Peter: Ya, that was a problem too because there wasn't any family discussions [at home]. There wasn't any time that we all sat down. And that [referring to the FNU] was a perfect forum for that, you know. It really was because it was a time we set apart, we said, you know, we're going to go there and we're talking....We had committed ourselves that we were going to meet at this time and talk about this.

It is important to note that one woman chose to participate in the therapeutic conversations on her own. What was significant to her was that her husband offered to 
join her "even though it would have been hard for him." Linda declined the offer because of her need to break her silence while still protecting her husband.

Linda: I knew if I was supposed to be -- like speak my feelings and that, there'd be certain things that I wouldn't say in front of him and I wanted to. And I think that's what helped me so much is 'cause I could just let it out.

The critical piece here is that Linda believed her husband is her "greatest supporter." Her family was brought together by the family focus that enabled Bill to sincerely offer to participate. Linda did not need the presence of her husband in the therapeutic sessions to believe that her family was with her.

\section{Comfort and Trust: Reciprocal Cornerstones of the Therapeutic Relationship}

Once these families came together in response to the women's efforts, it was necessary to establish therapeutic relationships between family members and the nurse. In this regard, the families emphasized the elements of comfort and trust. Based on their extensive histories with "helping" professionals, it is understandable that the families entered this therapeutic relationship hoping for help but wary of what might actually happen. Again, understandably, it was the women who were most concerned.

Margaret: I wasn't sure that I wanted to be there 'cause so often there were times when the doctors, I guess I was the one that ended up going to the doctors and they kind of chewed me out or something.

Jill: I mean there is that certain amount of -- of put feelers out and yet you don't trust people right away, especially with family problems.

Thus, trustworthiness needed to be earned and was accomplished by drawing forth comfort and trust. 


\section{Drawing forth comfort.}

One of the potential impedances to the development of a therapeutic relationship was the setting itself. All of the families agreed that the setting, replete with one-way mirrors, a therapeutic team behind the glass, video cameras, camera technician, nurse and telephone was somewhat daunting. As Leanne remarked, it had the potential to make "some people" nervous. "There's none of the comfort..." of a familiar setting. Most family members admitted being a bit nervous themselves at first but this quickly disappeared. The idea was worse than the experience.

Carole: Both of you said a lot of people would feel uncomfortable with the setup. The one-way glass -- all of that.

Samantha: It seems like when you tell people about it they --

Kevin: They kind of go, ooh. They're a little bit concerned.

Samantha: But I don't -- I think if you can get them there they'll realize --

Kevin: If you can get them there for the first visit --

Samantha: it's not that bad.

Three things assisted families to feel comfortable. The first was thorough explanation, in other words, "showing me everything."

Leanne: I'm saying that because she took the time to say, "Well here's where everything is. Here's this person, here's the people behind the glass" ....I think that would help.

Informed participation was an ongoing process, rather than a one-time affair.

Samantha: They always made sure that I knew everybody that was in there. If somebody came in during the session, they always -- afterwards always made sure that I met them....And nothing was hidden. It was out in the open.

The second key to comfort was access to persons involved in the process, 
particularly the team behind the one-way glass. It was important to have the opportunity to put faces to hidden persons.

Jill: But we did want to meet them -- we didn't want them to be faceless people behind the glass. Or, at least that was my feeling -- I really felt that I would like to see who was there....

Leanne: I think too, for me, when I saw those people I could put them behind me and that. Like the thought of having people watching you kind of freaks you out until you say, "This is what they look like."

Jill: We even met the man that ran the cameras (laughs).

The third key was access to the thinking of the team behind the one-way glass.

The families appreciated the idea of multiple minds working together in relation to their difficulties.

Samantha: I think it's just great. Because you're in the room one-on-one with the person. But at the same time they have a backup and so if they got stuck there was somebody there to help them.

Kevin: Or if they thought of something, they could tell the person to ask that question.

Leanne: We were focused on one person although we knew there were more helping.

However, initially, there was concern about the role of the team behind the mirror. In particular, the family members wondered what the team members were thinking.

Jill: I didn't want faceless strangers sitting there, watching me and not knowing what they were thinking.

Linda: Well I wasn't too sure about that -- those people behind the wall there. It was a little nerve wracking at first, 'cause you just wonder what...everybody's thinking. 
Carole: What was the scary part?

Kevin: Mine was one of the people behind the wall, behind the window, doing or what are they going to say.

Access to the team's thinking was provided by a telephone link, where the supervisor would call the nurse and introduce new ideas or questions from the clinical nursing team to the therapeutic conversation. In particular, the family needed evidence that they were not being judged.

Leanne: Even the people behind the glass, they phoned in occasional questions too. And it was questions that made us realize they were real people. They weren't sitting there criticizing us or analyzing us. They were just listening....

Jill: They were trying to help us. From what we said they were picking up a thought that maybe this would be another avenue of discussion....I think also the fact that it was a non-judgemental environment. I think if you think you're going to be on tape and...there are people behind you and they're judging what you're going to say, you may not speak frankly.

Another extremely powerful way of accessing the team's thinking was via the reflecting team (Andersen, 1987, 1991). Here the family and nurse exchanged places with the team. This enabled the family to hear the team discuss their ideas.

Leanne: We got to sit in on one of their sessions the same way that they sat in on ours. We got to sit behind the glass and listen to them talk. And I think that made us see it from their point of view, so we knew that they weren't judging us, you know. Just by sitting there and listening.

Margaret: They were talking to each other instead of to me. I was just listening to them.... They weren't basically looking at us and talking directly to us. They were talking to themselves....I remember at one point they said something, I can't remember what was said, 'cause it hit home so hard. I just got tears in my eyes just listening.

Once the family experienced the team's concern and interest, discomfort was banished.

A setting had been created that was different from what had been experienced before. 
Leanne: But we were kind of nervous about the Family Nursing Center because we didn't know what to expect - what they would say and what they would do.

Maia: Ya, I was thinking, like when I was little with my diabetes they have the specialists, the endocrinologist and then the normal physician and then a whole bunch of psychiatrists all in a room and I thought it was going to be sort of like that. You know, a whole bunch of people analyzing and criticizing. But it wasn't, it was comfortable.

Drawing forth trust.

The second facet of establishing the therapeutic relationship was drawing forth

trust. The families were clear that their relationship was with the nurse and not with the team. The team was a supporting backdrop for the therapeutic relationship that coevolved between the nurse and the family.

Carole: How about your relationship? Did you feel like your relationship was with the woman who was in the room with you or with the whole team? How did that feel for you two?

Samantha: I felt like it was with the woman who was in the room with me.

Kevin: Which relationship?

Carole: Who did you feel connected to there, at the Family Nursing Unit?

Samantha: Not the people in the background.

Kevin: No. No We were talking to her for sure, I mean, it was a -- I don't know, one-on-one.

Jill captured it succinctly: "Ya, that was our relationship."

This particular relationship between the family and "their" nurse was critical to the therapeutic process.

Jill: But just the fact that she needed to be there. We couldn't have gone if she wouldn't have been there -- if somebody else had been in her place it wouldn't have been the same. 
From the families' perspective, once a measure of comfort had been drawn forth it was important to establish the trustworthiness of the nurse in several domains before the therapeutic relationship could be characterized as trusting. Different families emphasized different domains of trust as pivotal to their therapeutic relationship. For example, Samantha's religious beliefs provided the foundation for her life and it was crucial to her process that they be respected.

Carole: [You needed] somebody you could trust, to respect -Samantha: My beliefs.

For some, the genuine interest of the nurse in the family's situation established trust and drew forth the experience of caring.

Margaret: I just thought they had a lot of compassion for the way I felt and what I was going through.

Genuine interest was part of what helped the family help itself since it invited a willingness among family members to participate more fully in the process.

Samantha: She even called a couple of times.

Kevin: Yeah. Her -- her interest in the interview was more than just the interview. I mean she called us. She sent the letters. There was more than just the interview, and I think that really helped us to talk more. Because we trusted her. We felt, yes, you are interested in what we're doing.

It was also important, particularly to the women, that the therapeutic relationship remain professional. In other words, the nurse was interested and caring but "she left [the family's concerns] in the room when she left." These women wanted to be free of the imperative to protect.

Samantha: I needed somebody that didn't know me. I mean didn't know me well. Yes, they knew me, but they didn't know me and could be impartial. I 
mean she cried with us and things but I wasn't her sister or I wasn't her best friend.

Linda: I just felt so comfortable with a stranger...' Cause I didn't have to -there was nobody beside me listening to what I said, you know. Like I didn't have to watch what I said or worry about hurting anybody's feelings.

The families found it helpful to be in relationship with someone who was at a distance from their concerns; "someone who wasn't affected by the extra family member [illness]....Someone completely outside our little circle."

Leanne: We were looking for somebody on the outside to say "Well this is what I see going on."

Maia: Objective, ya.

Jill: Ya, I think so too.

Leanne: 'Cause we were too close to Maia and we were inside the whole cycle and situation that I think we were too close to the problem to see the solution I think, you know.

They needed to trust that the nurse would not get entangled in the web of their difficulties. The families needed the nurse to use new eyes to see old concerns in a different way and to offer new perspectives for consideration.

Jill: I think a lot of times I need to check my perceptions with somebody, um, that's not involved - not involved. Like I know what I'm feeling and I know what I was feeling about the family or whatever at the time. Um, also I had no idea of where to start and I was really glad that I could know this person (laughs) that was going to help us. I felt that she will listen and she will be able to untangle the threads.

They also experienced a helper who was equally interested in all family members' perspectives, that is, someone who was on "everybody's side."

Maia: A person who can listen to all four sides of our stories and not -- 
Jill: non-judgementally --

Maia: butt in -- not have to say you're wrong.

Kevin: If someone knows Samantha they listen to her maybe a little bit more than they would me. And same with maybe my friends would listen to me, whereas they would -- they might listen to Samantha but not hear anything. And so by having someone there that really didn't know either of us, they could look - they would listen to both sides equally.

In other words, each family member needed to trust that the nurse was interested in their particular perspective. This enabled the families to help themselves because it invited the unconstrained participation of all involved family members.

Another critical aspect of evolving a therapeutic relationship for each of the families was the absence of judgements, regardless of whether they were offered in a critical or blaming manner or were intended to be positive.

Margaret: I guess that's what basically I'm getting back to is somebody that can talk to you in a -- in such a way and get things across without, um (pauses) you know, showing this angry emotion with me.

Linda: I guess that she didn't seem to pass judgement on me you know, and so I felt comfortable, at ease.

Samantha: And the non-judgemental because people who know you make judgements. Even if the judgement is "Oh, you're so strong." And you think (sighs) "I’m not strong."

Carole: Can't you see I'm falling apart?

Samantha: That's right.

A non-judgemental stance on the part of the nurse invited family members to speak from the heart, without reservation. The family members trusted that they would be heard and 
not rebuked.

Further, it was important to have a space of undivided time and attention in a setting that gave the women in particular, time-out from life's never-ending demands.

Linda: It was way different. I wished, which I know is pretty well impossible, but I wish doctors could take the time with you like that.

Samantha: I mean you know when you go there that you have this much time. That you have them all to yourself for that length of time. And you don't with anybody else.... There's always the doorbell that's going to ring or the child that's going to -- tugging on, on mom or -- whatever happens there's always the interruptions. But there it was I have this time.

All of the families commented on the assistance they desired in addressing their problems. As the following quotation highlights, they wanted a push in the right direction rather than a tow to a predetermined destination.

Leanne: I think that was one of the main reasons we were worried, we thought they were gonna tell us what to do....

Jill: I think what I wanted was somebody to help me find my starting point, you know. Like you've got a whole bunch of threads that are unravelled and there's just the key thread and you have to find it so you can have something to hang onto so you can start.

Carole: Sort of help you find the beginning not to --

Jill: Exactly, not to give you the end answer.

What happened in the Family Nursing Unit to draw forth the trust that was necessary for the evolution of highly effective therapeutic relationships between family members and nurses? The hallmarks of an effective therapeutic relationship, according to these five families, were: undivided attention; non-judgmental behavior and attitude; respect for their beliefs; and, compassion for their concerns. At the same time, the nurse 
maintained enough emotional and cognitive distance from the problems so a new perspective could be offered that would assist the family to change in a desired direction.

For all of the families, a measure of comfort and trust had been established by the end of the first therapeutic session.

Margaret: I was really pleased with what I was hearing. I was quite relaxed after the first time. I felt more comfortable about going back.

The care and time taken to establish comfort helped draw forth trust and trust helped draw forth comfort. Thus, the reciprocal influences of comfort and trust worked synergistically to create an environment in which the family, which had already come together in a new way, was open to further change. Furthermore, a context had been created in which the family could show its strengths as well as its difficulties.

Samantha: And then the comment I remember them making is, we held hands through most of the sessions or we were constant -- like we are now constantly looking at each other and the supportiveness. But in the state of depression, we forget that that's there.

\section{Getting Unstuck: Moving Beyond and Overcoming Problems}

The families did not expect nor desire magical solutions to their difficulties.

Instead, they were looking for assistance with the process of change, that is, help moving beyond a place of being mired in trouble.

Jill: But just to put you on the path that you can, like obviously I knew that we've been through a lot and we've always managed to do it but I was just too bombarded. And because, you know these guys, they're very caring but they're not me. They didn't quite understand where I was at and I just thought, well if I can understand where I'm at and they can sort of be with me and sort of start with me, that we could --

Carole: You could figure it out yourselves?

Jill: Ya, we could get through this, ya. And that's how it turned out. It was 
just wonderful really.

Maia: We weren't looking for a fortune teller, you know.

The families were clear about what helped them move beyond problems, with the first piece of the puzzle being "she got us talking."

Breaking the Silence: "She Got Us Talking"

The nurse encouraged family members to talk freely about the invasion of illness, which was immensely significant since illness had invited silence, fights and tears but few healing conversations. As Peter remarked: "I still think that the best thing about the whole thing was getting us all together and talking about it."

For the women, who had lost touch with self as they persevered with illness burden, it was very powerful to be able to give voice to their inner experience. The women remarked that "getting everything out on the table" was critical to gaining a measure of control over anxiety. For some, the rediscovery of just what was harbored inside and the life pressure it exerted was a revelation.

Linda: I just think I got a lot of things out like -- 'cause she started asking questions, um, you know (sighs) from when I was a child 'til now and I think I just was getting some things out that I've harbored inside me....It's just amazing the stress release that you get rid of, you know. Instead of sitting there thinking about it -- you're by yourself all the time.

Within the therapeutic context there was a clear expectation that the women would and could talk about their problems, troubles and concerns, which overrode the silence that accompanied the injunction to protect their families from illness.

Maia: My mum doesn't really like to talk about things a lot and this way she gets everything out that she needs to talk about.

Dr. Wright: So your mum's a person who doesn't like to talk about things a lot. 
That surprises me.

Maia: Well not to us. Maybe to her best friend or something. She just doesn't like to talk about her problems and stuff. I guess she wants to be supergirl or something and deal with it, you know.

Thus the women were invited to bring self into the foreground of family relationships.

The asking of useful and "good" questions influenced the conversations by drawing forth new information, which included differences in perspective, that enabled a better appreciation of the other.

Scott: She was very good. She asked good questions (laughs). She got us talking. I guess, um -- I think she, she had a way of getting us to see the other person's perspective.

This encouraged family members to "open space" for the other in their relationships because what the other was doing made more sense.

Carole: One thing I notice about you two is you're very tolerant of each other's perspectives if they're different. Like you'll, you'll say your piece Samantha and Kevin will say his and if it's different there's a whole lot of tolerance for that.

Kevin: $\mathrm{Mm}$ hm.

Carole: Do you make any connection of that tolerance to what happened in the Family Nursing Unit?

Samantha: Yes.

Carole: Tell me about that.

Kevin: Before, it was, you know, she would talk or say some things and I wouldn't want to listen to her and then she would get mad at me 'cause I wasn't listening. And after going to Family Nursing [Unit] and finding out what her point of views were and what she does when -- to get rid of her anxieties and then what I do and what my thoughts were, we were able to better understand what -- what the other person was doing.

Samantha: And the other thing what I think is I used to always just expect that if he looked a certain way, he was thinking something.... and I'm feeling this way 
so he must be. If I think this, he must think this.

Carole: So you didn't even think there were differences.

Samantha: That's right. I just expected him to think the way I did. And it was really interesting to find out that he didn't. Because we do so much alike that we just -- that I automatically think that we should be completely alike and we're not. I forget that we're individuals sometimes.... That was the first time, I think in our entire marriage that I actually realized that we were different. Or that we had different ideas on things....It's helped a lot.

Thus, family members were able to hear new things about themselves, others and their relationships. The unspoken was spoken; differences were celebrated.

Leanne: The family counselling helped relieve some of that tension so we knew what everybody was thinking at that particular time and what we were feeling. And got it out in the open and dealt with it.

As family members engaged in conversations with one another in a different way, critical new information became available to the system that challenged problematic beliefs. For example, Margaret heard of her husband's concern for her plight.

Margaret: I think we expressed a lot more stuff there than we probably did to each other you know. And uh, I remember Rob saying there that he was concerned about me and at the time I thought, "Concerned about me?" I didn't think anybody was concerned about me.

Samantha reshaped her ideas about her son's life expectancy based on information from her husband.

Samantha: And then when Kevin was talking about the blessings and the feelings, he had told me that he didn't think Cody would live very long -- very long being 30 or 40 . Well my very long was 6,7 -- we had a different concept. So every day I was looking at him to see if he was going to die tomorrow.... [Now] I expect he'll live a number of years, but he won't live to a ripe old age, but then who's to say any of us will. But it took the counselling it took that to get me to that point. Because I was grieving for him every day....Some of the things that he said cleared up some of my problems.

Thus the information her husband held, successfully challenged Samantha's belief that 
her son was dying before her eyes.

Although "just talking" was an important difference in and of itself for the family members, another critical facet was the nature and direction of the talk. The nurse had purposeful and focused conversations both within sessions and over time.

Scott: We would get talking about something and then she would, she would catch onto something and just get us to explore that and that brought out some, that just brought out some good dialogue.

Maia: Well I was gonna say that she had recorded the stuff we had talked about and, you know, our concerns and everything the time before. So she would bring up the main things that we still hadn't resolved. Like she was sort of like the memory.

The therapeutic conversations were focused in the direction of strengths. Attention was paid to change, even small change, that occurred in the direction desired by the family.

Leanne: I think too, they made us focus on the positive.

Maia: Not made, helped.

Leanne: Because they never brought up the negative really. I don't remember them bringing up the negative.

Maia: What do you mean by negative though?

Leanne: Like, have you gone backwards. They didn't focus on that. Like say, you're sleeping more but you're still going to school. Oh, she's going to have a relapse, she might have a relapse. They didn't do that. They said well, "It's good that she's going to school" rather than "Oh, my she's sleeping a lot more again" you know, maybe she'll go back to where she was. So they focused more on the positive.

This brings us to the crucial therapeutic influence of noticing and distinguishing positive things. 


\section{Nobody Ever Told Me I Was Doing A Good Job}

All of the families found the team's orientation to strengths, resources and possibilities to be an extremely important facet of the process. However, in order to be of value, the focusing had to be extremely sharp and clearly specific to the situation.

Samantha: And some of the things I really appreciated - the letters. The followup letters, after every appointment there was a letter. And in the letter she would say, because I needed it at this time, she would bring up all the positive things that happened during the session. And when you're in the state of depression or when the crisis, you don't think of those things. You don't think those of yourself. And if you hear them, and I had gotten to the point that people would say, "Oh I don't know how you're doing it. Boy you must be so strong." And I wanted to strangle them and say --

Kevin: Yeah, please don't say that.

Samantha: I'm not strong. Anybody could do this, it's just the way it is. You deal with it.

Carole: It's sort of like you don't have a choice, eh?

Samantha: So I got to the point that people would compliment me in those ways and I didn't want to hear it. So when I got the letter and she brought out a lot of positive things but yet she didn't -- it wasn't the pat answers that you get from just general people talking to you on the street, you know, acquaintances. You must be so strong. Well, it wasn't that type of thing.

Carole: I've often wondered about the difference because it's not okay to say you're strong but it is okay for you to say something about, well you did this.

Kevin: They were specifics.

Samantha: It was specifics.

Kevin: 'Cause in your -- in your conversation she notices, you know, things about you and in the letter she would say things about the session that were good.

Samantha: Like for instance, they started doing the Messiah about that time and we like to sing. And so we got started in the Messiah. Well that was an out for me. I had a place to go. And she said, the comment was "I'm very impressed that you noticed that you needed to get out. And so you took advantage and you 
did that." Now, so that was a specific thing that she said that complimented me in saying that I was-

Kevin: Just wasn't the big generic cover of all things, you know.

Samantha: Right, it was very specific.... And they rang true and then it really made me feel better.

The team's "noticing of positive things" was particularly significant for the women in the families and proved to be a powerful influence on the women's sense of self since personal and family strengths had gotten buried under the weight of problems.

Jill: I think that was really important.... We know we have skills and we have had accomplishments....Like, to me, it wasn't an empty thing that was said because when you're that--

Peter: She qualified her praise too, you know. It wasn't just, they weren't platitudes and you knew that.

Carole: It fit for you?

Jill: That's right, ya. Ya, 'cause when you're that scattered you really feel like you have, have no coping mechanisms. I was scattered, that's the only way I can use to describe it. It's like you couldn't pull it all together and, uh, I'd be talking and I'd still be feeling kind of low and [the nurse] would say, "Well, I hear what you're saying but you did this and you did that." And I'm going, ya, I've got it, I can do it.

Thus, the recognition and acknowledgement of situation specific strengths drew forth more strength. Further, the explicit noticing of strengths was extremely powerful since this was not usual professional behavior.

Margaret: They gave me some, which I found very uplifting for myself at the time, being at such a low state, uh, they gave us a lot of praise for coming there, and the fact that we cared, and um, what we'd gone through with Jared.

Carole: Your devotion.

Margaret: Yes. Nobody had ever told us we were doing a good job or anything. 
For Margaret, the experience of having a professional who "agrees with me and somebody [who] actually sees it my way" was a profound affirmation. Her sense of being understood was so marked that she commented: "They were actually reading my mind."

The Wake-up Call: Women Have Problems That Matter

Some of the information available to the system served as a "wake-up call" to family members, particularly husbands, that the women were experiencing serious difficulties and needed support. The information challenged the men's belief that the woman could and should manage her difficulties on her own. Professional support for the woman's concerns established them as credible in the eyes of family members, who before had been more dismissive.

Kevin: 'Cause before it was fine, you know. If you [Samantha] get out, you get out. Whereas, they said you need to do this so now I was saying, yeah get out and do this. Why don't you do this and why don't you do that.

Peter: It was an insight to me, because again, I was sort of rolling along. It made me realize, well maybe I should give her a bit more support, you know. Rather than letting it go.... It let us realize how bad it was for Jill, okay. So that we could focus a little more help for her.

Jill: I think that's what did it.

Rob: I think that really, maybe we sat him down but it wasn't effective but I think that when we were able to tell him, "Listen, it came from the University of Calgary group or whatever," ...I guess there's something there that clicked in for him.... They said we were on the right track by trying to get him to be more responsible and he listened.

Scott: I think it made me more aware of some of those issues. And, uh, it's probably kind of a good wake-up call. 
The woman's needs gained importance and the man was able to see a way to be helpful. It is interesting to note that professional attention to the women's concerns legitimized them in the eyes of some of the women as well. This enabled the women themselves to make space for illness problems rather than shoving them aside.

Samantha: One of the other things that they picked up on right away... was that I hadn't cried. And they...gave me an assignment, you know, they sent me home with an assignment rather than just saying, well thank you, we'll see you next week. It was, go home and do this. And they told me to sit down every day for 2 hours and try to cry. And I couldn't, but it helped because for that time period I was able to focus on my grief. I was able to be sad and allow myself to be sad and it was okay to be sad.

As the following excerpts illustrate, by drawing forth previously unacknowledged facets of experience, the team assisted the family to weave a new, more helpful story (White, 1988; White \& Epston, 1990) This new story triggered insights that supported new ways of behaving.

Kevin: Well they helped us to see things like they -- once they said "So this is what you did, so this what you felt like." Yeah [surprise], that's right you know.

Samantha: And "So this is what made you feel better." Oh [again, surprise].

Kevin: Yeah. So -- so now we say, oh we're getting that way, so let's do this, because we're going on an experience that we learn.

Peter: I think what it did more than anything, is it got us thinking about it as a unit again too. You know, so that we could -- 'cause there were a lot of things, like I think we each have our good points and it let us bring it out and discuss it so that we could say "Gee you're right, we're not really mapping the progress, we don't know where we are from the beginning." So let's start.

Further, the new story drew the family together so that the woman was no longer alone with the problem.

Leanne: Well I think with mum's family problems that were getting heaped on 
her, we started helping her out with those as well. I mean there was nothing we could really do about the work problems except to give her support where she needed it. But we started getting a bit more involved with her parents' problems.

Jill: I think what Leanne's saying is that we started supporting each other more.

Thus problem solution became a shared concern.

Kevin: No, it wasn't them telling us what to do. It was -- it was them helping us to realize what we needed to do and then we did it together.

\section{Putting Illness Problems In Their Place}

What each of the families needed to do was to put the problems that arose for the women and themselves, in the context of illness, in their place (White, 1984, 1985, 1986; White \& Epston, 1990). The families were clear that this change was a collaborative endeavor involving family members and nurse. It was the nurse's job to draw forth "lost" knowledge.

Samantha: It wasn't necessarily what they said, they helped us know it. Helped us to be able to come to that conclusion.

Carole: So it wasn't -- it wasn't so much that they told you things as they brought out things that were inside of you, but just weren't showing at that time or?

Samantha: Ya. Things that we knew but kind of checked at the back there -- at the back of the, didn't, I don't know.

Carole: Lost in the depression?

Samantha: (Laughs). Yeah, that's right. So they really did. It was wonderful.

There was a working together to expand vision beyond the narrow problem saturated focus that had brought the women and their families for help to seeing life beyond the problem. The nurse helped the family see previously unimagined possibilities. Where they had seen only failure, change could be now be drawn forth. 
As the women could see change, they were able to shift their beliefs and as they shifted their beliefs they were able to put illness in its place. For example, at the first session Margaret despaired that her grown son Jared would ever take on enough of the illness burden related to his diabetes for her to gain some freedom. She could not see his responsibility. After hearing the team's ideas, she and her husband sat Jared down, explained the necessity of doing more and asked him what he would like to add to what he was already doing. They offered him an opportunity to show responsibility, which he took. Margaret returned to the second session impressed with Jared's willingness and ability to take responsibility. She believed that it was possible for the burden to shift off her shoulders. As Rob stated, Margaret's confidence in herself grew and, in turn, she was able to support Jared's growth in responsibility rather than falling back into old patterns.

Despite reports to the contrary, Jill did not believe that it was possible for anyone to get better from chronic fatigue syndrome within one year. She only saw Maia going down hill. However, once all family members began charting the course of the illness and contributing to a complex vision of progress, she too could see improvement and believed that recovery was possible. As Peter remarked, improvement had probably been there but they had just not been able to see it. With improvement, Jill was able to let go of some of the burden of worry.

Linda believed she was a "bag of nerves," totally overcome by anxiety and panic attacks. However, through careful questioning she was able to see how effective she had actually been in pushing anxiety out of her life. When she could see her own strength 
in relation to the anxiety and panic attacks, she shifted her belief in herself and chose to continue working on her own rather than even hearing the team's suggestions.

Samantha came to the Family Nursing Unit in relation to grief about her son dying. Despite medical evidence to the contrary, she had come to believe that Cody was dying in front of her eyes. At the conclusion of the therapeutic conversations she was able to view her son as healthy and had adopted two new core beliefs. She now believed that her son would live for awhile and she believed there was no natural order to dying parents do not always die before children. This freed her to embrace living in a new way.

Thus, the process involved taking the problem blinders off and working together to actively draw forth strengths, resources and possibilities. Over time, illness burden was eased for these women as all or some of the dimensions of burden diminished. In some cases, illness got better and took with it elements of both responsibility and work. In other cases, illness responsibility and work were shared more equitably with family members. Yet in other cases, particularly the one where the woman herself experienced the chronic condition, there was no sharing of either responsibility or work. However, the dimension of burden that was most profoundly affected by the therapeutic process was that of illness problems. Each of the women were able to take a stand against the illness problems that had overcome them: uncertainty, grief, despair, anxiety, resentment and depression.

For the women in these families, finding a life beyond illness and the problems they experienced in living with illness meant having new views of their situation and thus 
behaving differently. Specifically, it meant not sacrificing their own lives and relationships for illness. They could now focus on "reclaiming their lives" (White \& Epston, 1990) and thus improving their relationships. To Samantha this meant finding everything she could to get out and do "something for me."

Samantha: And [Kevin] pushed me to get out. So I started playing church volleyball, that came up. And we went to Messiah. And I found everything I could to get out and do something for me. It was very hard though. But that's one of the things they suggested. It was also one of the things that I knew that I needed to do. Because Kevin got - he had lots of things for him but I didn't have anything. Except for church on Sunday. And church on Sunday isn't --

Kevin: You're not getting - going to get away. Everybody came with you.

Samantha: No. That's right (laughs). It's no break.

For Linda it meant keeping busy with her kids, for Jill it meant returning to work outside the home and for Margaret it meant thinking about today.

Margaret: I realized what was happening to me was like fear upon fear and I knew I had to let go. And I started to think about what I'm going to do today rather than what is going to happen tomorrow.

Putting illness and illness problems in their place involved gaining a measure of

control. The illness could no longer "run the show."

Jill: I think the fact that she would say, "What percentage are you in control?" Well that's a -- when I went in there I wasn't in control (laughs). But then you'd hear about what degree of control somebody else in the family had and you're going, holy cow, good for you, you know. And we were all sort of different, you know, and then as we would go through the sessions to the end it would be Maia, like who's in control? And she'd go, well I'm in control and you go, we've grown. And that feeling of control is what we, I think what we had lost....

Peter: Analytically we blocked it out. We said, "Okay, this is what we can do." We can do, you know, chart and start controlling the disease, instead of the disease controlling us.... So we started charting it and said, "Ya, we can see progress here." 
The women began to make decisions for themselves rather than for illness.

Linda: And so (sighs) now if I decided to have a piece of cake, I'll have a piece of cake. Whereas before I wouldn't dare touch -- put anything in my mouth of that kind of nature, you know. For fear of cholesterol -- but now I figure, well if I haven't had a piece of cake for three months I guess I could have one piece. It's not going to kill me.

Chronic illness could not be defeated, so it was more a coming to terms or a "living alongside of illness" (Wright \& Nagy, 1993) that was required.

Leanne: Gaining control over it. Not fighting it. 'Cause when you fight something you lose energy, but if you're taking control over something --

Peter: You can use the energy from it.

Putting illness in its place involved a gradual shift in the relationship with illness rather than a severing of connection.

Margaret: There's no way that you can do it cold turkey - you have to work up to it gradually. Then it's easier on both of us.... I don't think we knew that you couldn't do it cold turkey.

Thus, change was a process of small steps over time that reshaped relationships.

As illness and illness problems were put in their place, there was less room for unanswerable questions and more room for the women to consider themselves. For example, Samantha no longer asked "When is Cody going to die?" What is even more startling than the absence of the question that dominated Samantha's thoughts is that she did not notice its passing until questioned by the nurse. Linda worked at not being so hard on herself and tried to "accept things the way they are instead of always wondering when and what's going to happen....When am I going to die?"

Each of the women learned to be more gentle with and respectful of themselves. They were able to make more space for self in the practice of living. 
Margaret: I never used to give myself a chance before. Like I'd just push myself and push myself. I just started to be good to myself a little bit. I used to push myself beyond my limits.

\section{Reflections on "What I Learned From Getting Help"}

The therapeutic process enabled the women to give voice to their internal conversations in a community of caring where strengths and resources were highlighted and distinguished, and problematic beliefs could be challenged and/or modified.

Linda: I just came for a few sessions and um, I cried my eyes out lots. I just spoke about a lot of things and I'll tell you, by the time I ended, I was pretty well over those [panic] attacks.

Scott: Actually when you think about it, I'm not sure...we've had our standard fight since we've seen [the nurse].

Peter summed it up this way:

It was more, like the saying "God helps those who help themselves." I really do feel that, because it was focusing, getting us to focus on working as a family unit. Helping us out....Number one, just the fact that we got together, okay, that and there were certain things that [the nurse] did. Number one, she -- the first session was a little uncomfortable but she got us basically to be comfortable with her there. She was an excellent sounding board and she knew what questions to ask, what focus - you know, so she focused us as a group and basically let us run with it.

All of the families found the therapeutic conversations to be an extremely positive influence in their lives. As Rob stated: "It certainly helped us along the road. Very definitely." The family members were unanimous in their assessment that the member who was most helped was the woman/wife/mother.

Getting out of the pit the women had fallen into brought with it some very important life lessons. In terms of problem solving, the women learned about possibilities. Margaret talked about learning that there are other ways of doing things, 
that is, there are more choices than are apparent. Jill learned that there are always solutions even when she could not see them. This is closely related to a lesson learned about seeking help. As Margaret explained, she learned that problems can be resolved with help that cannot be solved alone. Thus, the women and their families learned about increasing problem solving options.

The women also learned about possibilities for self, that is increasing the options for life enhancing choices when one remembers to consider self.

Carole: If there was something to learn from going to the Family Nursing Unit, what would that have been for you?

Samantha: It helped me realize how important it is to have my -- to have an outlet. To do something for me.

As Linda put it, she learned to be less critical and to give herself credit for doing the best she could rather than being swamped by guilt. There was a choice about what to "see" what was being done or what was not being done. Linda chose to see herself and her efforts in a new light of accomplishment.

There were also new choices to be made about priorities and the important things in life.

Samantha: One of the things that we ended up telling them by the time we were through was the importance of life, the importance of our children. Pictures. We were really, got into taking pictures in the video camera and how precious all of those things are and I -- when I get to that point then I stop and things like, um, my two year old getting into the cat food and dumping it all over the floor. I used to yell and scream and holler and now I go in and go (sighs) and laugh. Say, "Well let's clean this up." And even though I may want to yell and scream and holler, I remember some of the things that we thought of how important this is. And what difference it's going to make in each day of life....

As part of a larger process of living with a chronic condition, the process of 
change did not stop when the therapeutic conversations stopped. It continued as the women took charge of their lives and worked toward a more healthy balance of concern for self and concern for others.

\author{
Stage Four \\ Taking Charge of Ones' Life
}

This final stage is where I encountered these women. My research conversations occurred with them and their families eight months to two years after the therapeutic sessions had ended. What they told me is that they have continued to celebrate the importance of their own lives and that they have continued to experience supportive family relationships in the process. This stage of taking charge of one's life represents the women's efforts at finding a life enhancing balance between self and all other family members, including the member called illness.

\title{
Women's Lives Matter
}

The women's recognition that women's lives, specifically their time, energy and feelings, matter was a long slow process of small steps. Some of the women came farther than others in drawing forth the new sense of self that emerged in the therapeutic context and which they called upon over time. As Jill reflected: "I now believe I have the strength to get through anything." In addition to nurturing a new story, the developmental process included making more room for oneself, looking out for oneself and hanging onto balance.

\section{Nurturing a New Story About a Life That Matters}

Having come, with their families, through the crisis of falling down and falling 
apart and having brought about change, these women felt and described themselves differently.

Carole: Would you say that your own confidence in yourself has shifted?....

Kevin: Nod your head and say "Yes" [to Samantha].

Carole: (laughs) You're very certain about this Kevin.

Kevin: You are [to Samantha].

Samantha: Yes, in a lot of ways.

One of the most noticeable shifts for these women was an increase in self confidence, which included greater clarity about their own perspective and desires. As Rob reported, this enabled Margaret to take a stance that "she means business" and to maintain that stance over time and resistance. Thus the women were more likely to stay connected to their own experiences and to stand behind their own perspectives.

Just as the women reimagined the future after crisis, they reimagined self. They came to appreciate and describe themselves as strong and resilient - able to get through tough things by relying on new resources.

Jill: I think with all the changes with me at work, just this last two weeks I've had to leave my unit and go into a whole new area and um, and learn a whole bunch of things. And even there, not know if I've got a job this next year, or month, or day or anything. But I think my attitude to change has really changed. I am a person that needs -- I've always been a person that needs a lot of security and there is none anymore in any sector -- well working sector anyway, or family or anything. And I guess, I feel inside now that I can adapt. Like it's not easy, it wasn't easy going to a new unit or doing stuff but I feel my attitude is okay.

Clearly the women had an ongoing appreciation for their own strengths. What had been learned in the therapeutic conversations stood the test of both trouble and time.

Jill: We've still had things happen after this. My mother passed away after we 
were in the Family Nursing Unit. There have been some very hard changes going on at work and in our lives but I don't feel as threatened. Like it was very hard to lose my mum but I felt that what we had learned about ourselves from the Family Nursing Unit are still things that I'm using you know. That I, devastated as you can be sometimes, that you will go through the grieving process. It's something that you can go through. That you have the strength to go through it and get through it and not be beaten down by it. And that, I don't know if I would have had that had I not, at that point in our lives, gone to the Family Nursing Unit and rediscovered the strengths that we had, or that I had.

Thus the women's rediscovered sense of their own competence grew with each success in managing difficulty. This new sense of self provided a secure foundation for taking charge of one's life.

\section{Making More Room for Oneself}

All of the women talked about making different choices for self in relationship with illness. They continued to be more considerate of and gentle with themselves and less sacrificing, by containing illness problems. In particular, worry was put in its place (White \& Epston, 1990). These women no longer permitted worry to push them into a corner.

Samantha: I'm a real worrier and so I have -- I learn that I can't sit and worry about things. I just -- I just have to. It's hard because I still worry. But I have to go on.

Carole: And you find you're able to stop that more easily than before?

Samantha: (pauses) I haven't had any more crises.

Carole: It's hard to know eh?

Samantha: It's hard to know. But yeah, even when he gets sick, things come up but I don't fret over it as much.

Linda: I'm just trying to focus on things that I have no control over like -- I cannot worry about things that I don't have control over and I don't have control 
over this. So I'm trying to take that attitude, because why worry myself into the ground over something that might never happen again.

Choosing to worry less was a facet of taking charge of one's life. The women now saw choices where before, none existed. They were more discriminating about the life burden they took to heart by distinguishing between things they could and could not influence. Worrying less meant there was more time and energy for self as well as relationships of choice rather than obligation.

Jill: I was spending all my time worrying. And after my Mum died I realized that all that worry really didn't change anything. So I've decided to try and be a more appropriate worrier (laughs).... But so, with all the changes going on, I've found I still have my sense of humor, I'm relatively calm at home, I'm really proud of myself for being that way. I'm okay at work, for the most part, you know, even with learning and meeting new people. I'm trying to look at the positive more than the negative, which is, when I was really upset and depressed, it was all the negatives I'd see first.

Carole: And does that have any connection to the Family Nursing Unit?

Jill: I believe it does actually, I believe it does. The fact that, if that was innate in me - I have those strengths and I have the ability to control. I can control if I'm going to be negative or positive.

Thus, for Jill, it was a major breakthrough to be able to see the opportunity associated with change rather than being overwhelmed by a sense of chaos. Being able to celebrate change was a remarkable accomplishment.

Illness problems and everyday problems of living remained; however they were not permitted to take over these women's lives.

Linda: And in some ways, I don't know, I'm still as scared as I ever was....Like I said, I still struggle with it, but I -- it doesn't overtake me anymore.

Uncertainty and fear no longer immobilized; rather, they were signals for action.

Carole: And the illness problems for you? Like the uncertainty and the anxiety, 
how about in relation to that? Would you say you're more the boss of those or is there something -- another way to characterize it?

Samantha: Yes, I'm in charge of those because I feel like I'm in charge of whether or not I believe that. When the uncertainty or the fear comes I have to stop and say, no, find out. You don't know for sure.... Instead of sitting and being uncertain, I now go and say, "What do I need to know."

The chronic nature of illness was seldom out of mind for long. As Linda reflected: "I think about it a lot, you know. I think about it all the time actually -everyday." Even during periods of remission, there was the persistent sense that there is always "more to come." However, the women chose to set future possibilities aside, in favor of "taking it one day at a time."

Life was moved beyond "being in constant care" for others. The unanswerable questions about life, death, remission and exacerbation that preoccupied thoughts during the crisis stage were still present and still unanswerable. However, like worry, the women chose to keep them in the background where they were less intrusive. As these women became more comfortable living alongside illness, the urgency for answers diminished.

Jill: And even, at the end point in time, even though we still weren't sure when [the illness] would be gone, it was okay. Do you know what I'm saying? At that point in time, we still didn't know whether she'd have it for 5 years or another month or whatever.

Maia: But we were willing to deal with whatever it was.

Jill: Ya, we were handling, we were in control sort of. Like it wasn't getting the best of us anymore.

These women worked hard to shed illness burden by making thoughtful choices about the power given to illness problems. Most notable was the stand the women took 
against the worry that had washed the color out of life. In this way they made more space for self.

\section{Looking Out for Oneself}

Each of the women were able to be more aware of their limits but also their strengths. They acknowledged the need to look out for themselves since the experience had taught them that this was their job and that limits were easy to cross. The difference now was that they knew what to watch for as signs of trouble.

Samantha: I've caught myself getting back into the [trouble]-- but see the difference is now I know, oh I'm doing this again.

Carole: Ah, doing what again?

Samantha: Locking myself out. Um, I love reading and I have -- I have to be careful because I become addicted to my books. But what happens is that's also my escape. And so I've known specific things about myself. If I'm overly tired, if I'm not eating right, if I'm not getting out of the house enough then I start getting that, "I don't care." I find a book, I go into a corner and read. I stop paying attention to what's going on around me. I yell. I have very specific things and since this, I've -- I don't know if I've had them before, but I know I have since.

Carole: So you're -- you've got your own white flags when those things start adding up.

Samantha: Yeah. I go, "Oh something's wrong here." Then I start thinking, okay, what's causing this.

Awareness of their own limits enabled these women to reset their priorities and to let some responsibilities and work go. However, this was a challenge since other family members often did not pick up the pieces. Thus, burden was lessened through the women's own efforts to let go but the process was complicated by old, nagging expectations about "doing it all." Vigilance against being too hard on oneself for not 
living up to outdated standards was crucial.

Jill: I'm not superwoman and I've -- I guess that acceptance is like, I guess is accepting my own limits. There are things that I can do and things that I can't do.... The emotional well-being of my family and their health and everything is -

Peter: More important than --

Jill: Like I don't care if the laundry isn't done....Like I -- I don't have the energy to do it. And I don't care if it isn't done, you know.

Peter: Well yeah, but you do because you --

Jill: As long as everything else is --

Peter: ragged on me the other night.

Jill: Yeah, but you had it coming.

Peter: You still worry about it.

Leanne: $\mathrm{Mm} \mathrm{hm}$, you do care.

Jill: Well, I do care but I'm not going to do it....I would really love to come home to a really clean house everyday but I'm not going to do it now....

Carole: So you're more gentle with yourself?

Jill: Well in some ways I'm still pretty uh, I think we're all our own worst critics and I think I still have really high expectations but I'm learning that...you have to let some things go. Like you have to...sort out what's important at the moment or at the time and I mean, my priority always will be my family, but the reality is I have to work and I want to do a good job at work so there's only so much I can do.... So I guess part of it is just accepting your limitations and not worrying about it anymore.

Carole: And is that a shift since the Family Nursing Unit would you say?

Jill: Well I think before I felt I had to fix absolutely everything that was going on with everybody, plus do this and plus do that and plus do, you know, like I had to be superwoman. That's what I thought.... And when I wasn't, I was really hard on myself....I felt like I was letting everybody down.

Expectations of self and others needed to be adjusted. 
Linda: My priorities are a little different now.

Carole: In what way?

Linda: Well, I used to clean the house twice a week and now, doesn't bother me anymore. 'Cause what for, you know. When you got kids it doesn't -- like it's neat and tidy but it's lived in and I don't care if I don't get it vacuumed three times a week or whatever. It's just life and I'm not going to drive myself into the ground doing it. Whereas before, it always, you know -- if they spilled or something I'd just scream and yell....

Carole: It strikes me about what you're saying is that in some ways at least you're easier with yourself.

Linda: In some ways, yeah.

Carole: Like the house doesn't have to be perfect.

Linda: No.

Carole: I don't know what else, in other ways you might be easier with yourself.

Linda: Well, if I feel like taking a nap, I take a nap or -- you know, I make the kids do more for themselves now instead of me doing it all, which I never used to do.

The women were able to look on themselves with a more compassionate eye and were able to ask for assistance at times of trouble rather than simply carrying on as they had done before. They were no longer caught by the belief that they needed to do it all, alone.

Samantha: Yeah, but now I know that when I'm going under that I put my white flag up and say, "Help."

Carole: Uh huh. Do you think you might know that earlier this time than last time.

Samantha: Yeah. Oh yeah.

Finding a comfortable balance was tricky; however these women were committed to making sure that their own needs were addressed. 
Samantha: It helped me realize how important it is to have my -- to have an outlet. To do something for me.

Carole: So that was one of the things you learned, was that, for you, you need to have something in addition to --

Samantha: Yeah.

Carole: being a mother and a wife. And is that something that...you carried on? 'Cause we sometimes wonder, well, is there just a problem you sort of -- it gets fixed and then that's the end of that or is there something that carries on over time?

Samantha: I've carried on like that. I have to be careful because there's the syndrome of "I want everything for me." Even go to extremes, but -- I just make sure that I have --

Kevin: No, you're pretty good.

Samantha: There's some days (laughs), but I just make sure that I have something for me -- all the time.

This "something for me" varied from woman to woman; however, the common facet was that it acted as a counterbalance to always doing for others. Margaret spoke eloquently about the world opening up for her when illness burden was lifted. Something for her included exercise, church and friendships.

Each of the five women worked courageously at maintaining the integrity of their new sense of self. They persevered on their own behalf as they had persevered for illness.

Hanging On To Life Enhancing Balance

The process of balancing multiple, competing demands in order to maintain a new equilibrium that consistently accounted for self was difficult. Like the tightrope artist, these women walked a fine line, dynamically responding to complex influences. Despite 
their success at moving in the direction of life enhancing balance, some of the women continued to show a willingness to diminish their own experience, which placed the process in jeopardy. The everyday stress of a woman's life can be daunting. It can literally narrow the focus of life. Once illness was put in its place, the pressure of "everyday" problems remained; however, they were often deemed unworthy of attention. Life was busy and it was easy to slip backwards into an unremitting focus outside the self.

Linda: 'Cause you have to be so tough all the time, you know. Like just with everyday stuff. I don't know, you just -- there's no time to sit and cry. You know what I mean? 'Cause you're busy with everything else....

When compared to the extraordinary stress associated with critical illness, the legitimacy of everyday stress was called into question.

Samantha: I have a lot of stress problems....I've gone in for physicals because I've had focusing problems. You know, things go black to here [showing narrow field with her hands] type of thing. Then I can't focus or I feel like I'm dizzy all the time or standing and talking to somebody else, just start shaking. Nerves. And I think the stress is building up, because I really -- I'm keying to that and so I try and find other things. I'm constantly looking for ways out (laughs) but the difference is now I say, well, I don't have an excuse for it. It was before, I felt like I had an excuse. I had a reason to go and get some help.

While being tough or questioning the legitimacy of one's problems may have enabled the women to carry on in the short run, the loss of connection with self that arose with these approaches had grave risks for new balance in the long run. For these women, it was not easy to keep oneself in the picture.

New balance was especially hard to achieve when the women were influenced by family members' struggle with the changes they needed to make in accepting some of the illness burden. For some, working toward new balance by shifting the burden was a 
slow, uphill climb.

Margaret: Sometimes him being at work, he can't make the calls cause he works in a lab now so he asks me to make the calls. But some of them he'll make himself. And he'll go down to, when he's not well sometimes, you know, I'll just tell him "Well phone the doctor." He's struggling like this, you know.

Carole: So mostly he keeps track and does things himself or asks you. I'm curious about how you got him to start making the phone calls.

Margaret: Ya, well that was a little difficult.

Rob: It wasn't that easy -- it still isn't.

The balancing act remained a work in progress.

Carole: Well some women talk about not being so hard on themselves and some of them talk about just having more time to do things that they personally enjoy and there's so many ways of expressing it. Some women say, well nobody'd ever -- would ever see it. I just feel --

Alison: Yeah, yeah. Sure.

Carole: differently about myself. I've got more confidence or I believe I can get through difficult times, or I believe different things about my marriage or my strength as a wife or a mother. Any of that ring true for you?

Alison: Yeah. All of it I guess. All of it...something I think I'm still working on.

Scott: Work in progress.

\section{Supportive Family Relationships}

The women's efforts on their own behalf were sustained by supportive family relationships. Support was experienced when the burden of illness was eased. Most of the families showed a redistribution of work during the crisis stage of falling down and falling apart that was necessitated by the women's unavailability. Further, a redistribution of responsibility occurred during the stage of therapeutic change in the 
context of nursing interventions when problem solving became a family affair. For some of the families, this redistribution of burden was temporary while for others, it was maintained over the long haul.

Linda: [My husband] has changed quite a bit. Like he just helps out a lot more and stuff. And with the kids and, um, if he thinks I look tired, he makes me rest and, you know. Whereas before it was -- well, I don't know if you're married, but you know how it is.... You're running the house and you're both working and it's just day after day, the same kind of stuff, you know. And you come home from work, you make supper for the kids, you do the dishes.... Whereas now he takes a lot bigger part in it.

The domain in which shifts occurred varied from family to family. For some, it was strictly illness related; while, for others it pertained more generally to family life. Thus, there tended to be an instrumental response among family members to the woman's difficulties that supported a slightly more equitable distribution of responsibility and work. However, in all the families, the woman remained the pivotal person around which the family organized its life and, thus, her overall sense of being the responsible one was not diminished. In this regard, work must be clearly distinguished from responsibility.

Carole: So do you have a sense of the responsibility moving around a little bit?

Peter: No, it's still on Jill....I think it's still -- Jill's still the pivotal point....

Leanne: I think she always will be.

During this stage, the women's concerns were more visible within the family because the women were more revealing of difficulty and family members were more attuned to the women's struggles. A common ground, forged during the therapeutic conversations, existed for day-to-day conversations that invited new reciprocity. 
Maia: Now that you've gone to the counsel[ling] and everything I can really see you worry when you do worry now....

Jill: So you feel more sensitive to my worry?

Maia: Yeah, and you talk about it more....

Jill: Before if I talked about it, you guys had no idea (laughs)....

Leanne: So we'll comment....on what you think. So it's like back -- backing you up.

Although there was some evidence that illness burden was eased through the sharing of work in particular, it was the emotional support of family members, the women's continuing sense of their families being with them, that seemed to be the most powerful influence on the women's wellbeing. "Being with" involved emotional presence in the relationship. Each of the women talked about the importance of her husband's emotional presence in the family as partner and as parent. Emotional support lightened the load of life burden.

Alison: Just lately I think that he's been much more of a full partner in that -in taking -- in caring for the kids and taking on that kind of stuff as to when they were babies.

Scott: I've taken them swimming twice, you know (laughs).

Alison: (laughs) Not -- it's not just physically taking them swimming, it's also, you know, being more concerned about -- it's, yeah, it's not just even just the physical stuff too like taking them to swimming.... It's being more concerned in what's happening with their life 'cause it's very, as you know, emotionally draining just to keep up with everything.

"Being with" also involved attentiveness. Each woman experienced being attended to differently in the sphere of family relationships. One of the lasting commitments that was drawn forth among family members involved communication. 
Jill: 'Cause I...think all of us, like will go for awhile and then all of a sudden you go, I really need to sit down and talk to these guys, you know. And it won't just be me, it'll be, you know, all of a sudden Maia or Leanne or whatever -- or I'll be sitting here and all of sudden it'll start happening, you know, we start talking.

Where earlier, the woman's worth, her contribution of knowledge and experience may have been dismissed, now there was evidence of acknowledgement and appreciation. This was shown in small ways like listening.

Carole: And how is it now? Do you still shrug it [mother's suggestions] off?

Jared: I listen to them more than I used to.

Rob noticed that Jared "really respects his mother;" while, Margaret was delighted to recount that "he just started caring more for me." Thus, the women were attended to with more consideration and respect.

The common purpose or vision that had been drawn forth in the therapeutic conversations clearly continued to unite family members. In this family the focus was on responsibilities.

Carole: How were you able to help each other to....give up some of the responsibility?

Margaret: We kept reminding each other, "You're not supposed to do that." (laughs) And he would tell me too.

Carole: So you watch out for each other.

Margaret: Yes.

In another family the focus was on the woman's need for a life beyond the family, that is, finding satisfying activities outside of the home. Thus, the families continued to work at maintaining the caring community that had been fostered in the therapeutic sessions 
and the women were sustained as they took charge of their lives. The process of managing family life when chronic illness becomes a member continued in a direction of strength, that is, the families remained united and the women experienced more options when making life choices.

\section{Conclusion}

Bateson (1989) reminds us that composing a woman's life involves the art of improvisation, creatively working with the materials at hand. It is like a patchwork quilt, a unity that is drawn forth through discontinuity and change. A woman's life is often not organized around singleminded activity corresponding to unwavering vision. It is organized around responsiveness rather than purpose. Nevertheless, it is a life of achievement. Life is work in progress. This was evident in the lives of these five women who worked hard at making life better for their families and eventually for themselves when faced with the challenge of living with chronic illness. As Bepko and Krestan (1990) note:

Taking small steps to change frees us to experience an enhanced sense of our own power. Being less responsible for others and more focused on ourselves sets us on a course in which we more deeply appreciate the power of choice.... One small experience or many painful ones may start us on the process of change. But the end result is that we experience ourselves at a new level of strength and integration.... Our beliefs change, our feelings change, our behavior changes.... We develop a new appreciation of our own worth (p. 207).

These women succeeded in changing some of the relational beliefs that created overwhelming burden in their lives and in so doing, affirmed "the deep power of our inner need for self definition and balance" (Bepko \& Krestan, 1990, p. 221). 


\section{CHAPTER FOUR}

\section{RECONTEXTUALIZING THE THEORY OF}

\section{WOMEN, FAMILIES, CHRONIC ILLNESS AND NURSING INTERVENTIONS}

Recontextualizing is the real power of qualitative research....In the process of recontextualization, the work of other researchers and established theory plays a critical role. Established theory may provide the context in which a researcher's model links the new findings with established knowledge. Established theory recontextualizes the new findings by providing a context in which to fit the new findings, and thus the discipline advances. Finally, established theory provides a mechanism with which to demonstrate the usefulness and implications of the findings. The goal is to be able to place the results in the context of established knowledge, to identify clearly findings that support established knowledge/theory, and to claim clearly new contributions (Morse, 1994).

The theory of Women, Families, Chronic Illness and Nursing Interventions that

has been drawn forth in the context of this study is related to a vast body of knowledge from several disciplines which include: family nursing, family therapy, feminist theory, psychology, social work and women's studies. I have theoretically sampled the literature from these disciplines and others in order to recontextualize the theory.

This recontextualization is organized by the stages of the theory and by questions that stood out for me during the analytic process. It is followed by a concluding section entitled "Where Do We Go From Here?" that addresses implications for policy, research and practice.

Women, Families, and Chronic Illness: Overwhelming Burden

Corbin and Strauss (1990b) assert that making arrangements is the key to home care (p. 59).

When we speak of the making of arrangements, we are referring to the process by which agreements are reached and maintained between persons for carrying out the tasks associated with home care. Just as the home is the center of care, 
arrangements are the heart that allows that center to function. What kinds of arrangements are necessary? Who makes them? How? Under what conditions? What happens when arrangements are in place, when they are not, or when they break down? To understand these matters, it is best first to conjure up an image of how a family unit ordinarily functions (Corbin \& Strauss, 1990b, p. 61).

Although the utility of this concept is limited by its sole attention to illness work rather than the totality of what I have termed illness burden, it is very valuable in demystifying the family's organization around illness. Arrangements do not just happen. As the authors suggest, in order to better understand the making of arrangements in the "special" context of chronic illness, one must first look at the family in "ordinary" circumstances.

\section{Ordinary Arrangements}

How is the ordinary burden of family life arranged? Despite the women's movement, which has drawn forth a "climate of possibilities never dreamed of by the preceding generation" (Haber, 1992), the ordinary arrangements of family life show a marked inequity between the burden shouldered by women and by men. Faludi (1991) persuasively argues that this climate of possibilities has drawn forth an illusion of equality that has stimulated a backlash against women of unprecedented proportion. Just what is the illusion concealing?

Women have become free to enter the arena of paid employment and have done so in droves (Hare-Mustin, 1992; Holder \& Anderson, 1989). However, this "freedom" has been two-edged, in that women have now become free to work at two full-time jobs (i.e. home work and office work); while their husbands have retained the freedom to work one (Hare-Mustin, 1992; Hochschild, 1989; Vannoy-Hiller \& Philliber, 1989). 
Hochschild's (1989) revealing study of dual-worker families has shown that women have absorbed the tension between work inside and outside the home. They have done this by doing most of the work at home, which amounts to working an extra month of twenty-four hour days per year when compared to their spouses. This is supported by a national longitudinal study that found when both spouses are employed outside the home, the man has two and one-half more leisure hours per day than the woman (Kahn, 1991). It is interesting to note that this figure is based on self-report data and that men have shown the tendency to exaggerate their contribution to household work (Schwartz cited in Hare-Mustin, 1988). Even when a working couple shares the ideology of equality the husband does little of the work in the home (Blumstein \& Schwartz, 1983). For women who engage in paid employment, work in the home has been termed the "second shift" (Hochschild, 1989). Men's reluctance to behave in a more equitable manner may reflect the belief that it is acceptable for a woman to work outside the home as long as it does not interfere with her primary role inside the home.

This inequality that favors men is not peculiar to families where both spouses work outside the home. Hare-Mustin $(1988,1992)$ notes that "in both traditional and modern societies it is the family that is the primary beneficiary and focus of women's labor as well as the source of women's most fundamental identity, that of mother" (p. 8). As Kahn (1991) highlights, marriage is a labor intensive endeavor for women: "regardless of paid employment, marriage increases hours of housework for women and decreases them for men" (p. 79). Among women who work solely in the home, $80 \%$ do more than twenty hours of housework a week (Blumstein \& Schwartz, 1983). Their 
husbands average four hours per week. However, it is difficult to determine the significance of this figures since the study by Blumstein and Schwartz (1983) has several major flaws, for example, the absence of a definition of "housework." Nevertheless, it can be inferred from their discussion that housework is exclusive of childcare and may be exclusive of such frequent tasks as cooking and grocery shopping. If childcare were to be included, the discrepancy between women's work and men's work would be even more marked since childcare also falls in the domain of women's labor (Ferguson, 1991; Wortman, Beirnut, \& Lang, 1991).

For men, work in the home clearly remains more of an option than it is for women (Blumstein \& Schwartz, 1983; Hochschild, 1989; Kahn, 1991). One hypothesis for men's choice to maintain distance from home-work is that "such a shift would entail a loss of status, money, and power" (Walters, Carter, Papp, \& Silverstein, 1988, p. 20). Another is the myth of the idealized family which men hold to more firmly than women (Blumstein \& Schwartz, 1983; Okin, 1989).

Dressel and Clark's (1990) study of family care found that ....a romanticized notion of the family is alive and well.... That is, the family is viewed as an arena of love and concern, such that whatever goes on among family members necessarily manifests care (p. 774).

I was struck by their finding that men construed simply being physically present as care (see also Rubin, 1983). Thus, perhaps to men, being present is equivalent to what women view as family care, for example, cooking a meal. Dressel and Clark (1990) explain this difference as being power based, that is, the more powerful family member whether it be the man in relation to the woman or parents in relation to children may use 
this definition of care. For women, caring is both labor and love; while, for men, caring may not necessarily entwine emotion and action (Finch \& Groves, 1983). Women experience caring as touching both who they are and what they do (Graham, 1983), which draws forth an imperative to act. Based on the inequality of participation in homework, one can conclude that men are relatively free of this imperative to demonstrate caring through action, at least this kind of action. Men have more control of their time and choose to spend it doing more of what they enjoy (Hochschild, 1989). Women feel they have no choice in the matter (Graham, 1983).

Hochschild's (1983) study of women flight attendants and male bill collectors gives us some insight into the emotional work that is involved when love and labor are combined. I believe that Hochschild's description of the emotional work of the flight attendants is also an apt description of women's emotional work in the context of the idealized family. That is, home as a safe haven or as a "benign environment in which one recuperates from work" (Hare-Mustin, 1988).

[Emotional] labor requires one to induce or suppress feeling in order to sustain the outward countenance that produces the proper state of mind in others - in this case, the sense of being cared for in a convivial and safe place. This kind of labor calls for a coordination of mind and feeling, and it sometimes draws on a source of self that we honor as deep and integral to our individuality (Hochschild, 1983, p. 7).

Hochschild (1983) refers to this emotional labor as "the managed heart."

What does this tell us about the arrangement of ordinary family life? I have made the case that the arrangement is characterized by inequality that consistently disadvantages women by constraining their life choices. Regardless of any other considerations such as health status or work outside the home, women shoulder the 
burden of home-work. Research has shown that this arrangement persists despite women's desires for change (Blumstein \& Schwartz, 1983; Hochschild, 1989). Thus, the arrangement can be characterized as imposed rather than negotiated.

Women have come a long way since The Feminine Mystique triggered profound change in our consciousness of women's issues. However, as Friedan (1962) notes twenty years after its first publication, "we have come about as far as we can with a male model of equality....We need a model of equality encompassing female experience, female values that men now begin to share.... We must come to terms with family and with work" (p. x). This is the ordinary context in which extraordinary illness arrangements are made. In terms of the families who participated in this study, there was evidence of underlying inequity in each of the family's ordinary arrangements. The women were carrying more of the burden of ordinary family life than were the men.

\section{Illness Arrangements}

Theorists and researchers note that when a child enters a family, even the most egalitarian arrangements move toward a traditional division of labor with the woman being responsible for home-work, including childcare (Hare-Mustin, 1988, 1992; Hochschild, 1989). I believe that this is true, whether the new member is a child or a chronic illness.

In their overview of family caregiving, Biegel, Sales and Schulz (1991) comment on the difference between "normal care," which I would term an ordinary arrangement, and caregiving in chronic illness.

In fact, caregiving due to chronic illness and disability represents something that, in principle, is not very different from traditional tasks and activities rendered to 
family members. The difference in real terms, however, is that caregiving in this situation represents the increment of extraordinary care that goes beyond the bound of normal or usual care. It is this extraordinary care that can be so burdensome (p. 16).

Thus, chronic illness serves to heighten the tensions between work inside and outside the home as it profoundly affects the extent and complexity of home-work (Corbin \& Strauss, 1988).

As in ordinary arrangements, illness arrangements revolve around women and women's work (Anderson \& Elfert, 1989; Baines, Evans \& Neysmith, 1991a; Biegel et al., 1991; Heller, 1986; Kahn, 1991; McGoldrick, 1989; Sommers \& Shields, 1987; Whyte, 1992). This is not to say that women are the only caregivers; however, the dominant figure is female (Horowitz, 1985). Men tend to become primarily involved with caregiving only in the absence of an available woman caregiver (Horowitz, 1985). Women are expected to care for family members in sickness or in health whether they be partners, children, parents or in-laws and, more often than not, they are expected to do it alone (Heller, 1986). They are also expected to care for themselves.

Chronic illness increases the burden of ordinary family life. As Featherstone (1980) attests from personal experience,

I stress the parallel between disability and relatively ordinary family ills for two reasons. One is to correct the view of those who perceive beleaguered parents and children as saints or heroes, outcasts or freaks. The second is to show families with disabled children that their difficulties differ only in degree from those of other families (p. 12).

What stood out for me is that even ordinary families experience burden; however, illness pushes the weight of burden to an extreme. "The work of the ill and their [families] bespeaks 'travail,' a French noun that has two appropriate meanings: 'work' and 
'suffering'" (Strauss et al., 1984). Among families who have a chronically sick member, it is women who carry a disproportionate amount of the burden and the travail draws forth suffering.

One of the questions that stood out for me in relation to the current study is: "Are the circumstances of these women's lives unusual?" The literature supports an answer of "no" to this question. The five women in this study were doing what women in this society are supposed to do; they were caring for their families in sickness and in health. Following from the work of Hochschild (1989), the women who worked solely in the home were primarily responsible for the second shift of illness arrangements and those who worked outside the home were primarily responsible for both the second shift of ordinary home-work and the third shift of illness work.

\section{The Nature of Women's Work: Devalued and Even Invisible}

I am indebted to Anderson and Elfert (1989) for their observation that "...the term family glosses over the work that women do in caretaking" (p. 735). They have sensitized me to the ways we devalue women's illness burden and even make it invisible. Certainly the idea that women's labor is undervalued is not new (Bepko \& Krestan, 1990; Dressel \& Clark, 1990; Walsh \& Scheinkman, 1989). Goodrich (1991) points out that the gifts and labors a woman provides are discounted "by the very reason of their being expected and considered natural" (p. 7). How do we make sense of the invisibility of women's travail both in the literature and in the lives of the five women who joined this study? I believe that it can be explained by the observations that women's labor is both expected and devalued. Women's contribution to family arrangements is both hard to 
measure and does not directly produce income (Hare-Mustin, 1988) and, as Kahn (1991) points out, we tend to value what we can count. Thus, the value of work is influenced by how much it pays (Holder \& Anderson, 1989).

The linking of "families" and "chronic illness" is a common and accepted occurrence in the health literature (Baird \& Doherty, 1986; Biegel et al., 1991; Cole \& Reiss, 1993; Gilliss, Rose, Hallburg, Martinson, 1989; Gubrium \& Sankar, 1990; Hobbs, Perrin, \& Ireys, 1985; Rolland, 1984, 1987, 1989, 1993; Tapp, 1993; Wright \& Leahey, 1987). Initially this link served to correct the overemphasis on illness as an individually based phenomenon rather than one that is socially drawn forth in the context of family (Kleinman, 1988). However, it seems that we have moved from a distinction to a dichotomy of individual or family which has served to erase the differential impact of illness on family members in favor of a global family impact and response. Thus the family is seen as a unit rather than a system where both family and family members can be considered simultaneously (Wright \& Leahey, 1990).

A very clear example of how language can erase women's unique contribution to illness arrangements is found in the work of Biegel and colleagues (1991). These authors note that most caregivers are women yet throughout their book they refer to "family" caregiving or use the gender neutral term "caregivers," which literally makes women's care invisible and, therefore, devalued. How can we value something that we do not see? In addition, these authors point to the impact of degrees of expectation on recognition of illness work. Their book focuses on caregiving in the context of adult chronic conditions because 
providing care to children who are developing organisms is a normal role expected of parents, but caregiving by spouses of disabled partners and by adult children of parents with disabilities have not traditionally been roles that individuals prepared for or expected to assume (Biegel et al., 1991, p. 8).

Thus, the extra burden women carry when children experience chronic conditions is considered to fall within the domain of "normal" parenting.

Another example can be found in the influential work of Corbin and Strauss $(1988,1990 \mathrm{~b})$. In their study of couples managing chronic illness, these authors included "...at least some healthy spouses who were husbands" (1988, p. 14). There is no discussion of the obvious discrepancy in who is caring for whom. This is their perspective on the issue of unbalanced work loads:

Another potential consequence of illness management in the home is unbalanced work loads, or what some refer to as a lack of equity in the distribution of tasks. Whether the partners' division of labor is based on traditional or more modern forms of task allocation is not the important issue here [italics added]; the issue is the degree of decreased abilities of the ill. When the ill mate can no longer perform his or her share of the work, then somebody has to take up the slack. That somebody is usually the spouse, unless he or she is unable or unwilling to do so. This means that a husband, in addition to holding a regular outside job, may now have to take over the grocery shopping, cooking and other household chores. In addition, a spouse is often called upon to assist the ill partner in the most personal and basic of self-care tasks. For example, a husband may have to get out of bed in the middle of the night to help his arthritic wife onto a bedpan because she is unable to walk to the bathroom (Corbin \& Strauss, 1988, p. 112).

What stood out for me in this passage is the emphasis on men caring for women, and the absence of women caring for men. This is a study in which male caregivers were in the minority. The examples they chose clearly perpetuate the belief that men caring for women is both more important and more onerous than women caring for men. Further, the authors perpetuate the idea that illness arrangements are based on some objective notion of ability. Corbin and Strauss $(1988,1990 \mathrm{~b})$ adhere to an idealized version of 
work allocation in the family based on the premise of inherent equality, a distortion that again serves to mask the discrepancy between women's and men's contributions to both ordinary and extraordinary arrangements.

Generally speaking, who does what work and when, varies according to the type of work to be done, the skill and knowledge level needed for its performance, and the physical and mental ability of people available to carry it out, as well as by daily variations of mood, fatigue level, convenience, and boredom (Corbin \& Strauss, 1988, p. 11).

I have focused extensively on two bodies of work in order to give explicit examples of how illness burden is both erased and devalued in the context of women's lives. The cited works are by no means unique; instead, they represent the literature on families and chronic illness that both reflects and perpetuates the myth of family caregiving. Kahn (1991) notes a

pervasive bias in national statistics and, by extension, in national politics and policy. That bias consists in treating paid employment as if it were synonymous with all forms of productive activity.... The ramifications of this failure to include goods and services generated without pay are discriminatory, primarily against women because they are the major contributors of unpaid societal work (p. 81).

What does this mean in terms of the women and their families who joined the current study? It is little wonder that these women experienced the illness burden they carried as being devalued and invisible. Their families mirror a societal bias that systematically erases the worth of women's labor. In addition, the women may have inadvertently contributed to the invisibility of their work by being so adept and competent that the need became invisible (Bateson, 1989) or by underestimating their work "...because they [took] it for granted as a routine feature of their lives" (Dressel \& Clark, 1990). It is clear that fundamental to any change in family arrangements is the 
recognition by both men and women that women's caring is work (Baines, 1991). As Hochschild (1989) asserts:

The more important cost to women is not that they work the extra month a year; it is that society devalues the work of the home and sees women as inferior because they do devalued work (p. 261).

This can amount to the devaluing of women's lives as seen in the work of Lewis, Beaver, Gossett and Phillips (1976). This widely referenced study of healthy family systems found that among adequately functioning families, the women were strained, worn out and reported being "tense, irritable, fatigued and more-or-less chronically frustrated" (p. 163). The majority of these women were both depressed and obese. In light of this, the central finding of the study was that the "...family is alive and well" (p. 220). "...the data revealed that even with considerable pain and struggle families could and did produce healthy children" (p. 203). These startling findings show that in terms of family health, women's health does not count. Women's suffering was both minimized and normalized as part of "healthy" family functioning.

\section{The Cost of Illness Arrangements}

The most common way of looking at cost is in terms of finances. For example, Hobbs and colleagues (1985) devote an entire chapter on the costs of care to financial implications. While the financial ramifications of caring are of immense significance even in Canada with our program of socialized health services (Evans, 1991), the human cost of caring can be equally devastating.

Although I have made the case that caregivers are predominantly female, clearly men and women both care about and for sick family members. A fine example of the 
depth and complexity of men's caring can be found in Wilson's (1991) grounded theory of men whose wives are receiving chemotherapy. However, there is strong evidence that when male and female caregivers are compared, they experience caregiving differently. Silverman and Huelsman's (1990) research with families engaged in long-term caregiving has led them to conclude that "male caregivers seem less likely to experience burden than females while assuming the role of primary caregiver" (p. 181; see also Pruchno \& Resch, 1989). Horowitz (1985) studied sons and daughters as caregivers to older parents and found that

sons tend to become caregivers only in the absence of an available female sibling; are more likely to rely on the support of their own spouses; provide less overall assistance to their parents, especially "hands-on" services; and tend to have less stressful caregiving experiences independent of their involvement.... [Whereas] daughters provide the full range of services needed by their parents. Many do so concurrent with having career responsibilities as well as primary responsibility for homemaking and childrearing. Furthermore, they are more likely than sons to engage in caregiving without the concrete or emotional support of their spouse. Added to their responsibilities as daughters, they will continue to be called upon as daughters-in-law to provide the assistance needed by their husbands' parents (p. 616).

Thus it can be seen that caregiving for men generally entails less burden; however, if level of illness involvement is equivalent between men and women, caregiving is a less stressful experience for men. This is supported by the research of Manne and Zautra (1990) who found that well husbands of women experiencing rheumatoid arthritis were not significantly distressed by their wives' illness. The work of Parks and Pilisuk (1991) also lends support although their study has numerous methodological limitations. Biegel and colleagues (1991) remind us that understanding differences between men and women on measures of distress is complicated by the fact that women typically score higher than 
men on these measures. Thus, at very least, distress may not be solely attributable to caregiving.

There are several ways to explain the difference between women's and men's experience of caregiving even when the level of involvement is equivalent. The first explanation hinges on emotional support, which is one aspect of social support. Biegel and colleagues (1991) identify social support as an important factor in mediating the stress associated with caregiving. It is my contention that since caregiving is an expected duty for women; while, it is an "unexpected expression of compassion for men" (Sommers \& Shields, 1987, p. 16) it is likely to draw forth different amounts and even kinds of emotional support for the caregivers. It is also possible that men may avail themselves of both formal and informal support more readily than women, since the women themselves may hold expectations of being able to manage (Silverman \& Huelsman, 1990). This was apparent among the sons and daughters in Horowitz' (1985) study where the "women often voiced appreciation that their husbands remained neutral toward the caregiving involvement; in contrast, men expected and depended upon both emotional and concrete support from their wives" (p. 615). Thus, men may seek and receive more affirmation for their caregiving activities than do women and so may experience caregiving as a valued endeavor (Neysmith, 1991).

Another explanation of the difference between women's and men's experience of caregiving relates to boundaries. Men may be able to maintain distance from illness with more ease than is the case for women (see also Kaschak, 1992). Heller (1986) found that women typically take care of others before they care for themselves and this occurs 
even when the woman herself is ill (Green, 1986). This can be contrasted to the men in Wilson's (1991) study where the men took care of themselves as a means of caring for their wives.

It is clear from Aronson's (1991) study of daughters caring for older mothers that, although problematic, setting limits is one way of resolving the tension between competing demands. Biegel and colleagues (1991) suggest that men, unlike the daughters in Aronson's (1991) study, may be able to limit their involvement with caregiving without feeling guilt. There is strong support for the idea that when men are primary caregivers, they limit their involvement (Horowitz, 1985; Manne \& Zautra, 1990). However, I have been unable to find direct empirical support for the idea that men experience less guilt than women. Indirect support can be found in the program of research Wortman and colleagues (1991) have designed to assess how individuals cope with chronic role strain and role conflict. They summarize their findings this way:

Data...suggest that women experience and cope with competing demands between work and family very differently than do their husbands. Women tend to take far more responsibility for household activities and child care, and they experience more role conflict than their husbands. However, this greater investment in the family is not reflected in higher evaluations of their performance. In contrast to their husbands' positive evaluations of their performance as wives and mothers, women judge their performance in the marital and family roles rather harshly and are critical of how things are going at home (p. 99).

Certainly Hochschild (1989) found that by absorbing the tension between work inside and outside the home for their husbands, women experience more role strain and role conflict. So perhaps women's experience of greater stress when they are caregivers reflects the overall burden of family life rather than simply illness burden. That is, even if illness burden is the same for men and women, one cannot overlook the underlying 
inequity in ordinary family life as predisposing women to overload and stress. These findings also suggest that women may inadvertently contribute to their experience of stress by judging their performance based on a deficit view of reality (Benner \& Wrubel, 1989). That is, they "measure" their performance against an ideal of what a "good" mother, wife or caregiver should do and invariably come up short.

In terms of the men and women in the five families who participated in the current study, it is not surprising that the men relied on their wives to carry the lionshare of the illness burden. Nor is it surprising that even the men who were most involved in illness care maintained a "normal" life and experienced relatively little distress.

What has the professional literature said about the costs to women of carrying illness burden? Costs include: inability of the woman to meet her own needs due to absence of time and resources; curtailment of activities outside the home (Horowitz, 1985; Ritchie, Stewart, McGrath, \& Thompson, 1994); impaired health status (Biegel et al., 1991; Sommers \& Shields, 1987); exhaustion; isolation and loneliness (Guberman, 1990; Sommers \& Shields, 1987); and, poverty (Evans, 1991; Guberman, 1990). When the woman engages in the emotional work of "managing her heart" the cost may be estrangement from the "margins of her soul" (Hochschild, 1983). In my estimation these costs add up to what Neysmith (1991) identifies as a dramatically decreased quality of life and perhaps even a decreased quantity of life.

Hochschild (1989) identifies the relationship cost incurred when women are responsible for the second shift, which I believe is also relevant in the context of illness arrangements. 
If there is one truth that emerges from all the others, it is that the most important injury to women who work the double day is not the fact they work too long or get too tired. That is only the obvious and tangible cost. The deeper problem such women face is that they can not afford the luxury of unambivalent love for their husbands (p. 260).

\section{Why Do Women Continue To Care?}

One question that arose for me in the context of the study is: "What kept the women going for so long in the face of such adversity?" The literature provides some insights into the complex influences that both prod and enable women to continue their caring endeavors.

\section{Dominant and Dominating Stories}

White and Epston (1990) draw our attention to the pervasive and oppressive nature of the dominant stories that "...provide the broader sociopolitical context of the person's experience" (p. 19). These stories not only have the power to repress but are also constitutive of persons' lives (White \& Epston, 1990). The dominant stories for women are those myths or idealized images of womanhood that put them on a pedestal (Harris, 1994). Harris (1994) argues:

it seems obvious...that reading the text of one's life from someone else's story does not make for an authentic life. Yet women continue to cling to the images which have both guided and trapped them in the past (Harris, 1994, p. xiii).

Although dominant stories can be useful in providing order and meaning to life (Braverman, 1989b), they both constrain and dictate life choices. Dominant stories shape beliefs and so, draw forth a reality that is held to be true (Braverman, 1989a). In this way they are constitutive of women's lives.

The images of midlife women all revolve around caretaking. These images are 
perpetuated in many story forms: the feminine mystique (Friedan, 1962); the ideology of the competent mother (Anderson \& Elfert, 1989); the ideology of the "normal" family (Ellman \& Taggart, 1993; Lewis et al., 1976); the myth of marriage (Heilbrun, 1988); the mother knot (Wylie, 1989); the myth of motherhood (Braverman, 1989a; Baines, Evans \& Neysmith, 1991b); and, the woman's code of goodness (Bepko \& Krestan, 1990). Idealized women are characterized in many ways: "Selfless Mother, Faithful Wife, Happy Homemaker, Super Mom, and Career Woman - all reflect the wishes, fears or needs of a young child for care, support and nurturance" (Harris, 1994, p. 74). Real, live women live out these all nurturing images by caring for others before they care for themselves (Boss \& Thorne, 1989; Heller, 1986; Horowitz, 1985), by caring for others at the expense of themselves (Bepko \& Krestan, 1990); by protecting loved ones from harm (Goodrich, 1991; Harris, 1994), by working the second (and third) shift (Blumstein \& Schwartz, 1983; Hochschild, 1989; Wortman et al., 1991), and by managing their hearts (Hochschild, 1983).

One of the most significant problems drawn forth by these dominant stories is what Benner and Wrubel (1989) term a "deficit view of reality," which arises when ideal stories or images become the standard against which "reality" is judged. There is always a deficit. As Wylie (1989) asserts, "mothers can only be all good or all bad" (p. 44). Two predictable consequences of the perceived deficit are mother blaming by self and others, and guilt (Anderson \& Elfert, 1989; Braverman, 1989a; McGoldrick, Anderson, \& Walsh, 1989; Wylie, 1989).

The research program of Wortman and colleagues (1991) gives evidence that old 
stories still dominate the lives of non-traditional women.

Anecdotal evidence suggests that women professionals, subject to traditional sexrole socialization, are strongly influenced by standards of home performance set by women who did not work outside the home. They also have not come to expect equity in household responsibility within their own marriages, even though their out-of-home demands equal or exceed those of their husbands (p. 106).

These women were harshly self critical, reporting strong feelings of not being "good enough."

Thus, one plausible explanation for the question of what keeps women caring in circumstances of prolonged adversity is the influence of dominant stories about womanhood and guilt over never measuring up (Biegel et al., 1991). The woman's own sense of guilt can be heightened by significant others, such as husbands (Oliver, 1983) or health care professionals (Anderson \& Elfert, 1989).

Another dominant narrative that influences women's caring is the story of normalization (Anderson, 1981; Green, 1986; Knafl \& Deatrick, 1986; Robinson, 1993b; Wiener, 1975). Researchers (Anderson, 1981; Robinson, 1984, 1993b) note the semantic definition of normalization in "real" life. It is not to be "as normal" but to be "as normal as possible." Thus, as with the dominant stories of womanhood, there is an ideal of normal life that is only approximated in the circumstances of chronic illness. The striving to draw forth and maintain a life that approximates normal as closely as possible may push women to continue their caring efforts over time.

\section{Situational Constraints}

Women have few options but to continue to care. They may experience external pressure from family members such as husbands who threaten to leave if the women do 
not provide care (Guberman, 1990) or from physicians who have the power to remove a child from a woman's custody if the level of care is not deemed satisfactory (Anderson \& Elfert, 1989). Financial considerations often dictate that the woman is the most logical caregiver since she typically has the least earning power (Guberman, 1990). Further, there are few alternatives beyond institutionalized care (Aronson, 1991; Guberman, 1990), which is a particularly difficult choice when the predominant story dictates that mother's/woman's care is best.

\section{Personal Choices}

Aronson (1991) contends "it is important to recognize that [care relationships] are structured in a coercive fashion" (p. 160). This is clearly evident when considering the ideological and material constraints that shape caregiving. However, this is not the whole explanation since women may experience pleasure and fulfilment in the context of caring. As Braverman (1989a) postulates, "perhaps what keeps women tied to the myth is the satisfaction they receive from fulfilling the myth" (p. 238). Further, Dressel and Clark (1990) found that personal need may be the impetus behind some of women's caring behaviors, that is, caring behaviors may be a means of making connections with other family members that meet a woman's unmet needs for closeness or affection.

Bepko and Krestan (1993) offer a perspective of women's lives that is particularly illuminating in terms of the five women who participated in the current study.

Sensing that love and creative energy are the core elements that determine the course of a woman's life, [Bepko and Krestan] wanted to understand the possibilities women have found for shaping their lives and how they create forms that become the external "medium" for their feelings (p. 8).

They studied over three hundred women and found four dominant patterns of being in 
the world that vary on a continuum anchored by energy for relationships at one end and energy for self-expression at the other. Those women whose lives were shaped by a passion for relationship were termed "Lovers." The majority of the women in their study fell within this traditional pattern, as do the five women who joined the current study. While this pattern can be deeply satisfying for some women, for others it entails a sacrifice of choice for conformity as well as an exclusionary focus on others.

I would say that for the women in the current study, this relational form exacted too high a price for too little fulfilment. Bepko and Krestan (1993) note that this pattern is particularly difficult to alter in response to changing needs because "...more than the other forms, one version of it has dominated the cultural narrative" (p. 94; see also Chafetz, 1990). Thus, while a passionate orientation to relationships may be a good fit for a woman, the form may be imprisoning if it is imposed rather than chosen.

It can be seen that the answer to the question of "What keeps women going in the face of adversity?" is complex. It involves both ideological and situational constraints, which make it difficult to do anything else. Further, for the five women in the current study, it involved the enactment of a passion for relationship that was a double edged sword bringing both fulfilment and suffering.

\section{Gender Differences in Illness Burden}

A question that was often on my mind as I interacted with the five families who participated in the current study was "What explains the discrepancy in illness burden between the men and women?" As Peter replied to a similar question that I posed during the research conversations, "Don't say it's because I don't care." Clearly the men cared 
deeply about their families and clearly they were effective primary caregivers when required to do so by the absence or inability of the women. So what explains the inequity?

One way of explaining the inequity is to see the difference as gender based. Hare-Mustin (1987, 1988, 1989, 1991, 1992; \& Marecek, 1990) warns of two biases in considerations of gender difference. Alpha bias represents the tendency to exaggerate differences; while, beta bias represents the tendency to minimize differences. A third possibility, which I term alpha-beta bias, is found in the prevailing gender ideology that sees "men and women as opposites but equal" (Hare-Mustin, 1992). Here, difference is exaggerated while, at the same time, the effect of difference is minimized.

\section{Essentialist Explanations}

Essentialist explanations are founded on the belief in fundamental and inherent differences between the genders. These explanations locate difference in people rather than between people. Thus women are seen to be "...essentially caring, close to nature, and oriented to meet the needs of others whereas men are essentially independent and achieving" (Hare-Mustin, 1992, p. 12). It follows that different experiences are the natural consequences of differences in people. Hare-Mustin $(1987,1988,1992)$ argues persuasively that essentialist or maximalist explanations are clear examples of alpha bias. I am indebted to Hare-Mustin for reminding me that explanations are never neutral. Explanations are manners of human relations (Maturana, 1992). They are answers to questions that satisfy the criteria of the listener and "every listener decides what are the answers to the questions he/she makes" (Maturana, 1992). 
The problem Hare-Mustin $(1987,1992)$ associates with alpha bias and which she finds most compelling is that essentialist explanations reify a false dichotomy between men and women. This dichotomy is also a hierarchy such that masculine versions of being and developing become the idealized standard against which women are measured and are judged deficient. Essentialist explanations serve to maintain the status quo and to locate women's difficulties internally as personal problems. Thus, alpha bias is quickly transposed into alpha-beta bias when essentialist explanations are used to "solve" human problems.

I see another problematic dichotomy hidden within the concerns about essentialist explanations. That is the dichotomy between mind and body, or in this case, the dichotomy between socialization and biology. This is an updated version of the old dichotomy of nature versus nurture which rests on the belief that biology is immutable, whereas socialization can be influenced. Essentialist explanations are equated with biological determinism (Baines et al., 1991b), which is then interpreted to be a more radical exaggeration of difference than is the explanation of difference that is based on socialization. Explanations that view difference as inherent or in persons are assumed to represent a biological perspective that ignores or dismisses the influence of socialization (Baines et al., 1991b; Kerber, 1993). Thus, the biggest problem that is drawn forth when biology and socialization are dichotomized is that any biologically linked explanation carries with it the impossibility of change. When the criteria for an acceptable explanation include the possibility for change, any explanation that alludes to inherent differences between men and women is judged to be inadequate (for example 
Rampage, 1991). I believe that this reasoning underlies the misinterpretation and misappropriation of the scholarly works of Belenky, Clinchy, Goldberger and Tarule (1986), Gilligan (1982), Jordan, Kaplan, Miller, Stiver and Surrey (1991), and Miller (1986).

Based on the work of Maturana $(1978,1983,1984 a, 1984 b, 1988 b, 1992$; \& Varela, 1992) I would argue that the dichotomy between biology and socialization is false. Further, I would argue that the assumption of the immutability of biology is false. Maturana asserts that humans are constantly changing, right down to their cells. This occurs in response to perturbations which arise from within the person and through interaction with the environment. Humans influence each other, again right down to the cellular level, through the process of structural coupling (Maturana \& Varela, 1992). There is reciprocal interaction between biology and socialization, which are both constitutive of persons. Thus, an adequate explanation for difference includes both biology and socialization. Difference is both within and between persons.

I have made the claim that the difference in illness burden carried by the men and women in the current study is not neutral. How do we account for a difference that is inequitable? That is, a difference that systematically privileges men over women. We must move beyond the dichotomies that have obscured the inequity that is present in relationships between men and women (Hare-Mustin, 1992) and consider the concept of power.

When I say we need to move beyond dichotomies I am including dichotomies that value the feminine way of being over the masculine (Gilligan, 1982; Jordan, Kaplan et 
al., 1991; Miller, 1986). Although these scholarly works were intended to correct the absence of women's voices and experience in developmental theory I believe, as do others (Hare-Mustin \& Marecek, 1990; Puka, 1993) that "whenever the 'specialness' of women is saluted...the recognition is bound to be double-edged" (Faludi, 1991). The Problem of Power

Some scholars believe that it is impossible to separate gender and power (Radtke \& Stam, 1994a). This is not surprising when one considers the longstanding and pervasive nature of power differentials in patterns of human relating (Baber \& Allen, 1992; Kerber, 1993). Through the process of structural coupling, sex and power become inextricably intertwined as part of the organization of social systems (Maturana \& Varela, 1992). Thus gender can be seen as a product of power relations between persons of a different sex (Radtke \& Stam, 1994b).

It is beyond the scope of this chapter to include an indepth discussion of the history and development of the concept of power. While not ignoring the fact that power is an "essentially contested concept" (Kitzinger, 1991, p. 114), I believe that it has been established as a credible and useful explanation for the inequities in family life (Goodrich, 1991; Hare-Mustin, 1989, 1992; \& Marecek, 1990; Miller, 1986, 1991). In fact, Goldner (1985) argues that power based inequities between men and women are social fact.

How can power be used to explain rather than summarize inequity (Kitzinger, 1991)? Kitzinger (1991) emphasizes the need to construct theories of power that are useful to feminists. I believe that Maturana's (1992; \& Varela, 1992) concepts of 
organization, structure and structural coupling provide a way of theorizing about how power becomes a "built-in" facet of family such that power differentials are perpetuated in the living of daily life. Power arises in the circumstance of obedience and obedience entails self denial (Maturana, 1992). When structural coupling occurs over time and encompasses obedience, a coupled ontogeny results such that power becomes a structural component of the social system. When a social system is dependent on obedience as a condition of continued existence, power becomes fundamental to that system's organization. Once power becomes a facet of a system's organization, it is perpetuated over time through the continued existence of the system and its governance of structural coupling.

The arrangements of ordinary family life and those drawn forth to meet the demands of chronic illness are gender arrangements which are rooted in power. I have argued that these arrangements simultaneously privilege men as they disadvantage women by constraining life choices.

What does this mean for the five families who participated in the current study? It does not necessarily mean that the husbands consciously subjugated their wives. It does mean that a power differential was a fundamental aspect of the network of conversations and relations that comprised the organization of these families (Maturana, 1988a). It is important to note that when patriarchy becomes part of a family's organization, it often becomes invisible and its influence is often unintended (Baber \& Allen, 1992). However, the invariant nature of this organization does serve to constrain women's lives. Women's choices are limited in order for the family to continue to exist. 
Under these circumstances, a second order change is required for the family to be both together and different. That is, the family must undergo a change of structure such that organization is not conserved; however, a passion for living together remains and a family of a different kind is drawn forth (Mendez et al., 1988; Watzlawick et al., 1974). This explains the perseverance of inequity since second order change occurs in the form of a radical discontinuity that is difficult to achieve (Watzlawick et al., 1974).

Clearly, "how we think about difference... make[s] all the difference" (Ellman \& Taggart, 1993, p. 382). If we can view difference without dichotomizing it and valuing it hierarchically then it can be a place to begin connection (Ellman \& Taggart, 1993). Further, it is time to eliminate the dichotomy exemplified by alpha and beta bias. We must begin to attend to both similarity and difference in order to develop a more complex appreciation of the patterns of caregiving (Baber \& Allen, 1992).

\section{Health Care Relationships}

The women who participated in the current study found that health care professionals often augmented rather than diminished illness burden. Again, this is not surprising since health care professionals are influenced by the same ideologies that influence family members. Like the family, the health care system "...is a microcosm of society. Patriarchy, capitalism, sexism: every disease of society is also found in our medical care system" (Begin, 1990).

From the women's accounts, it seems that health care professionals often operate as if women are received knowers (Belenky et al., 1986). This is a relatively undeveloped way of knowing that hinges on listening to the voice of external authority 
as the dominant means of gaining knowledge. Interactions based on the belief that women as a group are received knowers are inevitably diminishing and destructive of resources.

Women are caught in a paradoxical position in their health care interactions. If they behave in an "appropriately" feminine manner and show deference to health care professionals (Kaschak, 1992) the problematic belief that women are received knowers is supported. However, assertiveness may be judged as "inappropriate" feminine behavior (Kaschak, 1992) and may result in efforts to put women in their "proper place."

Further, health care professionals often interact from a belief in their own privileged access to objective reality (for example Anderson \& Elfert, 1989). This means that women's expertise is easily disregarded and dismissed (Ritchie et al., 1994). Women experience this as being talked down to and ignored (Heller, 1986). Kleinman (1988) argues that health care interactions are inherently problematic due to the different explanatory models or illness narratives that participants bring to the relationship. However, this does not explain the privileging of one narrative over another. Kleinman (1988) believes that this bias is systematically inculcated in medical school. I believe that it is another example of the influence of patriarchal ideology.

Mishler's (1984) study of the dialectics of medical interviews has led him to question the humaneness of medical practice. He has come to see the medical interview as a "...situation of conflict between two ways of constructing meaning" (p. 127) in which the voice of the lifeworld is dominated by the voice of medicine. The oppressive nature of such interactions is summarized this way: 
The physician's effort to control the discourse has the effect of absorbing and dissolving the patient's self-understanding of her problems into a system of purposive-rational action, namely, the framework of technical medicine (Mishler, 1984, p. 126).

Despite widespread recognition of the importance of "family" in circumstances of chronic illness, health care professionals often persist in viewing the family as extraneous to the important work of health care.

Although physicians and other health personnel are perfectly aware that family members are "in the picture" and can be useful or harmful in conjunction with their own professional efforts, nevertheless what happens at home is mostly over the horizon, is partly or completely invisible to them (Strauss et al., 1984, p. 99).

Thus, there is little space for such things as women's need for information. At the same time, health care professionals adhere to the dominant ideology that it is women's job to care for sick family members (Anderson \& Elfert, 1989). This leads to a paradoxical position. Women are held responsible and, at the same time, are unable to prepare for the job of caregiving.

Clearly, women's relationships with health care professionals can be diminishing and destructive. Complicating the matter is the fact that these women are required to interact with multiple helpers and larger systems over time by virtue of their responsibility for chronic illness (Imber-Black, 1988). Imber-Black (1988) asserts that this unique involvement is often "...ignored or otherwise made invisible" (p. 171). Thus, again women's choices are constrained by illness arrangements that dictate their participation in caring.

The special problem of the role medicine plays in oppressing women requires attention. As Sherwin (1992) notes, the literature in the field of biomedical ethics has 
been remarkably silent in this regard.

\section{$\underline{\text { Summary }}$}

It can be seen that the five women's experience of overwhelming illness burden can be explained in terms of the inequity inherent in both ordinary and illness arrangements that is drawn forth in the context of patriarchal societal norms. The women's perseverance in the face of adversity can be characterized as "everyday" heroism, for "courage, determination, and persistence are heroic qualities whether they are used in managing a household or in the halls of Congress" (Polster, 1992, p. 47). However, the personal and relational costs of this everyday heroism are immense.

\section{Women Falling Down and Falling Apart}

The situation of the five women in the current study as they entered the second stage of falling down and falling apart can be characterized as overload (Corbin \& Strauss, 1988). Carter and McGoldrick (1989) conceptualize such nodal points in time as convergences of horizontal and vertical stressors. Vertical stressors include socialized patterns of relating and functioning; while, horizontal stressors include "ordinary" developmental issues as well as the unpredictable stressors of acute and chronic illness. The women's pattern of caring for others before themselves coupled with the ordinary stressors of childbirth, caring for young children, working outside the home, and launching young adult children as well as the unpredictable stressors of chronic illness and extended family illness drew forth vulnerability. The addition of the unpredictable stress of loss tipped the scales and the women fell down. 


\section{Ambiguous Loss}

Boss' (1991) work on ambiguous loss is extremely helpful in clarifying both the nature and the impact of the losses the women in the current study experienced. Boss began her work with families in which a member was missing-in-action and determined that the phenomenon of boundary ambiguity is particularly relevant to how the situation is managed.

Boundary ambiguity, a phenomenon in families resulting from the stress of ambiguous loss, is defined as the family's not knowing who is in and who is out of the system.... If a family cannot clarify who is in and who is out of the family system (as in the case of ambiguous loss and separation), it cannot reorganize....(Boss, 1991, p. 165).

I am suggesting that the women in the current study all experienced an ambiguous loss, that is, a loss characterized by lack of information, lack of clarity and uncertainty (Boss, 1991). For example: Samantha nursed her critically ill son for six months and then "suddenly" he was better; Linda's mother unexpectedly required open heart surgery which triggered Linda's concerns about experiencing another, possibly fatal, heart attack herself; the symptoms of Scott's illness "went away" but Alison still carried Scott's load of ordinary family burden; Jared was grown up and making his own illness decisions but Margaret was still responsible for a large portion of illness burden; and, Jill's daughter Maia was physically present but her spirit was absent. For most of the women there was ambiguity about whether the family member called illness was in or out of their lives; whereas, for Jill there was an ambiguous loss of her daughter and perhaps her work outside the home. Ambiguous loss was certainly evident in the uncertainty and unanswerable questions that dominated the women's thinking. 
It is little wonder that the ambiguous loss coupled with extreme fatigue and depleted resources knocked the women over. Boss (1991) notes that one of the most important factors in reducing ambiguity is congruence among family members' perceptions. However, there is no indication from the families' accounts that other members experienced the loss. For example, the absence of illness was often experienced as a relief rather than a loss. This is one explanation for the lack of family support when the women fell down: other family members, in particular husbands, did not see or understand the ambiguous loss. This discrepancy within the family about the existence of loss would only serve to heighten the ambiguity for the women. As well, conventional expectations about what constitutes loss may have led some of the women to question or discount their own experience, again heightening the ambiguity. For example, the expectation that one should feel relief when illness gets better and goes away would conflict with feelings of distress, which might then be discounted as inappropriate. All of these factors mitigated against resolution of the ambiguity.

Boss (1991) notes that when boundary ambiguity persists over time, cognition is blocked, "...as well as the emotional and behavioral responses that begin the restructuring process" (p. 167). In order for the women to come to a new understanding that would enable change, they were called to engage in reflection.

The moment of reflection before a mirror is always a peculiar moment: it is the moment when we become aware of that part of ourselves which we cannot see in any other way - as when we reveal the blind spot that shows us our own structure; as when we suppress the blindness that it entails, filling the blank space. Reflection is a process of knowing how we know. It is an act of turning back upon ourselves (Maturana \& Varela, 1992, p. 23).

However, my belief is that ambiguity blocks reflection. The women could not bring 
themselves to a reflection and they did not have the family support that would have triggered a reflection. This is one explanation for why falling down escalated into the downward spiral of falling apart. It is also a plausible explanation for what Corbin and Strauss (1988) term the "domino effect" of crumbling illness arrangements. I offer this explanation as an alternative to the mechanistic explanation they propose:

The key element in the downward spiral of loss of control over management consequences is that the consequences keep ricocheting off one another, bouncing back and forth until the relative balance of trajectory management is so upset that it leads to major gaps in the work and to irreversible loss of control over illness or daily life or both (Corbin \& Strauss, 1988, p. 117).

Even if the women could have resolved the ambiguity, additional factors come into play over time that mitigated against reflection. These will be addressed in the next section.

\section{Silencing Inner Conversations}

One question that stood out for me in relation to the stage of women falling down and falling apart was: "What blocks the women from changing their behavior?" I have proposed one answer: the inability to engage in reflection in circumstances of ambiguous loss. However, I believe there are a host of other impedances.

Hare-Mustin (1987) and Miller (1986) assert that the power arrangements in our society result in women's experience of dual socialization. "[Women] are socialized in the dominant male culture, despite being largely excluded from it, as well as in the female subculture" (Hare-Mustin, 1987, p. 23). Part of this socialization involves developing a finely honed sensitivity to the consequences of one's actions. It is my contention that attunement to the perceived consequences of change acts to derail reflection by silencing inner conversations. 
Jack (1991) refers to the "inner tyrant" who is the internalized voice of dominant societal stories; the voice of beliefs. This voice demands adherence to socially prescribed images of womanhood. When a woman has difficulty managing a situation that her inner tyrant tells her is her job and well within the abilities of a competent woman, this generates tension in internal dialogue. The tension is typically resolved in favor of the dominant story, which draws forth a personalized sense of failure, guilt, shame (Aronson, 1991; Bepko \& Krestan, 1990), self blame (Anderson \& Elfert, 1989; Laird, 1993), feelings of selfishness (Bepko \& Krestan, 1990; Gilligan, 1982, 1993; Miller, 1991) and a renewed commitment to try harder (Bepko \& Krestan, 1990). Thus inner conversation is silenced and reflection is derailed. Further, this process compels the woman to engage in more of the same problematic activity: caring for others before herself (Heller, 1986).

\section{Silencing Voice}

It is little wonder that women conceal their concerns when they judge them to be evidence of personal failure (Aronson, 1991). However, again, this is only a partial answer to the question of "What constrains women from sharing their distress?"

Silence may reflect the belief that there are no other options (Aronson, 1991), that indeed, illness work is women's work (Heller, 1986). Silence may also reflect the past experience of being on one's own in difficult times despite requesting assistance (Wortman et al., 1991). This idea is supported by the voices of women in Heller's (1986) study who stated that when they are sick they cannot count on care. Thus, silence may reflect the "withdrawal toward an inner space of one's own...in an effort at simple 
self-preservation" (Heilbrun, 1979). Or silence may reflect longstanding communication difficulties that arise when women ask for understanding and men give advice (Tannen, 1990).

Silence may also reflect the women's continuing efforts to protect their families, this time from conflict. As Hochschild (1986) found, harmony often takes precedence over requests for change, which entails conflict. Jacobs (1991) points out that

a chronic illness is likely to increase the constraints a family already feels about expressing conflict. When there is a serious illness, family members are often afraid to disagree or fight...for fear of triggering a relapse, or [otherwise]... upsetting the patient (p. 249).

The mind/body connection underlying health/illness has been widely popularized (Moyers, 1993) and is empirically supported by the work of Gottman and Katz (1989). These researchers found that ongoing marital discord was predictive of a child's increased susceptibility to illness. Thus, avoiding conflict in the long term context of chronic illness may well be protective.

One final explanation is that the women's silence may have reflected dissociation, which is one consequence of the emotional work entailed in making labor appear easy and enjoyable (Hochschild, 1983). Brown and Gilligan (1992) point out that women have a long history of dissociation, since it typically begins in adolescence where girls show the tendency to "...dismiss their experience and modulate their voices" (p. 217). This is a response to a relational impasse: "...a paradoxical or dizzying sense of having to give up relationship for the sake of "relationships'" (p. 216). Brown and Gilligan (1992) postulate that this is what happens when girls attempt to live up to idealized images of womanhood. Thus women may be well practised in separating themselves 
from their feelings or, alternatively, their "...voice from their feelings and thoughts so that others [will] not know what they [are] experiencing" (p. 217).

It can be seen that many influences contribute to making women's concerns unspeakable, not the least of which is the fact that they are labelled women's problems. Women's silence perpetuates their isolation and the belief that difficulties are signs of personal failure rather than a common dilemma (Aronson, 1991). Therefore, inadvertently, women contribute to the perpetuation of the problem.

\section{Men's Silence}

The five women who participated in the current study experienced the absence of their husbands' emotional support as a profound loss (see also Ritchie et al., 1994). How can we make sense of the men's lack of responsiveness to their wives' plight?

A benevolent explanation can be drawn forth from the work of Dressel and Clark (1990). That is, the men may have construed their physical presence as evidence, which they believe their wives should recognize, of care. However, from the women's perspective, being there but not there would likely be construed as not caring. Rubin (1983) points out that husbands' physical presence and cognitive/emotional absence is a major point of contention among couples.

A more plausible explanation from my point of view is that the men were compelled to stay in the situation by feelings of obligation or duty; while, at the same time, wished to leave. Thus they remained physically present while withdrawing emotionally and cognitively as a means of managing stress. This is supported by the research of Parks and Pilisuk (1991) who found that male caregivers commonly use the 
coping mechanism of withdrawal as a means of dealing with difficulty.

[Withdrawal] represents a way in which the discrepancy between the individual and the situation is addressed by the pretence of "business as usual" to the outside world. This...[is] characterized by a sense of privacy - an unwillingness to let other people know how bad things really are or how the subject feels about the situation, and reluctance to be around people or to talk to anyone about the distressing situation (Parks \& Pilisuk, 1991, p. 505).

In other words, the men's lack of responsiveness to their wives may have reflected the way they manage their own distress. However, this does not address those men who explained their lack of responsiveness as related to their own lack of distress.

Manne and Zautra (1990) found a similar lack of distress among healthy husbands whose wives were experiencing rheumatoid arthritis. These husbands were most affected by their own perceived vulnerability to illness and perceived ability to cope with illness. Thus it seems that the wives' illness triggered concern for self rather than concern for other among the husbands. Translated to the circumstances of the five couples who participated in the current study, perhaps the women's vulnerability triggered the men's concerns for their own well-being which resulted in a protective withdrawal. Safier and Kofron (1993) link silence with perceived vulnerability and suggest that talking about illness [or illness problems] is a way of "spreading the disease."

One of the explanations that family members in the current study gave for their lack of responsiveness to the women's plight was their belief that things would get better, which reflects a piece of what Reiss, Steinglass and Howe (1993) term the "family identity." This is a shared family belief that the family has about itself which includes: "conceptions of its own competence, stature, intactness, and durability" (p. 175). Since these families had managed to get through difficult times before, it is not surprising that 
family identity embraced beliefs in high competence and durability. Perhaps these beliefs lulled family members into a false sense of security. Perhaps the women's distress was dismissed or minimized because they had always managed in the past. Perhaps the family identity failed to take into consideration that the women were pivotal to ongoing family competence and durability. Whatever the explanation, it is clear that at least some family members in the current study did not consider the women's distress to be a serious issue.

The Impact of Men's Silence

Maturana (1992; \& Varela, 1992) defines love as the opening of space for the existence of another beside oneself. When there is love, the circumstances of the life of the other become apparent. I believe that the husbands' silence was a profound loss to their wives because it was experienced as the opposite of love, which is indifference (Maturana, 1984b). The power of love in the context of chronic illness is just beginning to be addressed.

Lewis' (1994) program of research with families in which the mother had been diagnosed with cancer suggests that the relationship between the woman and her partner is the most important factor in how the family manages the experience. When the male partners are able to convey that they feel the pain of the experience in a way that is congruent with the woman's experience, the woman feels better both physically and emotionally. In Maturana's terms, when the male partner makes emotional space for the woman and the illness, the woman experiences this as love and it influences her biology. In contrast, Hough, Lewis and Woods' (1991) study of family response to 
mother's chronic illness draws forth a consistent theme among the poorly adjusted families. The male partners in these families showed consistent lack of emotional support coupled with verbal disparagement of their wives. Unfortunately, the power the men wielded in the lives of their wives and children was glossed over in the conclusion, which stated:

Both the quantitative and qualitative analyses of the data complement each other and support the notion that an emotionally satisfying and secure spousal relationship is tantamount to the family's successful adaptation to a mother's chronic illness (Hough et al., 1991).

I draw the conclusion from the studies cited and the current study that a critical factor in how families manage chronic illness is whether men open or close space for women who are suffering. In the current study, the men closed space for the women by not responding to their pain and the women's suffering increased. I believe that this was a particularly poignant loss since the women could not clarify whether silence meant the absence of love.

When the silence was transformed into conversations of accusations and recriminations there was mutual closing of space, which further isolated family members. As Jill stated: "We were all like islands." I believe that it is this closing of space that leads to the women's crisis since it compels them to question the essential meaning of family.

Gottman's (1994) program of research investigating why marriages fail lends credence to the women's fears that their marriages were falling apart. The research data suggest that

...it is the balance between positive and negative emotional interactions in a 
marriage that determines its well being - whether the good moments of mutual pleasure, passion, humor, support, kindness and generosity outweigh the bad moments of complaint, criticism, anger, disgust, contempt, defensiveness and coldness (Gottman, 1994, p. 44).

The critical overall balance is a five-to-one ratio of positive to negative moments. The families' accounts reflected a different kind of balance - one in which negative moments dominated. Thus, the women's "intuition" was probably correct. The couples were on a slippery downward slope (Gottman, 1994).

\section{Crumbling Resources}

The five women who participated in the current study were resourceful persons. They had managed well over time and under tremendous illness burden. A question that stood out for me was: "What happened to the women's resources?" Antonovsky's (1987) research exploring what keeps people healthy in the face of extremely challenging life events offers some insights relevant to this question. He found that what distinguishes those who manage well and those who do not, is their sense of coherence. This is defined by three elements:

1. comprehensibility, which is the extent that one can make cognitive sense of perturbations;

2. manageability, meaning "...the extent to which one perceives that resources are at one's disposal which are adequate to meet the demands posed by the [perturbations] that bombard one" (p. 17); and,

3. meaningfulness, which has to do with what is valued in life, what one is passionately involved in. This connection provides motivation to meet challenges.

The women's stories show that they were having difficulty with all three elements 
of the sense of coherence. They were having trouble making cognitive sense of their ambiguous loss and their families' lack of support. Thus, comprehensibility was compromised. In terms of manageability, the women's personal resources were clearly inadequate to meet the demands of the situation and expected family resources were not forthcoming. Perhaps most important, meaningfulness was endangered when fundamental beliefs about family were called into question. It can be seen that the women's sense of coherence was shattered during the process of falling down and falling apart.

\section{Transformative Moments}

Bepko and Krestan (1993) refer to transformation as a "...shifting of awareness at the deepest level in our experience of ourselves" (p. 195). Each of the five women came to the realization that they could not bring about change alone and made the decision to seek help. This realization entailed a transformation, that is, the women no longer held themselves solely responsible for fixing the family ills. "The essence of transformational experience is recognition and reconnection, a stab in the heart" ( $\mathrm{p}$. 197). I believe that each woman recognized and reconnected with her essential humanness and in so doing, shrugged off the mantle of idealized womanhood. This was the beginning of the healing process. Making the decision to seek help was a powerful act.

\section{$\underline{\text { Summary }}$}

Women's falling down and falling apart represents a desperate time of silence, isolation, shattered resources and damaged beliefs. It is also a time of reclaimed power 
to make a difference for one's family and for oneself.

Nursing Interventions: Helping Them That Help Themselves

Bell and Wright (1994) assert that the two most important questions we can ask about clinical work with families are: "Have we helped the family?" and "How do we make sense of what helped the family?" From the family's perspective, the answer to the first question is a resounding yes. Therefore, making sense of what helped will be the focus of this section.

\section{The Power of Language}

Sticks and stones can break your bones but words can never hurt you (Children's nursery rhyme).

It must be stressed that help was offered to the five families in the medium of language. As Maturana (1984a) attests,

a word is not something abstract. It is a blow on the head which triggers in you a structural change. Language is not abstract. Language is a concrete, structural dance between two systems or more that are in structural correspondence (p. 30).

In contrast to the children's rhyme, words can heal and words can harm (Hoffman, 1985). The language of strength draws forth strength; while, the language of pathology draws forth pathology (Mendez et al., 1988). Thus words are powerful therapeutic "tools" that convey a tremendous responsibility on the nurse for their ethical use.

\section{The Power of Stories}

White and Epston (1990) believe that

...persons organize and give meaning to their experience through the storying of experience, and that in the performance of these stories they express selected aspects of their lived experience....It follows that these stories are constitutive shaping lives and relationships (p. 12). 
Earlier, I made the case that dominant societal stories have had a marked influence on women's lives and in particular, women's choices (White \& Epston, 1990). Therapeutic conversations can bolster the oppressive power of dominant stories by confirming privileged meanings. Alternatively, space can be opened for new stories that are more reflective of lived experience and less constraining of personal authority (Hare-Mustin \& Marecek, 1990; White \& Epston, 1990). There are as many interpretations of a story as there are readers (White \& Epston, 1990). It is this possibility of multiple interpretations that draws forth therapeutic options for re-storying experience. Once a new story is introduced, its telling requires elaboration and with every performance of the story, persons reauthor their lives (White \& Epston, 1990). Thus, the public telling of one's life is a very powerful identity-making ritual (Laird, 1991). It must be remembered that the therapeutic context is part of the public domain.

There are few models available for the storying of a woman's life (Heilbrun, 1988; Polster, 1992). Laird (1989) contends that "women and their lives have been largely unsung, unstoried, unmythologized. Their accomplishments, if noted at all, are recorded in small and private ways" (p. 437). Heilbrun (1988) argues that this presents a problem for the storying of women's lives: "How are [women] to imagine forms and language they have never heard?" (p. 39). The process is further complicated by women's tendency to dismiss their experience as uninteresting to others (Brown \& Gilligan, 1992). Thus, restorying their lives may be both difficult and healing for women. 


\section{Drawing Forth a Healing Context}

Wright and colleagues (Wright \& Leahey, 1994; Wright \& Simpson, 1991; Wright et al., 1990) believe that it is the responsibility of the nurse to draw forth a context in which change can take place. The families who participated in the current study also emphasized contextual elements as crucial to the therapeutic process. Featherstone (1980) reveals that "in this often relentlessly upbeat culture it takes courage to confess to personal despair" (p. 11). I would add, that in this often relentlessly pathologizing culture, it takes courage for women to disclose problems. Thus, the therapeutic context is indeed critical as it influences what can be known and therefore, what can be changed. Nurses are not change agents (Wright \& Leahey, 1994), that is, nurses cannot specify change since instructive interaction is a biological impossibility (Wright \& Levac, 1992). However, nurses can influence change and one way of doing this is by creating a context that opens space for change.

The Therapeutic Relationship

Bergin and Lambert (1978) summarize their review of the research evaluating therapeutic outcomes this way:

It should come as no surprise that helping people to deal with inner conflicts, to form viable relationships, to become less threatened and defensive, or to engage in more productive behaviors can be greatly facilitated in an interpersonal relationship that is characterized by trust, warmth, acceptance, and human wisdom.... This is not to say that techniques are irrelevant but their power [to influence] change pales when compared with that of personal influence (p. 180).

The literature identifies several key elements of the therapeutic relationship that coincide with those identified by the families. Clearly, in order to be helpful, the nurse must understand the problem. The only way this can occur is to privilege the family's 
story of its experience (Kleinman, 1988; Wright \& Leahey, 1994). Further, each family member's story must be honored since there may be as many stories as there are family members (Maturana, 1992). This is particularly significant to women: many women experience a consistent absence of attention to and respect for their perspectives (HareMustin, 1978).

It must be recognized that the simple request to tell her story may not insure that a woman feels free to voice her perspective. The nurse's therapeutic stance is critical. As Rampage (1991) points out, the nurse must be an empathic audience who receives the story with care and respect. Care is demonstrated in terms of "...a quality of attention, a total commitment to looking and listening" (Bateson, 1989, p. 158). The stance must also be nonblaming (Reiss et al., 1993). Attributing blame only serves to make a situation worse and to block change (Hoffman, 1985). In fact, since women show the tendency to blame themselves for problems, the nurse must actively work to remove any attribution of fault that implicitly accompanies the work of change (Hoffman, 1985). One way to remove attribution of fault has to do with the naming of problems (HareMustin, 1978; McGoldrick, 1989). Too often, problems are named and identified as being inside the woman which implicitly assigns responsibility and blame.

While there must be clear boundaries in a therapeutic relationship (Bird, 1993; Leahey \& Wright, 1987), the nurse should strive for a nonhierarchical stance (Avis, 1991; Hare-Mustin, 1978). This means that a dynamic balance needs to be struck between connectedness and detachment. It is interesting to note that the women who participated in the current study were most concerned that the nurse maintain a measure 
of detachment, that is, the nurse not "take on" the family's problems.

Avis (1991) believes that the essentially hierarchical nature of therapeutic relationships must be recognized in order for the nurse to use power responsibly. Acting with integrity means

...walking the fine line of deliberately reducing hierarchy by demystifying therapy, using self-disclosure, and putting as much information and control as possible in a woman's hands, while at the same time not denying or undermining [one's] own personal authority and competence (p. 184).

Another way of reducing hierarchy is to invite questions from the family (Wright, 1989).

However, it is my contention that these strategies will only be truly effective in the context of reciprocal trust (Thorne \& Robinson, 1988b, 1989).

I have focused on describing a therapeutic relationship between a nurse and a family that opens space for women to both tell their stories and participate freely in the process of change. However, it must be noted that the attributes of this kind of therapeutic relationship were identified by both male and female family members in the context of the current study. Clearly, what is therapeutically helpful for women is also helpful for men. The kind of therapeutic relationship that has been described is characterized by the nurse's stance of "neutrality" (Selvini Palazzoli, Boscolo, Cecchin, \& Prata, 1980). Despite the fact that neutrality is a hotly contested concept (which will be discussed later), I believe that it is useful in drawing attention to the importance of curiosity in the therapeutic endeavor (Cecchin, 1987).

\section{$\underline{\text { Re-storying Women's Lives }}$}

The craft of questions, the craft of stories, the craft of the hands - all these are the making of something, and that something is soul. Anytime we feed soul, it guarantees increase (Estes, 1992, p. 15). 
The re-storying of the women's lives was drawn forth by the nurse through the asking of questions. Estes (1992) considers questions as soul-making and stories as medicine. Indeed, the five families who participated in the current study found the process to be healing. However, it must be recognized that the therapeutic process was not guided by just ordinary questions. As White (1988) notes, increasing attention has been given to the formulation of questions in family work. Questions can be both a means of assessment and a powerful intervention (Loos \& Bell, 1990; Tomm, 1987; White, 1988; Wright \& Leahey, 1994).

A key distinction to draw regarding questions is whether they are linear or circular (Loos \& Bell, 1990; Selvini et al., 1980; Tomm, 1984; Watson, 1992; Wright \& Leahey, 1994). Linear questions are asked for the purpose of gathering information; whereas, circular questions are intended to influence change by drawing forth new information about relationships or differences. Each of the five families that participated in the current study remarked on their new appreciation of differences within the family. It can be surmised that this new awareness was invited by the skillful use of circular questions.

The kind of conversation that was drawn forth through questioning was also not ordinary talk - it was therapeutic. Although ordinary talk, such as that found in self-help groups, may be satisfying, it has been found to do little to reduce illness burden (Biegel et al., 1991).

\section{Drawing Forth Love}

Each woman who participated in the current study was living in emotional conflict 
and despair due to her isolation with illness problems. Thus it was critical that the family join the therapeutic process. The family's presence permitted the drawing forth of love, that is, the opening of space for the woman and her concerns. The family's participation in the therapeutic process also enabled the clinical team to notice and comment on caring behaviors in the family system. In this way, the woman's growing belief that her family did not care about her suffering was challenged. A context was created for change: all family members were united in caring and achieved a better understanding of each other's perspective.

I believe that the women experienced a sense of community within the therapeutic context. As Bepko and Krestan (1990) state:

In community people feel accepted, supported, validated. They know they don't have to wear a false mask of goodness in order to be valued and cared for ( $\mathrm{p}$. 214).

The nurse drew forth the best from family members and this was experienced as healing.

\section{Drawing Forth Resources}

I believe that one way the therapeutic process drew forth healing was by buttressing each woman's sense of coherence (Antonovsky, 1987). The women's accounts give evidence that they were able to make better cognitive sense of the problem. They were no longer in conflict regarding the meaningfulness of family and were finding the illness burden more manageable by the end of the therapeutic sessions. Manageability was clearly influenced by the process of sharing the problem and responsibility for solution of the problem among family members. Being invited to place a boundary around illness and to determine the relative influence of the family on the 
illness and the illness on the family was also extremely helpful according to two families (White \& Epston, 1990). These families were able to gain a measure of control, which they said made the situation more manageable.

Other resources that were drawn forth by the nurse and clinical team were: an orientation toward possibilities rather than deficits (Benner \& Wrubel, 1989); an empathic attitude toward self among the women (Jordan, Surrey \& Kaplan, 1991); a revaluing of the woman's relational orientation and her caring behaviors (Bepko \& Krestan, 1993; Karpel, 1986); hope that the situation would change for the better (Karpel, 1986); and, tolerance for difference (Karpel, 1986). The relational resources that were drawn forth were: respect, repair of emotional and relational damage, a sense that family members were dependable (Karpel, 1986) and a renewed sense of family commitment (Imber-Black, 1986).

In sum, the interventions that were offered throughout the therapeutic process served to bolster each family's hardiness, which in turn enhanced resiliency or "the power of recovery" (McCubbin, 1994). Hardiness is related to the family's: ability to work together; ability to perceive new situations as opportunities for growth; and, sense of being able to control how things go (McCubbin, 1994). Each facet was positively influenced during the therapeutic process.

The families who participated in the current study identified few specific interventions as being helpful. However, all five families distinguished commendations as a critical aspect of the healing process (McElheran \& Harper-Jaques, 1994). Wright and Leahey (1994) draw a useful distinction between commendations and compliments: 
Commendations are observations of patterns of behavior that occur across time (e.g., "Your family members are very loyal to one another") whereas a compliment is usually an observational comment on a one-time event (e.g., "You were very praising of your son today") (p. 106).

What stood out for the families and for myself was that many had never received this kind of acknowledgement before from a health care professional. The families were articulate in describing the essential aspects of an effective commendation. A meaningful commendation offers the family a view of strengths and resources that has been overshadowed by their difficulties. It is sharply focused and clearly specific to the family's situation. One way of enhancing meaningfulness is to use the language of the family (McElheran \& Harper-Jaques, 1994).

Commendations help a family to recognize and re-value its strengths and resources at a time when they are most needed and most difficult to find. Further, commendations help the family to open space for other interventions (Wright \& Leahey, 1994). Families may be more receptive to additional interventions because commendations act to strengthen the nurse-family system by enhancing the therapeutic relationship (McElheran \& Harper-Jaques, 1994). Trust is built and a willingness to consider new options is invited. Commendations are an extremely powerful intervention, particularly for women who carry the lionshare of unrecognized and undervalued illness burden.

\section{Re-thinking What We Do}

Many feminist family therapists have made the compelling argument that the systemic concepts of circularity, neutrality and complementarity are rooted in and perpetuating of patriarchy (Hare-Mustin, 1989; Goldner, 1985; Luepnitz, 1988; Walsh 
\& Scheinkman, 1989; Walters et al., 1988). Based on the assumption of equality among all family members, these concepts obscure the power based inequities so pervasive in family life. When we treat couples as if they are equal partners we participate in maintaining the status quo (Ellman \& Taggart, 1993).

Certainly equal curiosity in every family member's perspective is critical to engagement and to assessment (Cecchin, 1987; Wright \& Leahey, 1994). However, neutrality is not equivalent to curiosity. It also involves "...noninvestment in any particular solution or outcome that the family may choose" (Watson, 1992, p. 384). Cecchin (1987) explains that curiosity coupled with concern for pattern generate respect for the logic of a family system's ways of interacting. He asserts that logic is neither good nor bad. I believe that this reasoning captures the fundamental problem with neutrality. Further, when neutrality is informed by a belief in circular causality then difference is seen as complementarity and inequity is made invisible.

While I wholeheartedly endorse the necessity of informing the therapeutic process by inclusion of feminist theories, I have trouble abandoning neutrality because of the slide I see toward elitist thinking. If we do not trust the family to find the best solutions to its problems then we drift toward reestablishing a hierarchy where we are privileged knowers. Perhaps if we trusted our ability to effectively introduce feminist perspectives as alternate stories within the therapeutic conversation, we could also trust families to consider feminist perspectives in their solutions.

At very least, the concepts of neutrality, circular causality and complementarity need re-definition. Perhaps the term neutrality is so inherently problematic that it should 
be abandoned in favor of the term curiosity. Perhaps the time has come for nurses to be more clearly invested in the direction of change, while still being noninvested in particular solutions.

Hare-Mustin (1992) argues that "what makes therapy oppressive is not so much what is included as what is excluded" (p. 14). Sensitivity to what is excluded means: acknowledging that therapeutic conversations are connected to the discourses of society (Hare-Mustin, 1991); taking into account the background narratives of a woman's life (Rampage, 1991); searching for the stories that are embedded in stories (Laird, 1989); and, accounting for the gendered nature of silence (Laird, 1993). Again, the only way of developing such a sensitivity is to inform systemic models with feminist discourse.

Finally, in attempting to influence second order change toward rebalancing family patterns, we must recognize that shifts in work do not necessarily mean shifts in responsibility (Hare-Mustin, 1988). Neither do they mean shifts in power (Goodrich, 1991). Without this appreciation, it is likely we will offer solutions that are only "more of the same" rather than "news of difference."

Summary

How do we make sense of what helped the family? Constraining beliefs were challenged, resources were drawn forth and alternate stories were made available to the women and their families in a context of therapeutic love. Despite the fact that the therapeutic process was clearly helpful to all family members, it is critical to remember that this research highlights the women's suffering. It is also important to acknowledge that the family members' were unanimous in their belief that the person who was helped 
the most was the woman/wife/mother.

\section{Taking Charge of One's Life}

Change continued, particularly for the women, long after the therapeutic sessions ended. This is a statement about the power of the therapeutic endeavor. Further, it attests to the fact that a second order change had indeed taken place (Maturana \& Varela, 1992; Watzlawick et al., 1974). A family of a new kind had been drawn forth that was not characterized by the emotional suffering of its predecessor (Mendez et al., 1988). The women were able to develop a new way of actualizing their relational passion that was more inclusive of self (Bepko \& Krestan, 1993; Gilligan, 1982) and the theme of balance became more prominent in their stories (Harris, 1994).

Most important, however, is that the power hierarchy in the family had shifted. The women experienced themselves as being more valued and more respected within the family system. Further, they were able to engage in the living of their lives with more personal authority (Rampage, 1991). What clearly made a difference for the five women who participated in the current study was the ongoing love they experienced as space was opened for themselves and their concerns over time (see also Vannoy-Hiller \& Philliber, 1989).

One could ask the question: "Was this enough change?" The answer depends on the yardstick against which change is measured (Chafetz, 1990). According to the families, who measured change against their previous suffering, they were satisfied and the answer was "yes." However, it must be acknowledged that change did not occur through explicit attention to the inequities in these families' lives. Therefore, the radical 
feminist would likely answer "no." Although I agree that a greater shift in power may have occurred if feminist thinking had informed the therapeutic endeavor, I do not believe that this is by any means an assured outcome. Feminists who believe that explicit attention to power in the course of therapeutic conversations means a "better" therapeutic outcome fall into the trap of specifying change through instructive interaction.

Further, measurable changes in work and responsibility seem to be more highly valued than changes in emotional connection and support as evidence of power shifts. To simply explain away the significance of these changes in the emotional domain of family life as making women happier with their circumstances diminishes what women experience as important. At the same time, it is absolutely essential that discrepancies in work and responsibility be addressed in efforts to shift family patterns toward more equitable arrangements.

\section{Where Do We Go From Here?}

The current study has implications for social policy, as well as nursing research and practice. Societal trends show that there are more people, with more chronic health conditions, living longer lives who require the services of more informal caregivers than ever before (Biegel et al., 1991). More and more women are being required to care for a sick relative and the demand for care will only increase as our population ages (Sommers \& Shields, 1987). If the burden of caregiving is not to be born on the backs of women, what changes must be made?

\section{Social Policy}

As long as care for the chronically ill...falls on "the family" (meaning women), unsupported by the rest of society, everyone is at the mercy of luck. With luck 
someone will do it with love rather than resentment. With luck someone will do it without sacrificing their own health, dreams, life (Sommers \& Shields, 1987, p. 181).

There is a marked trend in health policy toward moving health care into the community (British Columbia Royal Commission on Health Care and Costs, 1991; Rachlis \& Kushner, 1989, 1994; Roberts, 1994). Of course, this is likely to save money since community care equals women's care, which is largely unpaid (Anderson \& Elfert, 1989; Finch \& Groves, 1983; Wuest, 1993). However, because of the invisible nature of women's caregiving, the accounting of cost fails to consider the costs to women in terms of money, health and happiness (Wuest, 1993). How can we begin to account for women's work in the health care equation?

Rachlis \& Kushner (1994) propose a radical restructuring of the health care system that revolves around primary care centers which would control most of the health care budget based on capitation and funding "attached" to patients rather than services. Per-patient funding would vary according to the patient's need for care. This model goes a long way toward shifting the focus of care to health from disease/illness. There are clear incentives toward keeping individuals healthy since secondary and tertiary care would be paid for from the primary care budget. Thus, there is incentive for persons with chronic conditions to be kept well. However, I am not convinced that the same care would necessarily be taken of caregivers since Rachlis and Kushner fail to address the issue of women's informal caregiving.

The proposed funding structure provides incentive toward keeping patients out of secondary and tertiary care and is based on the assumption that this will be accomplished 
by keeping patients well rather than by increasing the burden for informal caregivers. As long as funding is attached to individuals there is little incentive to keep caregivers well. If they too become patients they simply bring more money into the system.

I believe that an even more radical restructuring of the health care system is required. That is, funding attached to families rather than individuals. This would mean that all family members would be registered at the same primary care center and would be seen by the same primary care team. Family focused care would permit a more systemic view of health/illness and would enhance the possibility of achieving an equitable balance between formal and informal care. Of course, all these possibilities are predicated on the acknowledgement of women's caregiving as work that has associated costs. In my opinion, it is only when there is incentive to keep all family members healthy in the circumstance of one family member's chronic condition that women's caregiving will figure into the health care equation.

A system that is concerned about insuring the continuation of women's informal caregiving would provide adequate respite and preparation for the job (Heller, 1986; Sommers \& Shields, 1987). This system would also recognize and value women's expertise in caregiving. Thus hierarchical relationships would be avoided in favor of collaborative partnerships (Sherwin, 1992; Strauss \& Corbin, 1988).

The suggested changes are ones that would enable women to continue caregiving with less burden. However, the fundamental problem remains: How do we "...make it morally possible for caregiving to be an option, freely chosen" (Sommers \& Shields, 1987)? Until women's position in society changes, the only way I see of addressing this 
question is to challenge the assumptions that home care is inherently best and that care is best provided by a family member (Dressel \& Clark, 1990; Wuest, 1993).

There is one other issue I believe needs attention, which pertains to women's work outside the home. It would be relatively easy for powerful proponents of "traditional family values" (York, 1992) to construe the costs of illness burden as evidence that women should give up paid employment in order to reduce stress. While this move could be couched in terms of "women's best interests," research shows that women who work outside the home tend to be more healthy, experience more respect from their husbands and enjoy more power within their families (Blumstein \& Schwartz, 1983; Holder \& Anderson, 1989). Further, Barnett \& Marshall's (1991) study of women in helping professions found that the personal rewards experienced from "outside" work buffered them from the negative effects of work overload. Thus policy efforts designed to push women back into the home are clearly not in women's best interests. The answer to work overload in the circumstances of chronic illness is to alleviate illness burden.

\section{Nursing Research}

I concur with Wright and Bell (1994) that "the future of family nursing research is interventions, interventions, interventions." The contribution that the current study makes to family nursing is the use of grounded theory methodology to account for both process and outcome in relation to family systems nursing interventions from the perspective of family members in interaction. This is the first time that such a study has been done. If we are to address the complexity of family system responses to actual or potential health problems and the influence of nursing interventions on those responses, 
I believe more research must be done at the family system level. That is, from a theoretical perspective of family as system, with the unit of data collection being the family system and the unit of analysis being the family system. This requires an approach where transactional level data (Fisher et al., 1985) can be analysed such that interaction and reciprocity among family members is the focus of attention. The current study demonstrates one way of addressing family system level research.

More specifically, I believe that we must begin to account for interventions that influence a more equitable distribution of illness burden within families. Further, we need to design studies that shed light on the reciprocal influence of ethnicity, gender and intervention.

This study has addressed the family's perspective of therapeutic change. Work currently being undertaken by Bell, Wright and Watson (1994) is exploring therapeutic change from the clinician's perspective. Another interesting avenue of research might combine both family and clinician perspectives of therapeutic change in a single project.

\section{Nursing Practice}

Nurses are in a pivotal position to influence both the ordinary arrangements of family life and the extraordinary arrangements drawn forth by the presence of chronic illness. Nurses have the knowledge, skills and opportunity to draw forth health and healing rather than the suffering that is commonly associated with illness burden. However, we must first consider the aspects of our beliefs and practice that indicate we too expect women to carry the brunt of illness burden. What can nurses do to alleviate and prevent women's experience of overwhelming illness burden? 
Clearly, women's illness related suffering is helped in the context of family. We must continue to see women's problems with chronic illness as family problems having family solutions. The stories of the families who participated in the current study offer encouragement to nurses who are striving for nonhierarchical therapeutic relationships where the therapeutic process is made as transparent as possible. The hallmarks of an effective therapeutic relationship, according the these five families, were: undivided attention; non-judgmental behavior and attitude; respect for their beliefs; and, compassion for their concerns. All of the families found the team's orientation to strengths, resources and possibilities to be an extremely important facet of the process. The team's "noticing of positive things" was particularly significant for the women in the families and proved to be a powerful influence on the women's sense of self since personal and family strengths had gotten buried under the weight of problems.

We must continue to be curious about each family member's perspective; while, at the same time, we must be sensitive to inequities that unfairly burden women. Nurses can participate in the crucial work of making women's labor and women's burden visible. The beliefs that underpin patriarchal family arrangements must be explored and challenged so that a context can be created for change. Further, through the offering of commendations, we can be influential in re-valuing illness responsibility and illness work. Although there was some evidence that illness burden was eased through the sharing of work in particular, it was the emotional support of family members, the women's continuing sense of their families being with them, that seemed to be the most powerful influence on the women's wellbeing. "Being with" involved emotional presence 
in the relationship. Each of the women talked about the importance of her husband's emotional presence in the family as partner and as parent. Emotional support lightened the load of life burden. Nurses can play a pivotal role in drawing forth love within the family by assisting family members to open space for both the woman and her experience with chronic illness.

I believe that nurses must offer interventions aimed at increasing women's decision-making options. It is not enough to reduce suffering by diminishing women's isolation, making their burden visible and valuing their labor. Nurses must offer interventions to families that invite balance rather than burden for women.

These implications for nursing practice all address the situation where women are experiencing difficulty with illness burden. What can be said of prevention? I am not convinced that widespread prevention of women's illness burden is possible within the present health care system. If nurses in institutions and in the community were to offer interventions aimed at establishing equitable illness arrangements, e.g. teaching whole families about illness management, this might make a difference to women's illness burden. However, the professional literature indicates that change is likely to be constrained by entrenched patriarchal beliefs. Thus we are back to the importance of creating a context for change, that is, the circumstances in which an equitable illness arrangement can be drawn forth rather than the usual arrangement that burdens women. Until patriarchal societal beliefs change, nurses must be prepared to address constraining beliefs that privilege men over women within each family they encounter. In this way perhaps prevention can be achieved, albeit on a small scale. 
What is clear, is that women who are at risk of falling down can be identified and that early intervention will likely make a difference. In this regard, nurses should be particularly sensitive to ambiguous losses that have the potential to trigger a woman's falling down.

\section{Concluding Remarks}

During the course of this study I have learned more about family relationships in the context of chronic illness than I thought possible. As a researcher I was curious about the patterns that connect the unique experiences of families who share one common piece of ground, that is, chronic illness. My initial focus was narrow, encompassing the therapeutic process initiated at a time of difficulty. Through this study, my question regarding what nurses can do that helps or hinders a family's ability to manage chronic illness has been answered. I have also learned of a broader pattern that connects families who experience difficulty with chronic illness. That is the pattern of overwhelming illness burden experienced by women. I have come to appreciate the heroic efforts of everyday women as they try to protect their families from harm.

As a clinician, I was curious about what I could do that would influence a difference that matters for families struggling with chronic illness. I have learned the value of bringing a feminist perspective to my work with families. I have changed. Never again will I overlook the illness burden that women carry. 


\section{REFERENCES}

Aboitiz, F. (1985). A critique of the modern concept of localization. Journal of Social and Biological Structure, $\underline{8}, 307-312$.

Andersen, T. (1987). The reflecting team: Dialogue and meta-dialogue in clinical work. Family Process, $\underline{26}, 415-428$.

Andersen, T. (1991). The reflecting team: Dialogues and dialogues about the dialogues.

New York: W. W. Norton \& Company.

Anderson, J. M. (1981). The social construction of illness experience: Families with a chronically-ill child. Journal of Advanced Nursing, $\underline{6}, 427-434$.

Anderson, J. M. (1991). Reflexivity in fieldwork: Toward a feminist epistemology. Image: Journal of Nursing Scholarship, 23(2), 115-118.

Anderson, J. M., \& Elfert, H. (1989). Managing chronic illness in the family: Women as caretakers. Journal of Advanced Nursing, 14, 735-743.

Antonovsky, A. (1987). Unraveling the mystery of health: How people manage stress and stay well. San Francisco: Jossey-Bass Publishers.

Aronson, J. (1991). Dutiful daughters and undemanding mothers: Constraining images of giving and receiving care in middle and later life. In C. T. Baines, P. M. Evans, \& S. M. Neysmith (Eds.), Women's caring: Feminist perspectives on social welfare (pp. 138-168). Toronto: McClelland \& Stewart Inc.

Artinian, B. (1986). The research process in grounded theory. In W. C. Chenitz \& J. M. Swanson, From practice to grounded theory (pp. 16-23). Menlo Park, CA: Addison-Wesley Publishing Company. 
Asen, K., Berkowitz, R., Cooklin, A., Leff, J., Loader, P., Piper, R., \& Rein, L. (1991). Family therapy outcome research: A trial for families, therapists and researchers. Family Process, 30, 3-20.

Avis, J. M. (1991). Power politics in therapy with women. In T. J. Goodrich (Ed.), Women and power: Perspectives for family therapy (pp. 183-200). New York: W. W. Norton \& Company.

Baber, K. M., \& Allen, K. R. (1992). Women and families: Feminist reconstructions. New York: The Guilford Press.

Baines, C. T. (1991). The professions and an ethic of care. In C. T. Baines, P. M. Evans, \& S. M. Neysmith (Eds.), Women's caring: Feminist perspectives on social welfare (pp. 36-72). Toronto: McClelland \& Stewart Inc.

Baines, C. T., Evans, P. M., \& Neysmith, S. M. (Eds.). (1991a). Women's caring: Feminist perspectives on social welfare. Toronto: McClelland \& Stewart Inc.

Baines, C. T., Evans, P. M., \& Neysmith, S. M. (1991b). Caring: Its impact on the lives of women. In C. T. Baines, P. M. Evans, \& S. M. Neysmith (Eds.), Women's caring: Feminist perspectives on social welfare (pp. 11-35). Toronto: McClelland \& Stewart Inc.

Baird, M. A., \& Doherty, W. J. (1986). Family resources in coping with serious illness. In M. A. Karpel (Ed.), Family resources: The hidden partner in family therapy (pp. 359-383). New York: Guilford. 
Barnett, R. C., \& Marshall, N. L. (1991). The relationship between women's work and family roles and their subjective well-being and psychological distress. In M. Frankenhaeuser, U. Lundberg \& M. Chesney (Eds.), Women, work, and health: Stress and opportunities (pp. 111-136). New York: Plenum Books.

Bateson, G. (1972). Steps to an ecology of mind. New York: Ballantine Books.

Bateson, M. C. (1989). Composing a life. New York: Penguin Group.

Begin, M. (1990). Redesigning health care for women. In V. Dhruvarajan (Ed.), Women and well-being (pp. 3-13). Montreal: McGill-Queens University Press.

Belenky, M. F., Clinchy, B. M., Goldberger, N. R., \& Tarule, J. M. (1986). Women's ways of knowing: The development of self, voice, and mind. New York: Basic Books.

Bell, J. M. (1994, May). Process and outcome in family intervention research: Methodological challenges. Paper presented at the International Nursing Research Conference, Making a Difference: Meeting the Challenge, Vancouver, B.C.

Bell, J. M., \& Wright, L. M. (1994, May). Helping versus assessing families: The shift to family nursing intervention research. Paper given at the Third International Family Nursing Conference, Montreal, Quebec.

Bell, J. M., Wright, L. M., \& Robinson, C. A. (1994). Families and therapeutic change [Abstract]. Proceedings of the International Nursing Research Conference, Making a Difference: Meeting the Challenge, 19. 
Bell, J. M., Wright, L. M., \& Watson, W. L. (1994, May). Drawing forth a new reality: Developing theory from family systems nursing practice. Paper presented at the Pre-conference Workshop, Critical Pathways to Theory Development in Family Nursing, Third International Family Nursing Conference, Montreal, Quebec.

Benner, P., \& Wrubel, J. (1989). The primacy of caring: Stress and coping in health and illness. Menlo Park, CA: Addison-Wesley Publishing Company.

Bepko, C., \& Krestan, J. (1990). Too good for her own good: Searching for self and intimacy in important relationships. New York: HarperCollins Publishers.

Bepko, C., \& Krestan, J. (1993). Singing at the top of our lungs: Women, love and creativity. New York: HarperCollins Publishers.

Bergin, A. E., \& Lambert, M. J. (1978). The evaluation of therapeutic outcomes. In S. L. Garfield \& A. E. Bergin (Eds.), Handbook of psychotherapy and behavior change: An empirical analysis (2nd ed.) (pp. 139-189). New York: John Wiley \& Sons.

Biegel, D. E., Sales, E., \& Schulz, R. (1991). Family caregiving in chronic illness. Newbury Park: Sage Publications.

Bird, J. (1993). Coming out of the closet: Illuminating the therapeutic relationship. Journal of Feminist Therapy, $\underline{5}(2), 47-64$.

Blumstein, P., \& Schwartz, P. (1983). American couples: Money, work and sex. New York: Pocket Books. 
Boss, P. (1991). Ambiguous loss. In F. Walsh \& M. McGoldrick (Eds.), Living beyond loss: Death in the family (pp. 164-175). New York: W. W. Norton \& Company.

Boss, P., \& Thorne, B. (1989). Family sociology and family therapy: A feminist linkage. In M. McGoldrick, C. M. Anderson, F. Walsh (Eds.), Women in families: A framework for family therapy (pp. 78-96). New York: W. W. Norton \& Company, Inc.

Bowers, B. J. (1988). Grounded theory. In B. Sarter (Ed.), Paths to knowledge: Innovative research methods for nursing (pp. 33-59). National League for Nursing, publication no. 15-2233.

Braverman, L. (1989a). Beyond the myth of motherhood. In M. McGoldrick, C. M. Anderson, \& F. Walsh (Eds.), Women in families: A framework for family therapy (pp. 227-243). New York: W. W. Norton \& Company, Inc.

Braverman, L. (1989b). Mother guilt. The Family Therapy Networker, 13(5), 46-47. Brink, P. J. (1991). Issues of reliability and validity. In J. M. Morse (Ed.), Qualitative nursing research: A contemporary dialogue (pp. 164-186). Newbury Park, CA: Sage Publications.

British Columbia Royal Commission on Health Care and Costs. (1991). Closer to home: The report of the British Columbia royal commission on health care and costs. Province of British Columbia. 
Brown, L. M., \& Gilligan, C. (1992). Meeting at the crossroads: Women's psychology and girls' development. Cambridge, MA: Harvard University Press.

Burman, B., \& Margolin, G. (1992). Analysis of the association between marital relationships and health problems: An interactional perspective. Psychological Bulletin, 112(1), 39-63.

Carter, B., \& McGoldrick, M. (1989). Overview: The changing family life cycle - a framework for family therapy. In B. Carter \& M. McGoldrick (Eds.), The changing family life cycle (2nd ed.) (pp. 3-28). Boston: Allyn and Bacon.

Cecchin, G. (1987). Hypothesizing, circularity, and neutrality revisited: An invitation to curiosity. Family Process, 26, 405-413.

Chafetz, J. S. (1990). Gender equity: An integrated theory of stability and change. Newbury Park: Sage Publications.

Charmaz, K. (1983). The grounded theory method: An explication and interpretation. In R. M. Emerson, Contemporary field research: A collection of readings (pp. 109126). Prospect Heights, Illinois: Waveland Press, Inc.

Charmaz, K. (1990). 'Discovering' chronic illness: Using grounded theory. Social Science and Medicine, $\underline{30}(11), 1161-1172$.

Chenail, R. J. (1992). A case for clinical qualitative research. The Qualitative Report, 1(4), 1, 3-7. 
Chenitz, W. C., \& Swanson, J. M. (1986). Qualitative research using grounded theory. In W. C. Chenitz \& J. M. Swanson, From practice to grounded theory: Qualitative research in nursing (pp. 3-15). Menlo Park, CA: Addison-Wesley Publishing Company.

Cole, R. E., \& Reiss, D. (Eds.). (1993). How do families cope with chronic illness? Hillside, NJ: Lawrence Erlbaum Associates, Publishers.

Corbin, J. M., \& Strauss, A. (1988). Unending work and care: Managing chronic illness at home. San Francisco: Jossey-Bass Publishers.

Corbin, J., \& Strauss, A. (1990a). Grounded theory research: Procedures, canons, and evaluative criteria. Qualitative Sociology, 13(1), 3-21.

Corbin, J., \& Strauss, A. (1990b). Making arrangements: The key to home care. In J. F. Gubrium \& A. Sankar (Eds.), The home care experience: Ethnography and policy (pp. 59-73). Newbury Park: Sage Publications.

Craft, M. J., \& Willadsen, J. A. (1992). Interventions related to family. Nursing Clinics of North America, 27(2), 517-540.

Dressel, P. L., \& Clark, A. (1990). A critical look at family care. Journal of Marriage and the Family, $\underline{52}, 769-782$.

Ellman, B., \& Taggart, M. (1993). Changing gender norms. In F. Walsh (Ed.), Normal family processes (2nd ed.) (pp. 377-404). New York: The Guilford Press. Emerson, R. M. (1983). Contemporary field research: A collection of readings. Prospect Heights, Illinois: Waveland Press, Inc. 
Estes, C. P. (1992). Women who run with the wolves: Myths and stories of the wild woman archetype. New York: Ballantine Books.

Evans, P. M. (1991). The sexual division of poverty: The consequences of gendered caring. In C. T. Baines, P. M. Evans, S. M. Neysmith (Eds.), Women's caring: Feminist perspectives on social welfare (pp. 169-203). Toronto: McClelland \& Stewart Inc.

Faludi, S. (1991). Backlash: The undeclared war against American women. New York: Anchor Books, Doubleday.

Fawcett, J. (1991). Spouses' experiences during pregnancy and the postpartum: A program of research and theory development. In A. L. Whall \& J. Fawcett, Family theory development in nursing: State of the science and art (pp. 109-119). Philadelphia: F. A. Davis Company.

Featherstone, H. (1980). A difference in the family: Life with a disabled child. New York: Basic Books, Inc.

Feetham, S. L. (1984). Family research: Issues and directions for nursing. In H. H. Werley \& J. J. Fitzpatrick (Eds.), Annual review of nursing research: Vol. 2 (pp. 3-25). New York: Springer Publishing Company.

Feetham, S. L. (1990). Conceptual and methodological issues in research of families. In J. M. Bell, W. L. Watson, \& L. M. Wright (Eds.), The cutting edge of family nursing (pp. 35-49). Calgary, Alberta: Family Nursing Unit Publications. 
Feetham, S. L. (1993). Family outcomes: Conceptual and methodological issues. In P. Moritz (Ed.), Patient outcomes research: Examining the effectiveness of nursing practice (pp. 103-111). Bethesda, MD: National Center for Nursing Research, National Institutes of Health, NIH Pub. No. 93-3411.

Ferguson, E. (1991). The child-care crisis: Realities of women's caring. In C. T. Baines, P. M. Evans, \& S. M. Neysmith (Eds.), Women's caring: Feminist perspectives on social welfare (pp. 73-105). Toronto: McClelland \& Stewart Inc. Fetterman, D. M. (1991). A walk through the wilderness: Learning to find your way. In W. B. Shaffir \& R. A. Stebbins (Eds.), Experiencing fieldwork: An inside view of qualitative research (pp. 87-96). Newbury Park, CA: Sage Publications.

Field, P. A., \& Morse, J. M. (1985). Nursing research: The application of qualitative approaches. Rockville, MD: Aspen Publication.

Finch, J., \& Groves, D. (Eds.). (1983). A labour of love: Women, work and caring. London: Routledge \& Kegan Paul.

Fisher, L., Kokes, R. F., Ransom, D. C., Phillips, S. L., \& Rudd, P. (1985). Alternative strategies for creating "relational" family data. Family Process, $\underline{24}, 213$ 224.

Friedan, B. (1962). The feminine mystique. New York: Del Publishing. Gilligan, C. (1982). In a different voice: Psychological theory and women's development. Cambridge, MA: Harvard University Press. 
Gilligan, C. (1993). Reply to critics. In L. K. Kerber (Ed.), An ethic of care: Feminist and interdisciplinary perspectives (pp. 207-214). New York: Routledge. Gilliss, C. L. (1983). The family as a unit of analysis: Strategies for the nurse researcher. Advances in Nursing Science, $\underline{5}(3), 50-59$.

Gilliss, C. L. (1989). Family research in nursing. In C. L. Gilliss, B. L. Highley, B. M. Roberts, \& I. M. Martinson (Eds.), Toward a science of family nursing (pp. 3763). Menlo Park, CA: Addison-Wesley Publishing Company.

Gilliss, C. L. (1990). Foreward. In J. M. Bell, W. L. Watson, \& L. M. Wright (Eds.), The cutting edge of family nursing (pp. iii-v). Calgary, Alberta: Family Nursing Unit Publications.

Gilliss, C. L. (1991). Family nursing research, theory and practice. Image: Journal of Nursing Scholarship, 23(1), 19-22.

Gilliss, C. L., \& Davis, L. L. (1992). Family nursing research: Precepts from paragons and peccadilloes. Journal of Advanced Nursing, 17, 28-33.

Gilliss, C. L., Rose, D., Hallburg, J. C., \& Martinson, I. M. (1989). The family and chronic illness. In C. L. Gilliss, B. L. Highley, B. M. Roberts, \& I. M. Martinson (Eds.), Toward a science of family nursing (pp. 287-299). Menlo Park, CA: Addison-Wesley Publishing Company.

Glaser, B. G. (1965). The constant comparative method of qualitative analysis. Social Problems, $\underline{12}, 436-445$.

Glaser, B. G. (1978). Theoretical sensitivity: Advances in the methodology of grounded theory. Mill Valley, CA: Sociology Press. 
Glaser, B. G. (1992). Basics of grounded theory analysis. Mill Valley, CA: Sociology Press.

Glaser, B. G., \& Strauss, A. L. (1965). Awareness of dying. Chicago: Aldine Publishing Company.

Glaser, B. G., \& Strauss, A. L. (1967). The discovery of grounded theory: Strategies for qualitative research. New York: Aldine Publishing Company.

Glaser, B. G., \& Strauss, A. L. (1970). Discovery of substantive theory: A basic strategy underlying qualitative research. In W. J. Filstead (Ed.), Qualitative methodology: Firsthand involvement with the social world (pp. 288-304). Chicago: Markham Publishing Company.

Goldner, V. (1985). Feminism and family therapy. Family Process, 24, 31-47.

Goodrich, T. J. (1991). Women, power, and family therapy: What's wrong with this picture? In T. J. Goodrich (Ed.), Women and power: Perspectives for family therapy (pp. 3-35). New York: W. W. Norton \& Company.

Gottman, J. (1994). Why marriages fail. The Family Therapy Networker, 18(3), 4148.

Gottman, J. M., \& Katz, L. F. (1989). Effects of marital discord on young children's peer interaction and health. Developmental Psychology, 25(3), 373-381.

Graham, H. (1983). Caring: A labour of love. In J. Finch \& D. Groves (Eds.), $\underline{A}$ labour of love: Women, work and caring (pp. 13-30). London: Routledge \& Kegan Paul. 
Green, C. P. (1986). Changes in responsibility in women's families after the diagnosis of cancer. Health Care for Women International, 7, 221-239.

Guberman, N. (1990). The family, women, and caregiving: Who cares for the caregivers? In V. Dhruvarajan (Ed.), Women and well-being (pp. 67-78). Montreal: McGill-Queens University Press.

Gubrium, J. F., \& Sankar, A. (1990). The home care experience: Ethnography and policy. Newbury Park: Sage Publications.

Haber, S. (1992). Introduction: The thirty-something woman: Companionship, children and career choices. In B. R. Wainrib (Ed.), Gender issues across the life cycle (pp. 69-70). New York: Springer Publishing Company.

Hare-Mustin, R. T. (1978). A feminist approach to family therapy. Family Process, 17, 181-194.

Hare-Mustin, R. T. (1987). The problem of gender in family therapy theory. Family Process, 26, 15-27.

Hare-Mustin, R. T. (1988). Family change and gender differences: Implications for theory and practice. Family Relations, $\underline{37}, 36-41$.

Hare-Mustin, R. T. (1989). The problem of gender in family therapy theory. In M. McGoldrick, C. M. Anderson, F. Walsh (Eds.), Women in families: A framework for family therapy (pp. 61-77). New York: W. W. Norton \& Company, Inc.

Hare-Mustin, R. T. (1991). Sex, lies, and headaches: The problem is power. In T. J. Goodrich (Ed.), Women and power: Perspectives for family therapy (pp. 63-85). New York: W. W. Norton \& Company. 
Hare-Mustin, R. T. (1992). Changing women, changing therapy: Clinical implications of the changing role of women. Journal of Feminist Family Therapy, 4(3/4), 7-18. Hare-Mustin, R. T., \& Marecek, J. (1990). Making a difference: Psychology and the construction of gender. New Haven: Yale University Press.

Harris, M. (1994). Down from the pedestal. New York: Doubleday.

Hayes, V. E. (1993). Nursing science in family care, 1984-1990. In S. L. Feetham, S. B. Meister, J. M. Bell, \& C. L. Gilliss (Eds.), The nursing of families: Theory/research education/practice (pp. 18-29). Newbury Park: Sage Publications. Hazelrigg, M. D., Cooper, H. M., \& Borduin, C. M. (1987). Evaluating the effectiveness of family therapies: An integrative review and analysis. Psychological Bulletin, 101(3), 428-442.

Heilbrun, C. G. (1979). Reinventing womanhood. New York: W. W. Norton \& Company.

Heilbrun, C. G. (1988). Writing a woman's life. New York: Ballantine Books.

Heller, A. F. (1986). Health and home: Women as health guardians. Ottawa: Canadian Advisory Council on the Status of Women.

Hobbs, N., Perrin, J. M., \& Ireys, H. T. (1985). Chronically ill children and their families: Problems, prospects, and proposals from the Vanderbilt study. San Francisco: Jossey-Bass Publishers.

Hochschild, A. R. (1983). The managed heart. Berkeley: University of California Press.

Hochschild, A. (1989). The second shift. New York: Avon Books. 
Hoffman, L. (1985). Beyond power and control: Toward a "second order" family systems therapy. Family Systems Medicine, $\underline{3}(4), 381-396$.

Holder, D. P., \& Anderson, C. M. (1989). Women, work, and the family. In M. McGoldrick, C. M. Anderson, \& F. Walsh (Eds.), Women in families: A framework for family therapy (pp. 357-380). New York: W. W. Norton \& Company.

Horowitz, A. (1985). Sons and daughters as caregivers to older parents: Differences in role performance and consequences. The Gerontologist, $\underline{25}(6), 612-617$.

Hough, E. E., Lewis, F. M., Woods, N. F. (1991). Family response to mother's chronic illness: Case studies of well- and poorly adjusted families. Western Journal of Nursing Research, 13(5), 568-596.

Hutchinson, S. (1986). Grounded theory: The method. In P. L. Munhall \& C. J. Oiler (Eds.), Nursing research: A qualitative perspective (pp. 111-130). Norwalk, CT: Appleton-Century-Crofts.

Imber-Black, E. (1986). Toward a resource model in systemic family therapy. In M. A. Karpel (Ed.), Family resources: The hidden partner in family therapy (pp. 148174). New York: Guilford.

Imber-Black, E. (1988). The family system and the health care system: Making the invisible visible. In F. Walsh \& C. Anderson (Eds.), Chronic disorders and the family (pp. 169-183). New York: The Haworth Press.

Jack, D. C. (1991). Silencing the self: Women and depression. New York: HarperPerennial. 
Jacobs, J. S. (1991). Families with a medically ill member. In F. H. Brown (Ed.), Reweaving the family tapestry: A multigenerational approach to families (pp. 242261). New York: W. W. Norton \& Company.

Jordan, J. V., Kaplan, A. G., Miller, J. B., Stiver, I. P., Surrey, J. L. (1991). Women's growth in connection: Writings from the Stone Center. New York: The Guilford Press.

Jordan, J. V., Surrey, J. L., Kaplan, A. G. (1991). Women and empathy: Implications for psychological development and psychotherapy. In J. V. Jordan, A. G. Kaplan, J. B. Miller, I. P. Stiver, \& J. L. Surrey, Women's growth in connection: Writings from the Stone Center (pp. 27-50). New York: Guilford Press.

Judd, C. M. (1987). Combining process and outcome evaluation. In M. M. Mark \& R. L. Shotland (Eds.), Multiple methods in program evaluation (pp. 23-41). San Francisco: Jossey-Bass.

Kahn, R. L. (1991). Forms of women's work. In M. Frankenhaeuser, U. Lundberg, \& M. Chesney (Eds.), Women, work, and health: Stress and opportunities (pp. 6583). New York: Plenum Press.

Karpel, M. A. (1986). Testing, promoting, and preserving family resources: Beyond pathology and power. In M. A. Karpel (Ed.), Family resources: The hidden partner in family therapy (pp. 175-232). New York: Guilford.

Kaschak, E. (1992). Engendered lives: A new psychology of women's experience. New York: BasicBooks. 
Kerber, L. K. (1993). Some cautionary words for historians. In L. K. Kerber (Ed.), An ethic of care: Feminist and interdisciplinary perspectives (pp. 102-107). New York: Routledge.

Kitzinger, C. (1991). Feminism, psychology and the paradox of power. Feminism \& Psychology, 1(1), 111-129.

Kleinman, A. (1988). The illness narratives: Suffering, healing and the human condition. New York: Basic Books, Inc.

Knafl, K. A., \& Deatrick, J. A. (1986). How families manage chronic conditions: An analysis of the concept of normalization. Research in Nursing and Health, 9 , 215222.

Laird, J. (1989). Women and stories: Restorying women's self-constructions. In M. McGoldrick, C. M. Anderson, F. Walsh (Eds.), Women and families: A framework for family therapy (pp. 427-450). New York: W. W. Norton \& Company, Inc.

Laird, J. (1991). Enactments of power through ritual. In T. J. Goodrich (Ed.), Women and power: Perspectives for family therapy (pp. 123-147). New York: W. W. Norton \& Company.

Laird, J. (1993). Women's secrets - women's silences. In E. Imber-Black, Secrets in families and family therapy (pp. 243-267). New York: W. W. Norton \& Company. Leahey, M., \& Wright, L. M. (1987). Families and chronic illness: Assumptions, assessment, and intervention. In L. M. Wright \& M. Leahey, Families \& chronic illness (pp. 55-76). Springhouse, PA: Springhouse Corporation. 
Lewis, F. (1994, May). Helping families manage a childrearing mother's cancer in her home: Development of a nursing theory. Paper presented at the Pre-conference Workshop Program "Critical Pathways to Theory Development in Family Nursing" at the Third International Family Nursing Conference, Montreal, Quebec.

Lewis, J. M., Beaver, W. R., Gossett, J. T., \& Phillips, V. A. (1976). No single thread: Psychological health in family systems. New York: Brunner/Mazel Publishers.

Lincoln, Y. S., \& Guba, E. G. (1985). Naturalistic inquiry. Newbury Park, CA: Sage Publications.

Loos, F., \& Bell, J. M. (1990). Circular questions: A family interviewing strategy. Dimensions of Critical Care Nursing, 9 (1), 46-53.

Lowenberg, J. S. (1993). Interpretive research methodology: Broadening the dialogue. Advances in Nursing Science, 16(2), 57-69.

Luepnitz, D. A. (1988). The family interpreted: Feminist theory in clinical practice. New York: Basic Books, Inc., Publishers.

Manne, S. L., \& Zautra, A. J. (1990). Couples coping with chronic illness: Women with rheumatoid arthritis and their healthy husbands. Journal of Behavioral Medicine, $13(4), 327-342$.

Marshall, C. (1990). Goodness criteria: Are they objective or judgment calls? In E. G. Guba (Ed.), The paradigm dialog (pp. 188-197). Newbury Park, CA: Sage Publications. 
Maturana, H. R. (1978). Biology of language: The epistemology of reality. In G. Millar \& E. Lenneberg (Eds.), Psychology and biology of language and thought (pp. 27-63). New York: Academic Press.

Maturana, H. R. (1983). What is it to see? Archives of Biological Medicine, 16, 255269.

Maturana, H. R. (1984a). The bringing forth of reality. Unpublished transcription of a presentation at the conference "The Construction of Therapeutic Realities," Calgary, Alberta, Canada.

Maturana, H. R. (1984b). Maturana elaborates on his theory of the nervous system and responds to questions. Unpublished transcription of a presentation at the conference "The Construction of Therapeutic Realities," Calgary, Alberta, Canada.

Maturana, H. R. (1988a). Telephone conversation with Humberto Maturana and N651 class: The Calgary/Chile coupling. Unpublished transcription of conversation, Calgary, Alberta, Canada.

Maturana, H. R. (1988b). Reality: the search for objectivity or the quest for a compelling argument. The Irish Journal of Psychology, $\underline{9}(1), 25-83$.

Maturana, H. R. (1992). Knowledge, human understanding and the origin of human culture. A conference presented by H.R. Maturana, Calgary, Alberta, Canada. 
Maturana, H. R., \& Varela, F. J. (1992). The tree of knowledge: The biological roots of human understanding (rev. ed.). Boston: Shambhala.

May, K. A. (1991). Interview techniques in qualitative research: Concerns and challenges. In J. M. Morse (Ed.), Qualitative nursing research: A contemporary dialogue (rev. ed.) (pp. 188-201). Newbury Park, CA: Sage Publications.

May, K. A. (1994). Abstract knowing: The case for magic in method. In J. M. Morse (Ed.), Critical issues in qualitative research methods (pp. 10-21). Thousand Oaks, CA: Sage Publications.

McCubbin, M. (1994, May). Tracking resiliency in families: One nurse's journey. Paper presented at the Pre-conference Workshop "Critical Pathways to Theory Development in Family Nursing" at the Third International Family Nursing Conference, Montreal, Quebec.

McElheran, N. G., \& Harper-Jaques, S. R. (1994). Commendations: A resource intervention for clinical practice. Clinical Nurse Specialist, $\underline{8}(1), 7-10$.

McGoldrick, M. (1989). Women and the family life cycle. In B. Carter \& M. McGoldrick (Eds.), The changing family life cycle: A framework for family therapy (pp. 29-68). Boston: Allyn and Bacon.

McGoldrick, M., Anderson, C. M., \& Walsh, F. (1989). Women in families and family therapy. In M. McGoldrick, C. M. Anderson, F. Walsh (Eds.), Women in families: A framework for family therapy (pp. 3-15). New York: W. W. Norton \& Company, Inc. 
Mendez, C. L., Coddou, F., \& Maturana, H. R. (1988). The bringing forth of pathology. The Irish Journal of Psychology, 9(1), 133-172.

Mercer, R. T., Ferketich, S. L., DeJoseph, J., May, K. A., \& Sollid, D. (1991). Effect of stress on family functioning during pregnancy. In A. L. Whall \& J. Fawcett, Family theory development in nursing: State of the science and art (pp. 121-138). Philadelphia: F. A. Davis Company.

Miller, J. B. (1986). Toward a new psychology of women (2nd ed.). Boston: Beacon Press.

Miller, J. B. (1991). Women and power: Reflections ten years later. In T. J. Goodrich (Ed.), Women and power: Perspectives for family therapy (pp. 36-47). New York: W. W. Norton \& Company.

Mishler, E. G. (1984). The discourse of medicine: Dialectics of medical interviews. Norwood, NJ: Ablex Publishing Corporation.

Mishler, E. G. (1986). Research interviewing: Context and narrative. Cambridge, MA: Harvard University Press.

Morse, J. M. (1991). Qualitative nursing research: A free-for-all? In J. M. Morse (Ed.), Qualitative nursing research: A contemporary dialogue (rev. ed.) (pp. 14-22). Newbury Park, CA: Sage Publications.

Morse, J. M. (Ed.). (1992). Qualitative health research. Newbury Park, CA: Sage Publications.

Morse, J. M. (1993). Editorial: The perfect manuscript. Qualitative Health Research, 3(1), 3-5. 
Morse, J. M. (1994). "Emerging from the data": The cognitive processes of analysis in qualitative inquiry. In J. M. Morse (Ed.), Critical issues in qualitative research methods, (pp. 23-43). Thousand Oaks, CA: Sage Publications.

Morse, J. M., \& Johnson, J. L. (Eds.). (1991). The illness experience: Dimensions of suffering. Newbury Park, CA: Sage Publications.

Moyers, B. (1993). Healing and the mind. New York: Doubleday.

Neysmith, S. M. (1991). From community care to a social model of care. In C. T. Baines, P. M. Evans, \& S. M. Neysmith (Eds.), Women's Caring: Feminist perspectives on social welfare (pp. 272-299). Toronto: McClelland \& Stewart Inc.

Norris, J. (1991). Mothers' involvement in their adolescent daughters' abortions. In J. M. Morse \& J. L. Johnson (Eds.), The illness experience: Dimensions of suffering (pp. 201-236). Newbury Park, CA: Sage Publications.

Okin, S. M. (1989). Justice, gender, and the family. New York: Basic Books.

Oliver, J. (1983). The caring wife. In J. Finch \& D. Groves (Eds.), A labour of love: Women, work and caring (pp. 72-88). London: Routledge \& Kegan Paul.

Opie, A. (1992). Qualitative research, appropriation of the 'other' and empowerment. Feminist Review, 40, 52-69.

Parks, S H., \& Pilisuk, M. (1991). Caregiver burden: Gender and the psychological costs of caregiving. American Journal of Orthopsychiatry, 61(4), 501-509.

Polster, M. F. (1992). Eve's daughters: The forbidden heroism of women. San Francisco: Jossey-Bass Publishers. 
Pruchno, R. A., \& Resch, N. L. (1989). Husbands and wives as caregivers: Antecedents of depression and burden. The Gerontologist, 29(2), 150-155.

Puka, B. (1993). The liberation of caring: A different voice for Gilligan's "different voice." In M. J. Larrabee (Ed.), An ethic of care: Feminist and interdisciplinary perspectives (pp. 215-239). New York: Routledge.

Rachlis, M., \& Kushner, C. (1989). Second opinion: What's wrong with Canada's health-care system and how to fix it. Toronto: Collins.

Rachlis, M., \& Kushner, C. (1994). Strong medicine: How to save Canada's health care system. Toronto: HarperCollins Publishers Ltd.

Radtke, H. L., \& Stam, H. J. (Eds.). (1994a). Power/gender: Social relations in theory and practice. Thousand Oaks, CA: Sage Publications.

Radtke, H. L., \& Stam, H. J. (1994b). Introduction. In H. L. Radtke \& H. J. Stam (Eds.), Power/gender: Social relations in theory and practice (pp. 1-14). Thousand Oaks, CA: Sage Publications.

Rampage, C. (1991). Personal authority and women's self-stories. In T. J. Goodrich (Ed.), Women and power: Perspectives for family therapy (pp. 109-122). New York: W. W. Norton \& Company.

Reiss, D., Steinglass, P., \& Howe, G. (1993). The family's organization around illness. In R. E. Cole \& D. Reiss (Eds.), How do families cope with chronic illness? (pp. 173-213). Hillsdale, NJ: Lawrence Erlbaum Associates, Publishers. 
Ritchie, J. A., Stewart, M. J., McGrath, P. J., \& Thompson, D. (1994, May). Support and burden in mothers of children with chronic conditions: Spina bifida, cystic fibrosis, diabetes. Paper presented at the International Nursing Research Conference, Vancouver, BC.

Roberts, D. (1994, July 21). A radical prescription for health-care reform. The Globe and Mail, pp. A1, A5.

Robinson, C. A. (1984). When hospitalization becomes an "everyday thing." Issues in Comprehensive Pediatric Nursing, 7(4), 363-370.

Robinson, C. A. (1993a). Grounded theory: Glaser \& Strauss or Glaser vs Strauss? Unpublished manuscript.

Robinson, C. A. (1993b). Managing life with a chronic condition: The story of normalization. Qualitative Health Research, $\underline{3}(1), 6-28$.

Robinson, C. A., Wright, L. M., \& Watson, W. L. (1994). A nontraditional approach to family violence. Archives of Psychiatric Nursing, $\underline{8}(1), 30-37$.

Rolland, J. S. (1984). Toward a psychosocial typology of chronic and life-threatening illness. Family Systems Medicine, $\underline{2}, 245-263$.

Rolland, J. S. (1987). Chronic illness and the family: An overview. In L. M. Wright \& M. Leahey, Families \& chronic illness (pp. 33-54). Springhouse, PA: Springhouse Corporation.

Rolland, J. S. (1989). Chronic illness and the family life cycle. In B. Carter \& M. McGoldrick (Eds.), The changing family life cycle (2nd ed.) (pp. 433-456). Boston: Allyn and Bacon. 
Rolland, J. S. (1993). Mastering family challenges in serious illness and disability. In F. Walsh (Ed.), Normal family processes (2nd ed.) (pp. 444-473). New York: The Guilford Press.

Rubin, L. B. (1983). Intimate strangers: Men \& women together. New York: Harper \& Row Publishers.

Safier, E., \& Kofron, E. (1993, October). When chronic illness strikes the therapist. Paper presented at the 51st Annual Conference, AAMFT, Anaheim, CA.

Sandelowski, M. (1993). Rigor or rigor mortis: The problem of rigor in qualitative research revisited. Advances in Nursing Science, 16(2), 1-8.

Sandelowski, M. (1994). The proof is in the pottery: Toward a poetic for qualitative inquiry. In J. M. Morse (Ed.), Critical issues in qualitative research methods (pp. 46-63). Thousand Oaks, CA: Sage Publications.

Schon, D. A. (1983). The reflective practitioner: How professionals think in action. New York: HarperCollins Publishers.

Selvini Palazzoli, M., Boscolo, L., Cecchin, G., \& Prata, G. (1978). Paradox and counterparadox. New York: Jason Aronson, Inc.

Selvini Palazzoli, M., Boscolo, L., Cecchin, G., \& Prata, G. (1980). Hypothesizing circularity - neutrality: Three guidelines for the conductor of the session. Family Process, $\underline{19}(1), 3-12$.

Sherwin, S. (1992). No longer patient: Feminist ethics and health care. Philadelphia: Temple University Press. 
Silverman, M., \& Huelsman, E. (1990). The dynamics of long-term familial caregiving. In J. F. Gubrium \& A. Sankar (Eds.), The home care experience: Ethnography and policy (pp. 173-188). Newbury Park: Sage Publications.

Sommers, T., \& Shields, L. (1987). Women take care: The consequences of caregiving in today's society. Gainesville, FL: Triad.

Stern, P. N. (1985). Using grounded theory method in nursing research. In M. M. Leininger (Ed.), Qualitative research methods in nursing (pp. 149-160). Philadelphia: W. B. Saunders Company.

Stern, P. N. (1986). Conflicting family culture: An impediment to integration in stepfather families. In W. C. Chenitz \& J. M. Swanson, From practice to grounded theory (pp. 168-180). Menlo Park, CA: Addison-Wesley Publishing Company.

Stern, P. N. (1991). Affiliating in stepfather families: Teachable strategies leading to stepfather-child friendship. In A. L. Whall \& J. Fawcett, Family theory development in nursing: State of the science and art (pp. 179-193). Philadelphia: F. A. Davis Company.

Stern, P. N. (1994). Eroding grounded theory. In J. M. Morse (Ed.), Critical issues in qualitative research methods (pp. 212-223). Thousand Oaks, CA: Sage Publications.

Stern, P. N., Allen, L. M., \& Moxley, P. A. (1984). Qualitative research: The nurse as grounded theorist. Health Care for Women International, $\underline{5}, 371-385$.

Strauss, A. L. (1987). Qualitative analysis for social scientists. Cambridge: Cambridge University Press. 
Strauss, A., \& Corbin, J. M. (1988). Shaping a new health care system: The explosion of chronic illness as a catalyst for change. San Francisco: Jossey-Bass Publishers.

Strauss, A., \& Corbin, J. (1990). Basics of qualitative research: Grounded theory procedures and techniques. Newbury Park, CA: Sage Publications.

Strauss, A., \& Corbin, J. (1994). Grounded theory methodology: An overview. In N. K. Denzin \& Y. S. Lincoln (Eds.), Handbook of qualitative research (pp. 273-285). Thousand Oaks, CA: Sage Publications.

Strauss, A. L., Corbin, J., Fagerhaugh, S., Glaser, B. G., Maines, D., Suczek, B., \& Wiener, C. L. (1984). Chronic illness and the quality of life (2nd ed.). St. Louis: C. V. Mosby Company.

Swanson, J. M., \& Chapman, L. (1994). Inside the black box: Theoretical and methodological issues in conducting evaluation research using a qualitative approach. In J. M. Morse (Ed.), Critical issues in qualitative research methods (pp. 66-93). Thousand Oaks, CA: Sage Publications.

Tannen, D. (1990). You just don't understand: Women and men in conversation. New York: Ballantine Books.

Tapp, D. M. (1993). Family protectiveness: A response to ischemic heart disease. Canadian Journal of Cardiovascular Nursing, 4(2), 4-8.

Thomas, R. B. (1984). Nursing assessment of childhood chronic conditions. Issues in Comprehensive Pediatric Nursing, $\underline{7}, 165-176$.

Thorne, S. E., \& Robinson, C. A. (1988a). Health care relationships: The chronic illness perspective. Research in Nursing and Health, 11, 293-300. 
Thorne, S. E., \& Robinson, C. A. (1988b). Reciprocal trust in health care relationships. Journal of Advanced Nursing, 13, 782-789.

Thorne, S. E., \& Robinson, C. A. (1989). Guarded alliance: Health care relationships in chronic illness. Image: Journal of Nursing Scholarship, 21(3), 153-157.

Tomm, K. (1984). One perspective on the Milan systemic approach to family therapy: Part II. Description of session, format, interviewing style and interventions. Journal of Marital and Family Therapy, 10(3), 253-271.

Tomm, K. (1987). Interventive interviewing: Part II. Reflexive questioning as a means to enable self-healing. Family Process, 26, 167-183.

Uphold, C. R., \& Strickland, O. L. (1989). Issues related to the unit of analysis in family nursing research. Western Journal of Nursing Research, 11, 405-417.

Vannoy-Hiller, D., \& Philliber, W. W. (1989). Equal partners: Successful women in marriage. Newbury Park: Sage Publications.

Vickers, J. M. (1984). Sex/gender and the construction of national identities. Canadian Issues, $\underline{6}, 34-49$.

Walsh, F., \& Anderson, C. (1988). Chronic disorders and families: An overview. In F. Walsh \& C. Anderson (Eds.), Chronic disorders and the family (pp. 3-18). New York: The Haworth Press.

Walsh, F., \& Scheinkman, M. (1989). (Fe)male: The hidden gender dimension in models of family therapy. In M. McGoldrick, C. M. Anderson, \& F. Walsh (Eds.), Women in families: A framework for family therapy (pp. 16-41). New York: W. W. Norton \& Company. 
Walters, M., Carter, B., Papp, P., \& Silverstein, O. (1988). The invisible web: Gender patterns in family relationships. New York: The Guilford Press.

Watson, W. L. (1992). Family therapy. In G. M. Bulechek \& J. C. McCloskey, Nursing interventions: Essential nursing treatments (2nd ed.) (pp. 379-391). Philadelphia: W. B. Saunders Company.

Watson, W. L., \& Lee, D. (1993). Is there life after suicide? The systemic belief approach for "survivors" of suicide. Archives of Psychiatric Nursing, $7(1), 37-43$.

Watzlawick, P., Weakland, J. H., \& Fisch, R. (1974). Change: Principles of problem formation and problem resolution. New York: W. W. Norton \& Company, Inc.

Whall, A. L., \& Fawcett, J. (1991). Family theory development in nursing: State of the science and art. Philadelphia: F. A. Davis Company.

Whall, A. L., \& Loveland-Cherry, C. (1994, May). Past, present and future: Family research in nursing. Paper presented at the Third International Family Nursing Conference, Montreal, Quebec.

White, M. (1984). Pseudo-encopresis: From avalanche to victory, from vicious to virtuous cycles. Family Systems Medicine, 2, 150-160.

White, M. (1985). Fear busting and monster taming: An approach to the fears of young children. Dulwich Center Review.

White, M. (1986). Negative explanation, restraint and double description: A template for family therapy. Family Process, 25, 160-184. 
White, M. (1988, Winter). The process of questioning: A therapy of literary merit? Dulwich Center Newsletter, 8-14.

White, M., \& Epston, D. (1990). Narrative means to therapeutic ends. New York: W. W. Norton \& Company.

Whyte, D. A. (1992). A family nursing approach to the care of a child with a chronic illness. Journal of Advanced Nursing, 17, 317-327.

Wiener, C. L. (1975). The burden of rheumatoid arthritis: Tolerating the uncertainty. Social Science and Medicine, 9, 97-104.

Wilson, S. (1991). The unrelenting nightmare: Husbands' experiences during wives' chemotherapy. In J. M. Morse \& J. L. Johnson (Eds.), The illness experience: Dimensions of suffering (pp. 237-314). Newbury Park, CA: Sage Publications.

Woods, N. F., \& Lewis, F. M. (1992). Design and measurement challenges in family research. Western Journal of Nursing Research, 14(3), 397-403.

Wortman, C., Biernut, M., \& Lang, E. (1991). Coping with role overload. In M. Frankenhaeuser, U. Lundberg, \& M. Chesney (Eds.), Women, work, and health: Stress and opportunities (pp. 85-110). New York: Plenum Press.

Wright, L. M. (1989). When clients ask questions: Enriching the therapeutic conversation. Family Therapy Networker, 13(6), 15-16.

Wright, L. M., \& Bell, J. M. (1994). The future of family nursing research: Interventions, interventions, interventions. The Japanese Journal of Nursing Research, 27(2-3), 4-15. 
Wright, L. M., \& Leahey, M. (1987). Families and chronic illness. Springhouse, PA: Springhouse Corporation.

Wright, L. M., \& Leahey, M. (1990). Trends in nursing of families. Journal of Advanced Nursing, 15, 148-154.

Wright, L. M., \& Leahey, M. (1994). Nurses and families: A guide to family assessment and intervention (2nd ed.). Philadelphia: F. A. Davis Company.

Wright, L. M., \& Levac, A. M. (1992). The non-existence of non-compliant families:

The influence of Humberto Maturana. Journal of Advanced Nursing, 17, 913-917. Wright, L. M., \& Nagy, J. (1993). Death: The most troublesome family secret of all. In E. Imber-Black (Ed.), Secrets in families and family therapy (pp. 121-137). New York: W. W. Norton \& Co.

Wright, L. M., \& Simpson, P. (1991). A systemic belief approach to epileptic seizures: A case of being spellbound. Contemporary Family Therapy, 13(2), 165180.

Wright, L. M., \& Watson, W. L. (1988). Systemic family therapy and family development. In C. J. Falicov (Ed.), Family transitions: Continuity and change over the life cycle (pp. 407-430). New York: Guilford Press.

Wright, L. M., Watson, W. L., \& Bell, J. M. (1990). The family nursing unit: A unique integration of research, education and clinical practice. In J. M. Bell, W. L. Watson, \& L. M. Wright (Eds.), The cutting edge of family nursing (pp. 95112). Calgary, Alberta: Family Nursing Unit Publications. 
Wuest, J. (1993). Institutionalizing women's oppression: The inherent risk in health policy that fosters community participation. Health Care for Women International, $\underline{14}, 407-417$.

Wylie, M. S. (1989). The mother knot. The Family Therapy Networker, 13(5), 43-51. York, G. (1992, June 3). Tory politicians form family compact. The Globe and Mail, pp. A1, A4. 


\section{APPENDIX A}

Consent for Use of Videotape Recording

I/WE

[Please Print Family Name(s)]

authorize the Family Nursing Unit to record on videotape my/our interview. In addition, I/we voluntarily authorize the use of the videotape(s) for:

1. Education of nurses and/or other health

care professionals

Yes No

2. Research within the Faculty of Nursing Yes No

3. Written clinical case material prepared for publication, after suitably insuring anonymity, which may be copyrighted Yes No I/we understand reserves the right to edit or erase the tape(s) as she sees fit. I also understand that she will respect my/our privacy and will assume responsibility for protecting the anonymity, as is reasonably possible, of our family in any use of the videotape(s).

I/we reserve the right to have any or all of the recording(s) erased upon delivery of notice in writing to the Director, Family Nursing Unit, The University of Calgary.

I/we grant that this consent is a voluntary contribution in the interest of education and research. I/we understand that there is no financial compensation for the use of the videotape recording(s).

I/WE CERTIFY THAT I/WE HAVE READ AND UNDERSTAND THE ABOVE CONSENT FOR USE OF VIDEOTAPE RECORDING(S) AND DO SO CONSENT: 
SIGNATURE OF FAMILY MEMBERS: (This release must be signed by all family members present who are 16 years of age of older.)

Date of Consent: Witness: 


\section{APPENDIX B \\ Information/Invitation to Participate}

Dear Family:

I am a doctoral student in the Faculty of Nursing at the University of Calgary. I am interested in learning how families manage the difficulties associated with a member's health problem. We, as nurses, know very little about what health care professionals do that helps or hinders the process. Therefore, I am involved in a study to explore this with families.

Your name was suggested by Drs. Wright and Bell at the Family Nursing Unit as a family who might be particularly able to help me learn about families who are managing a long-term health problem. I have been speaking with families who attended the Family Nursing Unit for assistance managing chronic illness and with families, like yourself, who approached the Family Nursing Unit and decided to manage their concern in a different way. If you are willing, I would like to speak with your family. This would occur at a time that is mutually convenient at your home and would take about an hour and a half. Since I am interested in as many viewpoints as possible, I would like to meet with as many family members (together) as possible. As well, we may want to meet more than once so that I can more fully understand your ideas and thoughts. There will be no monetary reimbursement for participation in the study.

I will telephone you within one week and if you are interested in hearing more about the project or in assisting my learning by participating, we can set up a meeting. Thank you in advance for considering this request. 
Sincerely,

Carole Robinson, RN, MSN

Doctoral Candidate, Faculty of Nursing 


\section{APPENDIX C}

\section{Family Consent}

We, the Family, agree to participate with Carole Robinson in the study on Families and Health Problems. This means that we will be involved in one or more family discussions that will last about $1 \quad 1 / 2$ hours each. These conversations will be audiotaped. We understand that we can stop the discussion at any time or can request that any portion of the audiotape be erased. Further, we understand that we can end participation in the study at any time. Participation or non-participation will in no way influence any future care that may be sought in the Family Nursing Unit.

The findings from this study may be used in scholarly publications. We understand that our family and individual identities will not be revealed in any publications. The audiotapes and transcriptions will be coded so that again, our identity will not be revealed. Further, false names will be used to identify our family and family members in transcriptions unless we wish otherwise. All of the information gained in this study will be kept under lock and key, with only Carole Robinson and her research committee having access to the information.

We understand that there are no known risks associated with participating in a study of this kind. However, there is always the chance that family conversations may result in change - for example, new ideas or information my emerge. Many families find it useful to talk about their experiences and so there may be some benefit for our family in participating.

If we have any questions, we can reach Carole Robinson at 220-7892. Our 
signature(s) on this form indicate that we understand to our satisfaction the information regarding our participation in the research project and agree to participate as research informants. In no way does this waive our legal rights nor release the investigator or involved institutions from their legal and professional responsibilities. If we have any questions concerning our participation in this project, we can contact the University of Calgary Research Services (220-6354) and ask to speak to the Chair of the Conjoint Areas Research Ethics Committee.

Witness

Date

I have received a copy of this consent. 


\section{APPENDIX D}

Steps of the Analytic Procedure

1. The audiotaped research conversation was transcribed.

2. The transcript was open coded, that is, I read the transcript asking "What does this reflect" and coded segments with theoretical labels. Here the data were "fractured" into pieces and given an interpretive label.

3. The transcript was reread for patterns among the pieces.

4. Theoretical memo(s) were written regarding the codes and patterns.

5. Process memo(s) were written outlining areas/questions for clarification and follow-up with the family and/or for exploration with another family.

6. Each research conversation was analysed before another conversation took place.

7. Constant comparative analysis was used to push the codes toward higher levels of abstraction and then to "lump" the data (codes) into categories and subcategories. Thus, there was constant comparison of coded "pieces" of data within and between transcripts of research conversations with a particular family and between research conversations among families.

8. Based on open and theoretical coding of the transcripts of all the research conversations, the categories and subcategories were organized into a tentative analytic framework.

9. Using Word Perfect, I began open coding again, this time in relation to the tentative analytic framework (tentative theory). The switch command and copy commands were used to "cut and paste" the data. This meant that pieces of data were "cut" from the 
transcript and placed in a category or subcategory with an interpretive note explaining how the data fit. Data were often placed in more than one category, which reflected the tentative nature of the theory and overlap between categories.

10. Categories were renamed, elaborated or eliminated as necessary during this phase of analysis. Again, constant comparative analysis was the foundation on which decisions were made about what data belonged where and how the categories, subcategories related.

11. Once all the transcripts had been open coded using computer cut and paste, the categories and subcategories became the data. The categories and subcategories were printed along with all the supporting data and interpretive notes in order to provide a working copies for further analysis.

12. The categories and subcategories were organized in terms of their relationships. Here, I separated the categories and subcategories according to which stage they "belonged" in and then within each stage, I organized the categories and subcategories according to patterns of relationship.

13. Analysis proceeded stage by stage, using constant comparison. I read each category/subcategory (which included all supporting "pieces" of data and interpretive notes). Constant comparison of the data within categories/subcategories enabled decisions to be made regarding the "fit" of data and category/subcategory. This resulted in data being moved or reorganized as necessary in order to gain internal consistency within each category/subcategory. Categories/subcategories were elaborated, eliminated and renamed as necessary in response to the moving and reorganizing of data. 
14. Constant comparison of the categories/subcategories within each stage enabled the relationships and patterns among the categories/subcategories to be developed. This resulted in a reorganization of the evolving theory. I went back to transcripts as required when data were "missing" or difficult to interpret.

15. Once analysis of the categories/subcategories was complete and I had a coherent but still tentative theory, the videotapes of the therapeutic sessions were theoretically sampled in relation to the framework. That is, I looked for data that supported, refuted or elaborated upon the evolving theory.

16. Throughout this process I continued to write theoretical and process memos. The theoretical memos kept account of the evolving theory; while, the process memos documented the analytic decisions and concerns.

17. Once the videotapes of the therapeutic sessions had been theoretically sampled and the data were incorporated into the evolving theory, the process was repeated with the outcome studies.

18. Lastly, the theory was written, all the while continuing the constant comparative analysis in order to develop a theory that was consistent, coherent, fit the data and worked to explain what was going on in relation to the women's evolving relationship with chronic illness. 